\title{
Large Faraday Rotation in Optical-Quality Phthalocyanine and Porphyrin Thin Films
}

Zachary Nelson, ${ }^{\dagger}$ Leo Delage-Laurin,${ }^{\dagger}$ Martin D. Peeks, ${ }^{\dagger+}$ Timothy M. Swager* ${ }^{\dagger}$

'Department of Chemistry, Massachusetts Institute of Technology, Cambridge, MA 02139, United States.

School of Chemistry, University of New South Wales, Sydney, NSW 2052, Australia

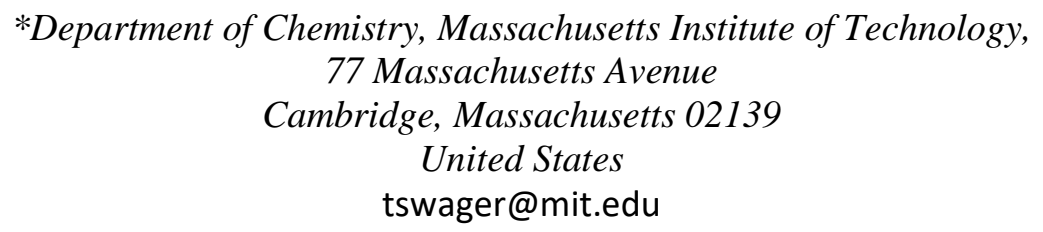

\section{Supporting Information}

Table of Contents

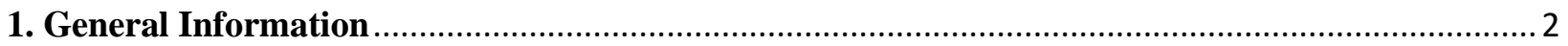

2. Additional Optical and Magneto-Optical Characterization ........................................................ 3

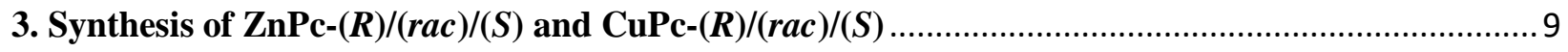

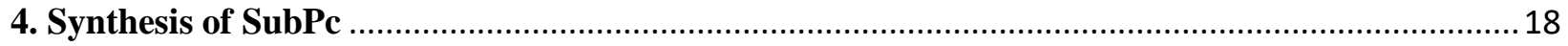

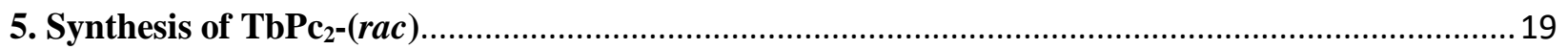

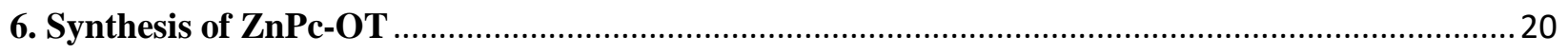

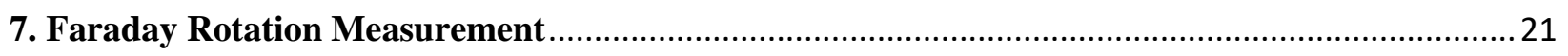

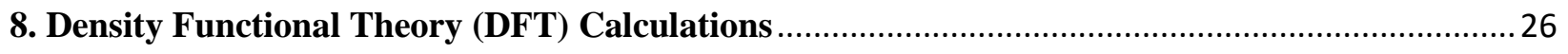

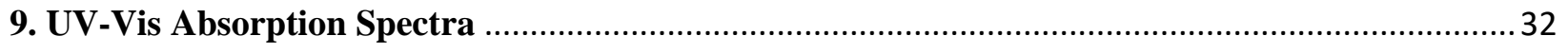

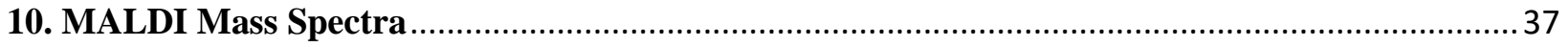

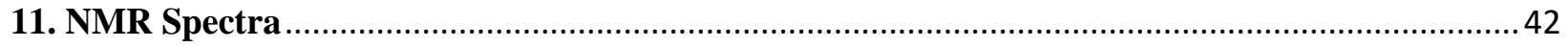

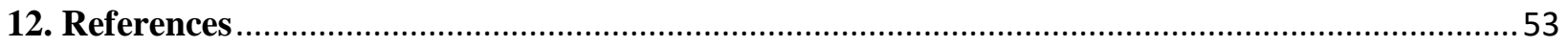




\section{General Information}

Unless otherwise stated, all reactions were carried out in oven-dried glassware under an atmosphere of argon using standard Schlenk techniques. Hydrogenations were carried out using a Parr 3920 hydrogenation apparatus. Toluene and tetrahydrofuran (THF) were purified by passage through two alumina columns of an Inert solvent purification system. All other chemicals were of reagent grade and used as received.

${ }^{1} \mathrm{H}$ NMR spectra were recorded on a Bruker Avance $400 \mathrm{MHz}$, or Bruker Avance Neo 500 or 600 $\mathrm{MHz}$ spectrometer. Chemical shifts $(\delta)$ are reported in ppm downfield from tetramethylsilane using the residual solvent signals $\left(\mathrm{CDCl}_{3}: \delta_{\mathrm{H}} 7.26 \mathrm{ppm}\right)$. Data for ${ }^{1} \mathrm{H} \mathrm{NMR}$ are reported as follows: chemical shift $(\delta$, ppm), multiplicity $(\mathrm{s}=$ singlet, $\mathrm{d}=$ doublet, $\mathrm{t}=$ triplet, and $\mathrm{m}=$ multiplet, coupling constant $(\mathrm{s})$ in $\mathrm{Hz}$, integration). ${ }^{13} \mathrm{C}$ NMR spectra were recorded on a Bruker Avance 400 (101 MHz), or Bruker Avance Neo 500 or 600 spectrometer $(126$ or $151 \mathrm{MHz})$. Chemical shifts $(\delta)$ are reported in ppm with residual solvent signals as a standard $\left(\mathrm{CDCl}_{3}: \delta_{\mathrm{C}} 77.16 \mathrm{ppm}\right)$. CHN Elemental analysis performed by Robertson Microlit Laboratories (Ledgewood, NJ). Mass Spectra were obtained using either a JEOL AccuTOF 4G equipped with an ionSense direct-analysis-in-real-time (DART) source, or a Bruker Autoflex Speed matrix-assisted laser desorption/ionization time-of-flight (MALDI-TOF) spectrometer for high molecular weight species. Mass spectra were calibrated using poly(ethylene glycol) of the appropriate mass range as external standards. Specific optical rotation was measured on a Jasco model P-1010 polarimeter at $20^{\circ} \mathrm{C}$ at $589 \mathrm{~nm}$ (sodium D line). UV-vis spectra were recorded on an Agilent Cary 4000 spectrometer at room temperature using a quartz cuvette. 


\section{Additional Optical and Magneto-Optical Characterization}

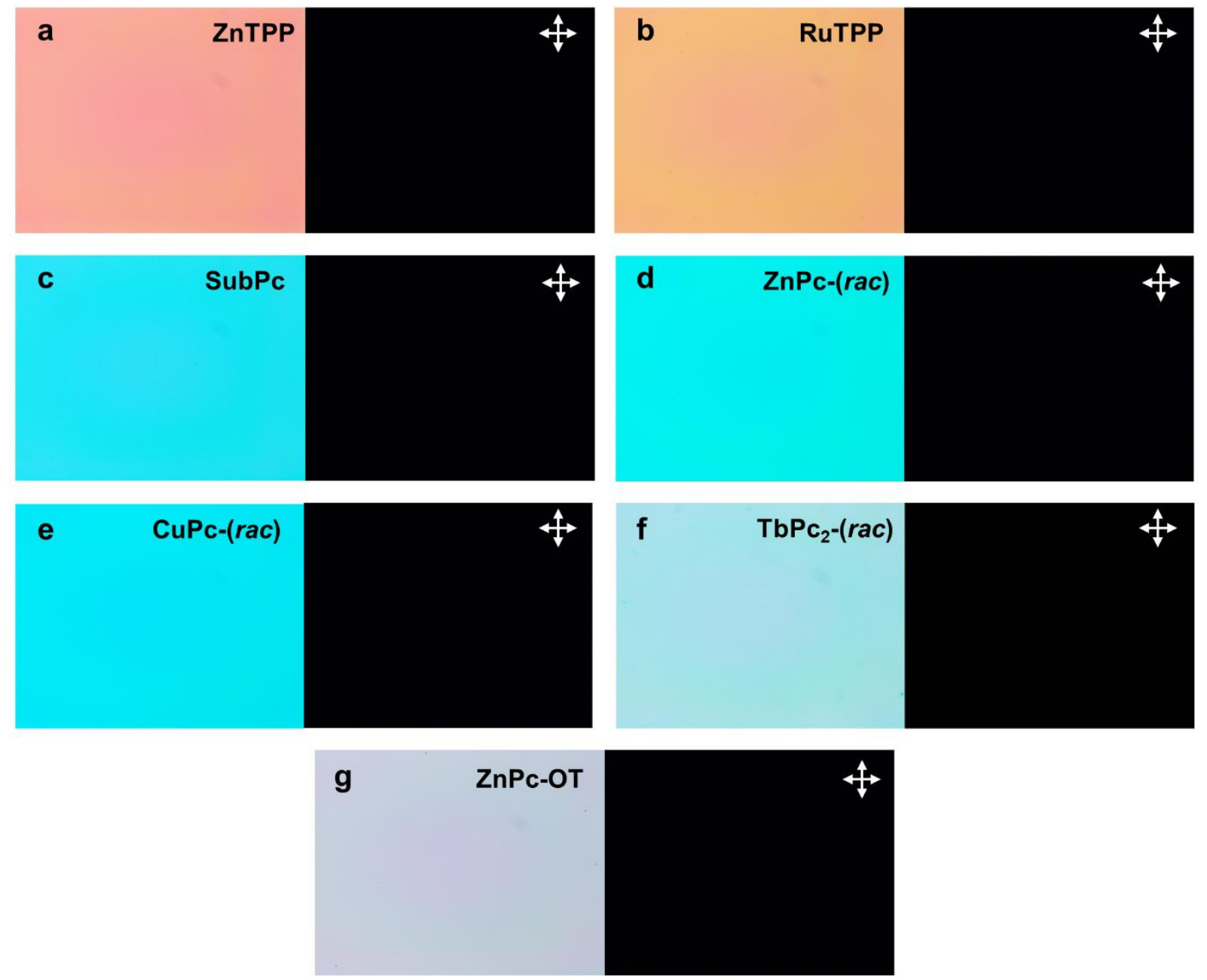

Figure S1 Optical microscopy images at 10x magnification with (right) and without (left) crossed polarizing filters demonstrating the high optical quality of the as-cast thin films of (a) ZnTPP, (b) RuTPP, (c) SubPc, (d) ZnPc-(rac), (e) CuPc-(rac), (f) TbPc--(rac), and (g) ZnPc-OT. 

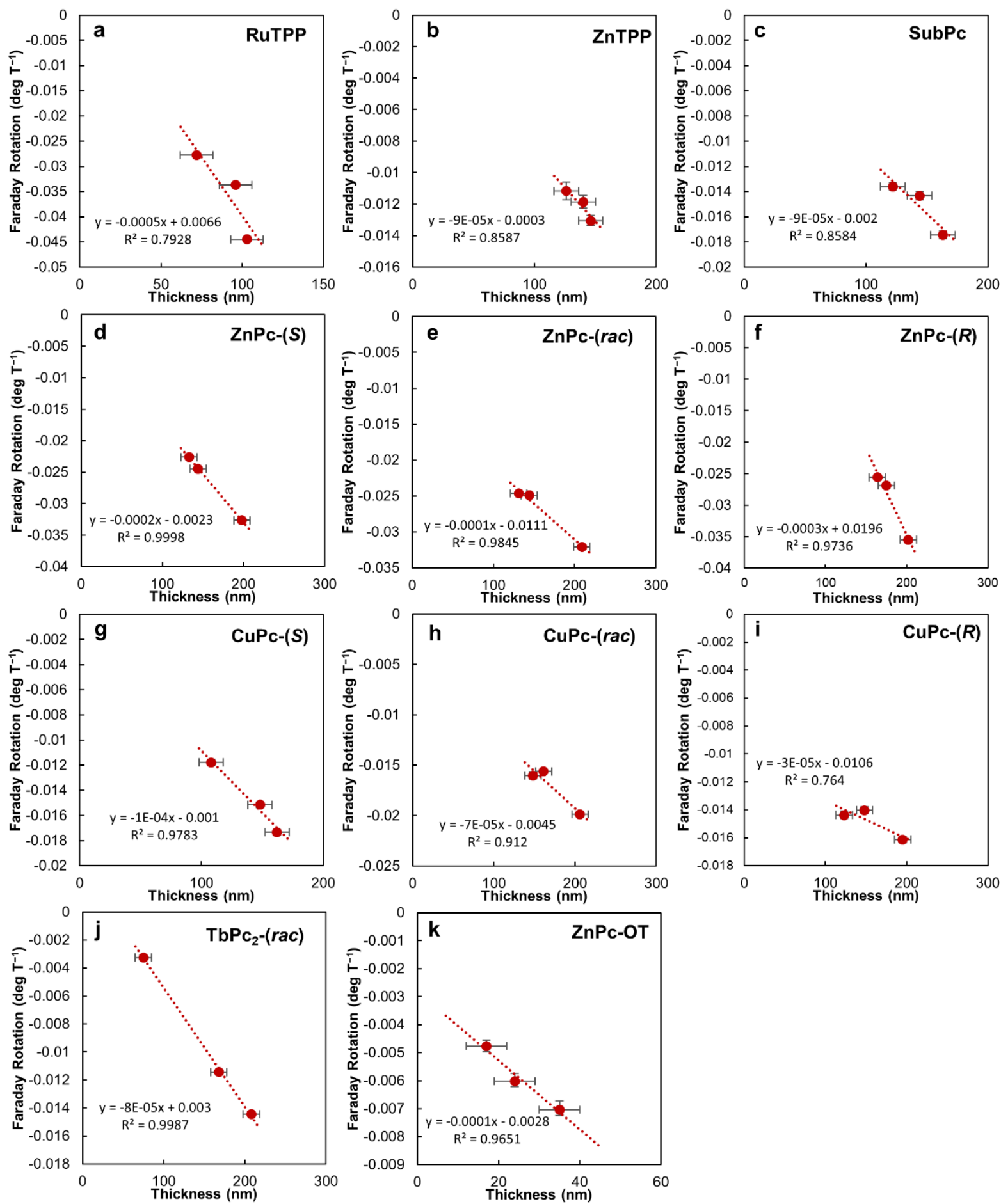

Figure S2 The Faraday rotation of thin films measured at three thicknesses for (a) RuTPP, (b) ZnTPP, (c) SubPc, (d) ZnPc-(S), (e) ZnPc-(rac), (f) ZnPc-(R), (g) CuPc-(S), (h) CuPc-(rac), (i) CuPc-(R), (j) TbPc $\mathbf{2}^{-}$ $(\boldsymbol{r a c})$, and (k) ZnPc-OT, showing a linear relationship for each molecular species in accordance with Equation 1 from the main text. 

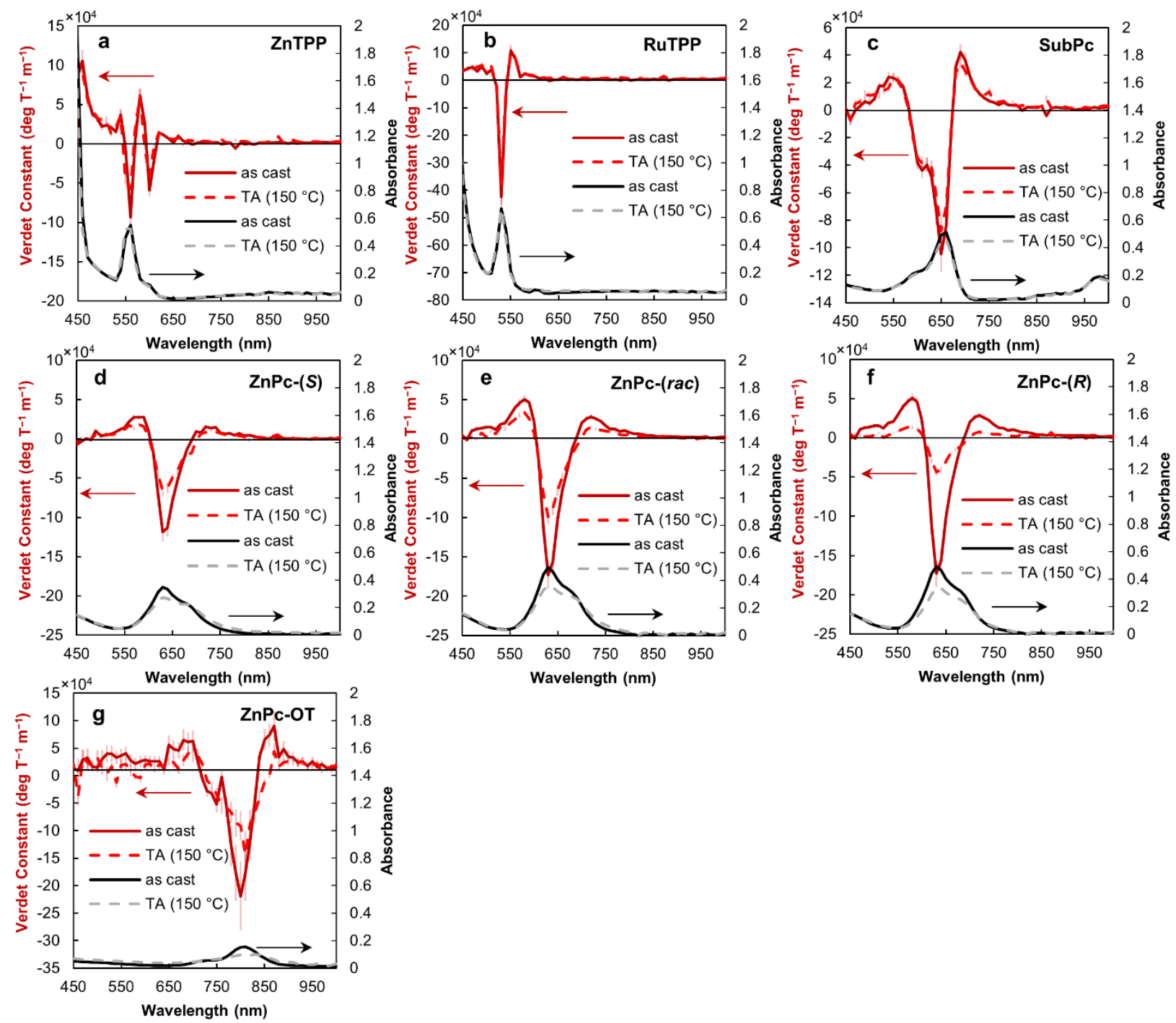

Figure S3 Verdet constant and absorbance spectra for as-cast and thermally annealed (TA) thin films of (a) ZnTPP, (b) RuTPP, (c) SubPc, (d) ZnPc-(S), (e) ZnPc-(rac), (f) ZnPc-(S), (g) ZnPc-OT. Thermal annealing procedure: heated to the indicated temperature at a rate of $30{ }^{\circ} \mathrm{C} \mathrm{min}^{-1}$, then to room temperature at a rate of $1^{\circ} \mathrm{C} \mathrm{min}-1$ under an ambient atmosphere. 


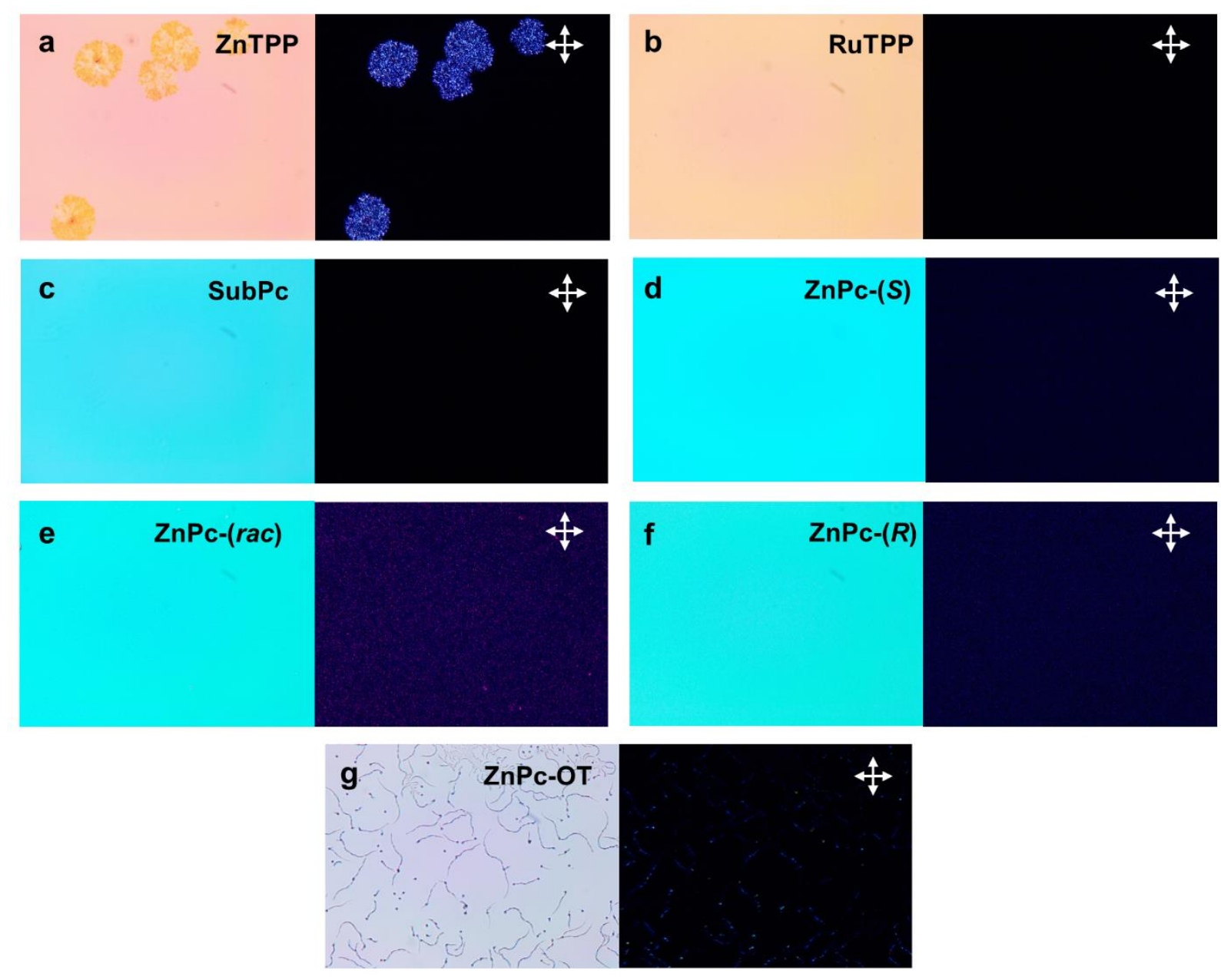

Figure S4 Optical microscopy images at 10x magnification with (right) and without (left) crossed polarizing filters demonstrating the effect of thermal annealing on thin films of (a) ZnTPP, (b) RuTPP, (c) SubPc, (d) ZnPc-(S), (e) ZnPc-(rac), (f) ZnPc-(S), (g) ZnPc-OT. Thermal annealing procedure: heated to the indicated temperature at a rate of $30^{\circ} \mathrm{C} \mathrm{min}^{-1}$, then to room temperature at a rate of $1{ }^{\circ} \mathrm{C} \mathrm{min}{ }^{-1}$ under an ambient atmosphere. 

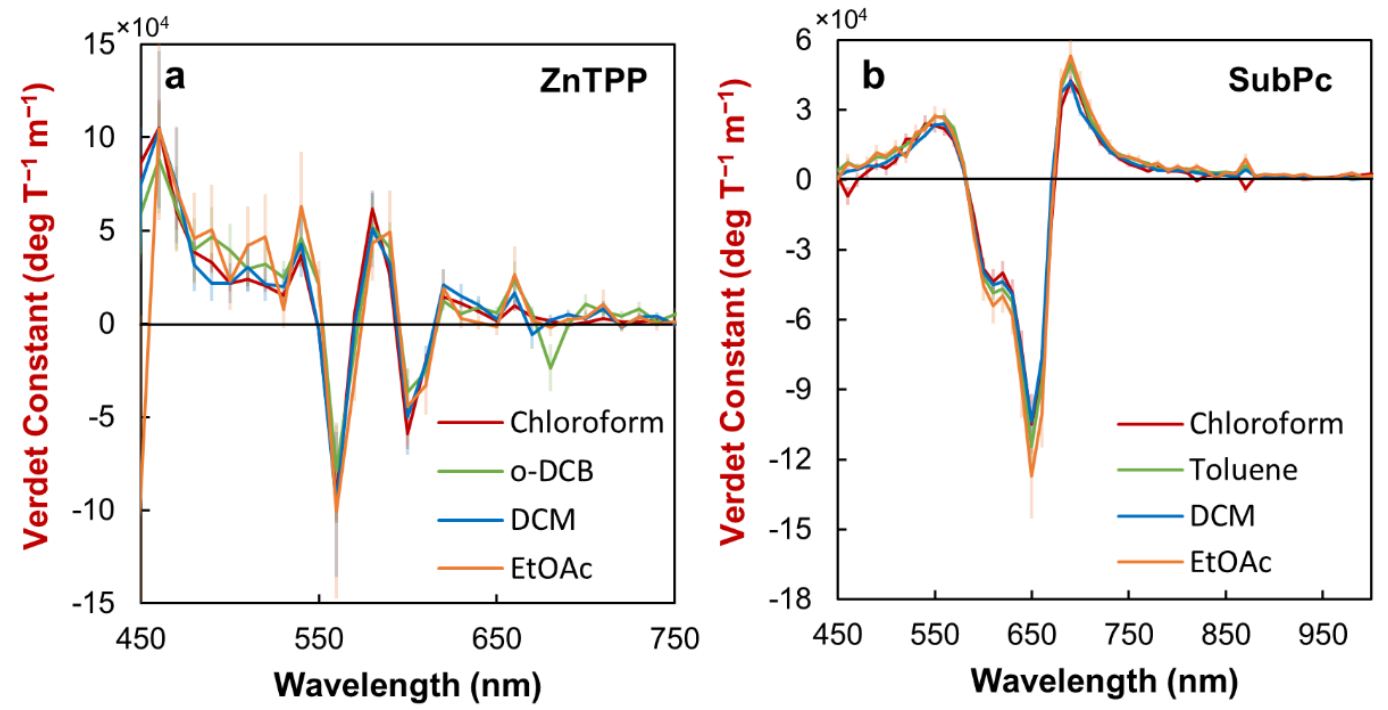

Figure S5 Verdet constant spectra of thin films of (a) ZnTPP and (b) SubPc spin coated from solutions of chloroform (red), orthodichlorobenzene (o-DCB, green) or toluene (green), dichloromethane (DCM, blue), and ethyl acetate (EtOAc, orange). 

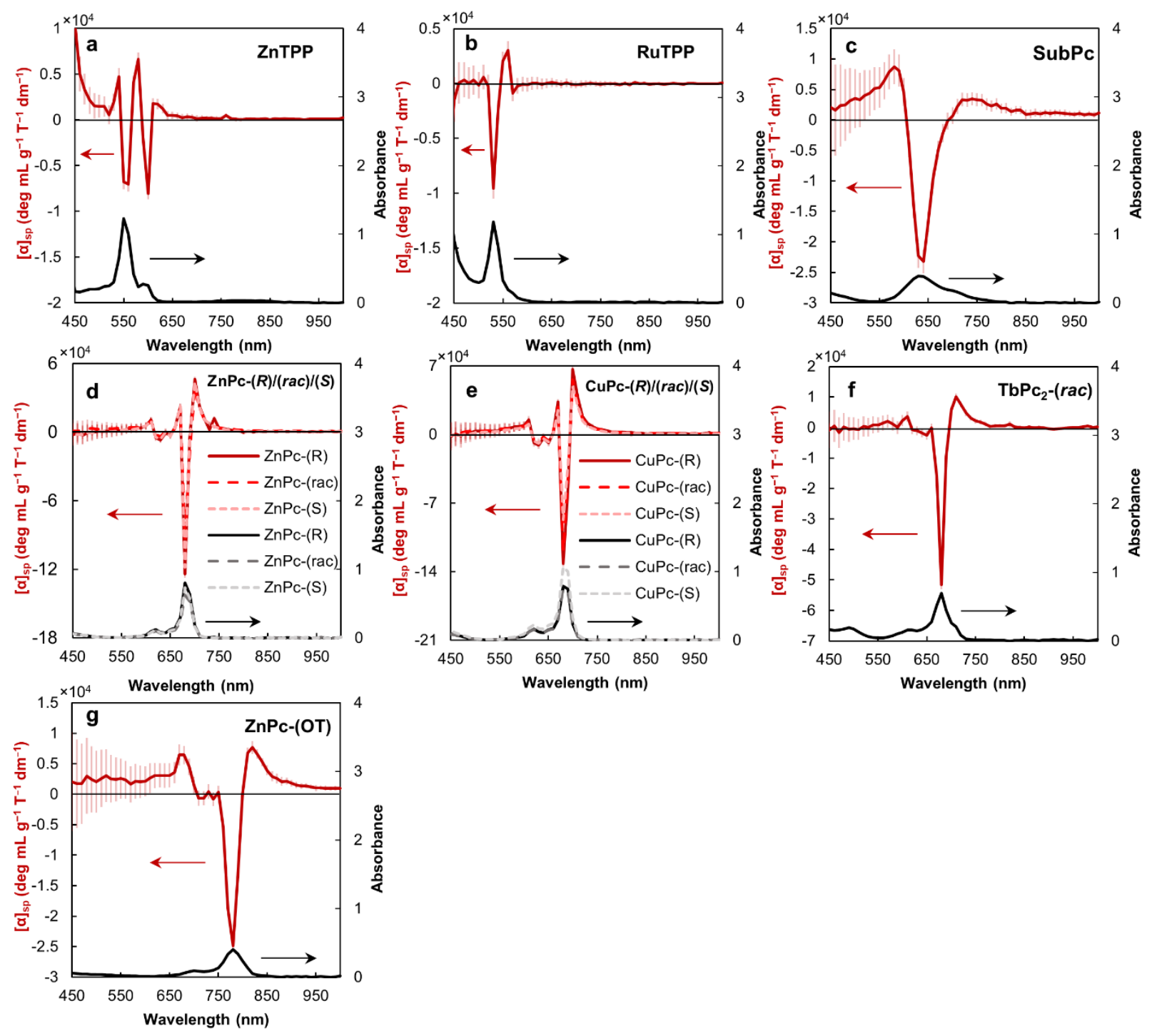

Figure S6 Specific magnetic rotation spectra $\left(\left[\alpha_{\mathrm{sp}}\right]\right)$ and absorbance spectra in chloroform solutions of (a) ZnTPP, (b) RuTPP, (c) SubPc, (d) ZnPc-(R)/(rac)/(S), (e) CuPc-(R)/(rac)/(S), (f) TbPc $\mathbf{2}_{2}(r a c)$, (g) ZnPcOT. 


\section{Synthesis of ZnPc- $($ R $) /($ rac $) /(S)$ and $\mathrm{CuPc}-(R) /($ rac $) /(S)$}

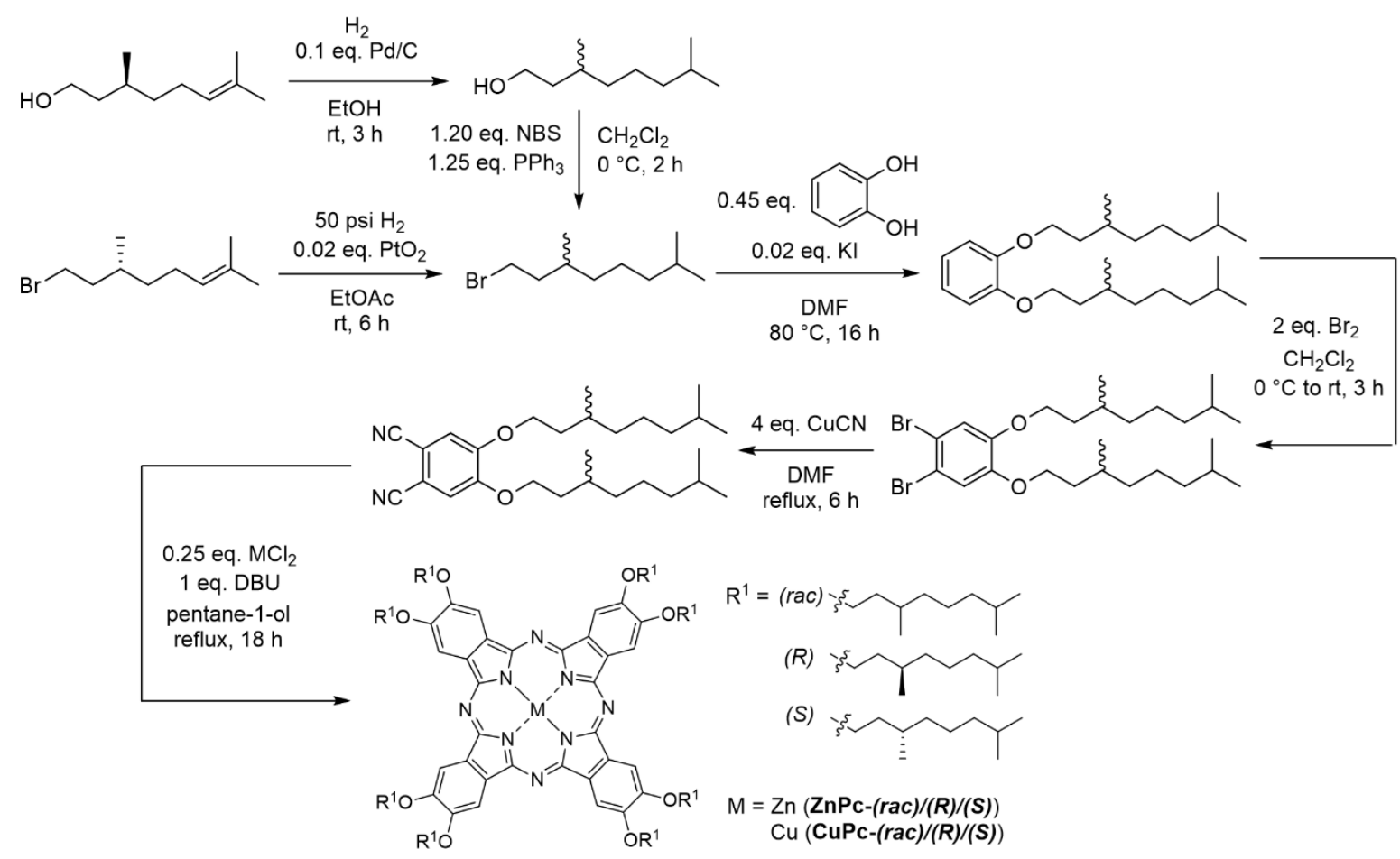

Figure S7 Synthetic route for $\mathrm{ZnPc}-(\mathrm{R}) /(\mathrm{rac}) /(\mathrm{S})$ and $\mathrm{CuPc}-(\mathrm{R}) /(\mathrm{rac}) /(\mathrm{S})$.

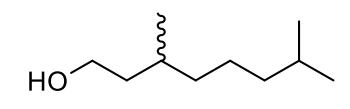

3,7-dimethyloctan-1-ol

(S)-3,7-dimethyloctano-1-ol To a $100 \mathrm{~mL}$ round-bottomed flask was added $10 \%$ palladium on carbon (2.5 g, $2.35 \mathrm{mmol} \mathrm{Pd}, 0.015$ equiv. Pd) under an atmosphere of nitrogen. Then $40 \mathrm{~mL}$ ethanol and (S)-(-)citronellol (25.0 g, $159.98 \mathrm{mmol}, 1$ equiv.) were added. Hydrogen gas was bubbled through the solution for three hours under stirring. The apparatus was left stirring under an atmosphere of hydrogen for a further 12 hours. The solution was filtered over Celite and washed with ethanol, and concentrated under reduced pressure. The residue was filtered through a plug of silica gel with dichloromethane as the eluant, giving the product as a colorless oil (19.11 g, 75\%). NMR spectral analysis was in agreement with the literature. ${ }^{1}$ ${ }^{1}$ H NMR (400 MHz, Chloroform- $d$ ) $\delta 3.75-3.60$ (m, 2H), $1.66-1.46$ (m, 3H), $1.45-1.09$ (m, 7H), 0.89 $(\mathrm{d}, \mathrm{J}=6.6 \mathrm{~Hz}, 3 \mathrm{H}), 0.86(\mathrm{~d}, \mathrm{~J}=6.6 \mathrm{~Hz}, 6 \mathrm{H})$.<smiles>CC(C)CCC[C@@H](C)CCBr</smiles> 
(R)-1-bromo-3,7-dimethyloctane Synthesized following a modified literature procedure. ${ }^{2}$ Platinum(IV) oxide (300 mg, $1.32 \mathrm{mmol}, 0.02$ equiv.), then ethyl acetate, then $(R)$-(-)-citronellyl bromide (15.0 g, 68.44 mmol, 1 equiv.) were added to a Parr shaker hydrogenation apparatus. The vessel was charged with 50 psi hydrogen gas and allowed to react for six hours. Upon returning to atmospheric pressure, the reaction mixture was filtered over Celite, and washed with dichloromethane. The solution was concentrated under reduced pressure, yielding a colorless oil contaminated with residual ethyl acetate (16.67 $\mathrm{g})$. This intermediate was used without further purification to avoid evaporative losses of the product. Characterization was consistent with the literature. ${ }^{3}{ }^{1} \mathbf{H}$ NMR $(400 \mathrm{MHz}$, Chloroform- $d$ ) $\delta 3.52-3.34$ (m, $2 \mathrm{H}), 1.94-1.80(\mathrm{~m}, 1 \mathrm{H}), 1.74-1.57(\mathrm{~m}, 2 \mathrm{H}), 1.56-1.45(\mathrm{~m}, 1 \mathrm{H}), 1.37-1.20(\mathrm{~m}, 3 \mathrm{H}), 1.19-1.05(\mathrm{~m}$, $3 \mathrm{H}), 0.96-0.81(\mathrm{~m}, 9 \mathrm{H})$.

(rac)-1-bromo-3,7-dimethyloctane Synthesized following a modified patent procedure. ${ }^{4}$ 3,7-dimethyl-1octanol (35.7 g, $225.54 \mathrm{mmol}, 1.0$ eqiv.), dichloromethane (200 mL), and triphenylphosphine (73.95 g, $281.93 \mathrm{mmol}, 1.25$ equiv.) were added to a dry $500 \mathrm{~mL}$ round-bottomed flask under a nitrogen atmosphere. The apparatus was cooled to $0{ }^{\circ} \mathrm{C}, \mathrm{N}$-bromosuccinimide $(48.17 \mathrm{~g}, 270.65 \mathrm{mmol}, 1.2$ equiv.) was added portion-wise, the reaction was allowed to warm to room temperature. After three hours, the solution was concentrated under reduced pressure, and hexane $(250 \mathrm{~mL})$ was added to the solid residue. The slurry was stirred for two hours. Then the supernatant was filtered through a pad of silica gel, washed with hexane and concentrated under reduced pressure. The resulting oil was dissolved again in hexane, and a solution of zinc(II) chloride in diethyl ether was added. The slurry was then filtered over Celite, washed with hexane, and concentrated under reduced pressure, giving a colorless oil (39.6 g, 79\%). Characterization was consistent with the literature. ${ }^{3}{ }^{1} \mathbf{H}$ NMR (400 MHz, Chloroform- $d$ ) $\delta 3.59-3.26(\mathrm{~m}, 2 \mathrm{H}), 1.96-1.82(\mathrm{~m}$, $1 \mathrm{H}), 1.71-1.56(\mathrm{~m} 2 \mathrm{H}), 1.58-1.45(\mathrm{~m}, 1 \mathrm{H}), 1.36-1.19(\mathrm{~m}, 3 \mathrm{H}), 1.20-1.01(\mathrm{~m}, 3 \mathrm{H}), 0.95-0.79(\mathrm{~m}$, 9H). ${ }^{13}$ C NMR (151 MHz, Chloroform- $d$ ) $\delta$ 40.22, 39.32, 36.86, 32.42, 31.82, 28.10, 24.70, 22.84, 22.75, 19.11 .

(S)-1-bromo-3,7-dimethyloctane Synthesized following a modified patent procedure. ${ }^{4}$ To a dry $250 \mathrm{~mL}$ round-bottomed flask was added (S)-3,7-dimethyloctano-1-ol (19.1 g, $120.73 \mathrm{mmol}, 1$ equiv.) and $120 \mathrm{~mL}$ dichloromethane under an atmosphere of nitrogen. Then triphenylphosphine (39.58 g, $150.91 \mathrm{mmol}, 1.25$ equiv.) was added while stirring. The solution was cooled to $0{ }^{\circ} \mathrm{C}$ and $\mathrm{N}$-bromosuccinimide $(25.79 \mathrm{~g}, 144.88$ mmol, 1.2 equiv.) was added. The reaction was stirred at $0{ }^{\circ} \mathrm{C}$ for a further two hours. Upon warming to room temperature, the solution was concentrated under reduced pressure, and the remaining white solid was washed with hexanes. The hexanes solution was collected and concentrated under reduced pressure. The residue was then filtered through a plug of silica gel using hexanes as the eluant, which was again collected and concentrated under reduced pressure, giving a colorless oil (23.5 g, 88\%). Characterization 
was consistent with the literature. ${ }^{3}{ }^{1} \mathbf{H}$ NMR $(400 \mathrm{MHz}$, Chloroform- $d$ ) $\delta 3.55-3.30(\mathrm{~m}, 2 \mathrm{H}), 1.96-1.80$ $(\mathrm{m}, 1 \mathrm{H}), 1.76-1.57(\mathrm{~m}, 2 \mathrm{H}), 1.57-1.46(\mathrm{~m}, 1 \mathrm{H}), 1.34-1.24(\mathrm{~m}, 3 \mathrm{H}), 1.22-1.08(\mathrm{~m}, 3 \mathrm{H}), 0.93-0.84$ (m, 9H).

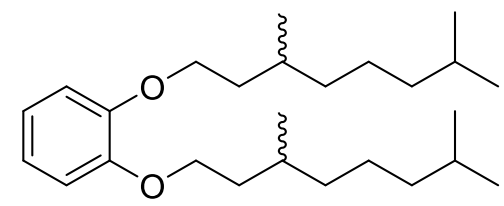

1,2-bis((3,7-dimethyloctyl)oxy)benzene

(R)-1,2-bis((3,7-dimethyloctyl)oxy)benzene Synthesized following a modified literature procedure. ${ }^{5} 1,2-$ dihydroxybenzene (1.5 g, $13.62 \mathrm{mmol}, 1$ equiv.), potassium carbonate (7.91 g, $57.21 \mathrm{mmol}, 4.2$ equiv.), potassium iodide (113.1 $\mathrm{mg}, 0.68 \mathrm{mmol}, 0.05$ equiv.), and dry dimethylformamide (30 $\mathrm{mL}$ ) were added to a dry $100 \mathrm{~mL}$ round-bottomed flask under a nitrogen atmosphere. Then $(R)$-1-bromo-3,7-dimethyloctane (6.63 g, $29.27 \mathrm{mmol}, 2.2$ equiv.) was added. The reaction was stirred at $80{ }^{\circ} \mathrm{C}$ for 16 hours. After cooling to room temperature, the reaction mixture was poured into water $(500 \mathrm{~mL})$. In a separatory funnel, the aqueous solution was extracted three times with dichloromethane, and the combined organic layers were washed twice with a 5\% aqueous solution of lithium chloride, and washed once with water. The organic fraction was dried over magnesium sulfate, filtered, and concentrated under reduced pressure. The crude product was purified by silica gel column chromatography with a 0-3\% solution of diethyl ether in hexanes gradient as the eluent, giving a colorless oil (2.2 g, 32\%). NMR characterization was consistent with (rac)1,2-bis((3,7-dimethyloctyl)oxy)benzene. ${ }^{1} \mathbf{H}$ NMR (400 MHz, Chloroform- $d$ ) $\delta 6.89$ (s, 4H), $4.12-3.93$ $(\mathrm{m}, 4 \mathrm{H}), 1.94-1.80(\mathrm{~m}, 2 \mathrm{H}), 1.75-1.45(\mathrm{~m}, 6 \mathrm{H}), 1.39-1.22(\mathrm{~m}, 6 \mathrm{H}), 1.22-1.08(\mathrm{~m}, 6 \mathrm{H}), 0.94(\mathrm{~d}, \mathrm{~J}=$ $6.5 \mathrm{~Hz}, 6 \mathrm{H}), 0.87(\mathrm{~d}, \mathrm{~J}=6.6 \mathrm{~Hz}, 12 \mathrm{H}) .{ }^{13} \mathrm{C}$ NMR $(151 \mathrm{MHz}$, Chloroform- $d$ ) $\delta$ 149.36, 121.09, 114.10, 67.72, 39.42, 37.52, 36.44, 30.08, 28.14, 24.88, 22.86, 22.76, 19.86. HRMS (DART/AccuTOF) m/z: [M] ${ }^{+}$

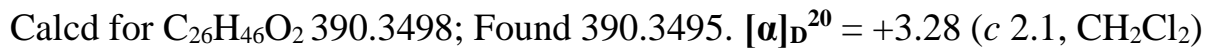

(rac)-1,2-bis((3,7-dimethyloctyl)oxy)benzene Synthesized following a modified literature procedure. ${ }^{5}$ 1,2-dihydroxybenzene (4.5 g, $40.87 \mathrm{mmol}, 1$ equiv.), potassium carbonate (23.72 g, $171.64 \mathrm{mmol}, 4.2$ equiv.), potassium iodide (339.2 $\mathrm{mg}, 2.04 \mathrm{mmol}, 0.05$ equiv.), and dry dimethylformamide (100 mL) were added to a dry $250 \mathrm{~mL}$ round-bottomed flask under a nitrogen atmosphere. Then ( $\mathrm{rac}$ )-1-bromo-3,7dimethyloctane (19.9 g, $89.91 \mathrm{mmol}, 2.2$ equiv.) was added. The reaction was stirred at $80{ }^{\circ} \mathrm{C}$ for 16 hours. After cooling to room temperature, the reaction mixture was poured into water $(500 \mathrm{~mL})$. In a separatory funnel, the aqueous solution was extracted three times with dichloromethane, and the combined organic layers were washed twice with a 5\% aqueous solution of lithium chloride, and washed once with water. The organic fraction was dried over magnesium sulfate, filtered, and concentrated under reduced pressure. 
The crude product was purified by silica gel column chromatography with a 0-5\% solution of diethyl ether in hexanes gradient as the eluent, giving a colorless oil (3.3 g, 27\%). Characterization was consistent with the literature. ${ }^{6}{ }^{1} \mathbf{H}$ NMR (400 MHz, Chloroform- $d$ ) $\delta 6.89$ (s, 4H), $4.13-3.93$ (m, 4H), $1.93-1.80(\mathrm{~m}, 2 \mathrm{H})$, $1.73-1.50(\mathrm{~m}, 6 \mathrm{H}), 1.38-1.24(\mathrm{~m}, 6 \mathrm{H}), 1.23-1.09(\mathrm{~m}, 6 \mathrm{H}), 0.94(\mathrm{~d}, \mathrm{~J}=6.4 \mathrm{~Hz}, 6 \mathrm{H}), 0.87$ (d, J = 6.5 Hz, $12 \mathrm{H})$.

(S)-1,2-bis((3,7-dimethyloctyl)oxy)benzene Synthesized following a modified literature procedure. ${ }^{5}$ 1,2dihydroxybenzene (5.30 g, 48.13 mmol, 1 equiv.), potassium carbonate (27.94 g, 202.16 mmol, 4.2 equiv.), potassium iodide (399.5 mg, $2.41 \mathrm{mmol}, 0.05$ equiv.), and dry dimethylformamide (100 mL) were added to a dry $250 \mathrm{~mL}$ round-bottomed flask under a nitrogen atmosphere. Then (S)-1-bromo-3,7-dimethyloctane (23.42 g, $105.89 \mathrm{mmol}, 2.2$ equiv.) was added. The reaction was stirred at $80{ }^{\circ} \mathrm{C}$ for 16 hours. After cooling to room temperature, the reaction mixture was poured into water $(300 \mathrm{~mL})$. In a separatory funnel, the aqueous solution was extracted three times with dichloromethane, and the combined organic layers were washed twice with a 5\% aqueous solution of lithium chloride, and washed once with water. The organic fraction was then dried over magnesium sulfate, filtered, and concentrated under reduced pressure. The crude product was purified by silica gel column chromatography with a $20 \%$ solution of dichloromethane in hexanes as the eluent, giving a colorless oil (16.3 g, 87\%). NMR characterization was consistent with (rac)-1,2-bis((3,7-dimethyloctyl)oxy)benzene. ${ }^{1} \mathbf{H}$ NMR (400 MHz, Chloroform- $d$ ) $\delta 6.89$ (s, 4H), $4.09-$ $3.96(\mathrm{~m}, 4 \mathrm{H}), 1.93-1.81(\mathrm{~m}, 2 \mathrm{H}), 1.73-1.48(\mathrm{~m}, 6 \mathrm{H}), 1.40-1.25(\mathrm{~m}, 6 \mathrm{H}), 1.22-1.10(\mathrm{~m}, 6 \mathrm{H}), 0.94(\mathrm{~d}$, $\mathrm{J}=6.5 \mathrm{~Hz}, 6 \mathrm{H}), 0.87(\mathrm{~d}, \mathrm{~J}=6.6 \mathrm{~Hz}, 12 \mathrm{H}) .{ }^{13} \mathrm{C}$ NMR $(151 \mathrm{MHz}$, Chloroform- $d$ ) $\delta 149.37,121.10,114.10$, 67.72, 39.43, 37.53, 36.44, 30.07, 28.13, 24.87, 22.86, 22.75, 19.86. HRMS (DART/AccuTOF) m/z: [M] ${ }^{+}$

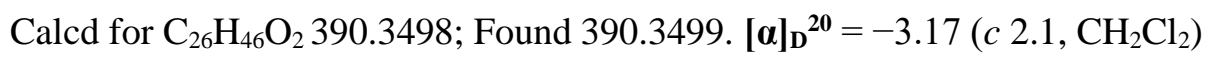

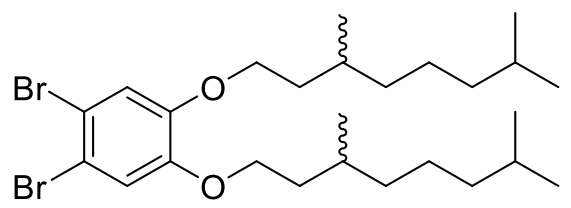

1,2-dibromo-4,5-bis((3,7-dimethyloctyl)oxy)benzene

(R)-1,2-dibromo-4,5-bis((3,7-dimethyloctyl)oxy)benzene Synthesized following a modified literature procedure. ${ }^{2}$ To a dry $100 \mathrm{~mL}$ round-bottomed flask was added (R)-1,2-bis((3,7-dimethyloctyl)oxy)benzene (1.7 g, $4.35 \mathrm{mmol}, 1$ equiv.) and dichloromethane $(40 \mathrm{~mL})$ under a nitrogen atmosphere. The apparatus was cooled to $0{ }^{\circ} \mathrm{C}$ and a solution of bromine $(1.39 \mathrm{~g}, 8.70 \mathrm{mmol}, 2.0$ equiv.) in $3 \mathrm{~mL}$ dichloromethane was added dropwise over the course of one hour, with the solution allowed to warm to room temperature during the final 30 minutes of the one-hour addition. The reaction was then stirred for two hours at room temperature. At the completion of the reaction, a saturated aqueous solution of sodium bicarbonate $(50 \mathrm{~mL})$ 
was added. The layers were separated, and the organic fraction was washed twice with water, dried with magnesium sulfate, filtered, and concentrated under reduced pressure. The resulting colorless oil was used without further purification $(2.4 \mathrm{~g}, 92 \%)$. NMR characterization was consistent with ( $\mathrm{rac}$ )-1,2-dibromo4,5-bis((3,7-dimethyloctyl)oxy)benzene. ${ }^{1} \mathbf{H}$ NMR (400 MHz, Chloroform- $d$ ) $\delta 7.06$ (s, 2H), $4.04-3.90$ $(\mathrm{m}, 4 \mathrm{H}), 1.91-1.78(\mathrm{~m}, 2 \mathrm{H}), 1.70-1.48(\mathrm{~m}, 6 \mathrm{H}), 1.39-1.22(\mathrm{~m}, 6 \mathrm{H}), 1.20-1.08(\mathrm{~m}, 6 \mathrm{H}), 0.93(\mathrm{~d}, \mathrm{~J}=$ $6.4 \mathrm{~Hz}, 6 \mathrm{H}), 0.87$ (d, J = 6.6 Hz, 12H). ${ }^{13} \mathrm{C}$ NMR (151 MHz, Chloroform- $d$ ) $\delta 149.16,117.99,114.76$, 68.10, 39.38, 37.40, 36.12, 30.02, 28.14, 24.86, 22.85, 22.75, 19.81. HRMS (DART/AccuTOF) m/z: [M] ${ }^{+}$

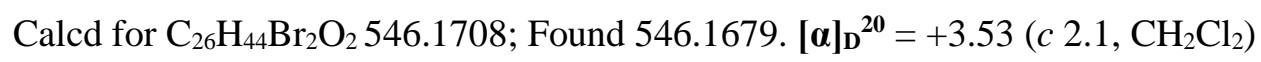

(rac)-1,2-dibromo-4,5-bis((3,7-dimethyloctyl)oxy)benzene Synthesized following a modified literature procedure. $^{2}$ To a dry $250 \mathrm{~mL}$ round-bottomed flask was added (rac)-1,2-bis((3,7dimethyloctyl)oxy)benzene ( $3.3 \mathrm{~g}, 8.45 \mathrm{mmol}, 1$ equiv.) and dichloromethane $(150 \mathrm{~mL})$ under a nitrogen atmosphere. The apparatus was cooled to $0{ }^{\circ} \mathrm{C}$ and a solution of bromine $(2.7 \mathrm{~g}, 16.89 \mathrm{mmol}, 2.0$ equiv. $)$ in $10 \mathrm{~mL}$ dichloromethane was added dropwise over the course of two hours. The reaction was then stirred for an additional two hours at room temperature. At the completion of the reaction, a saturated aqueous solution of sodium bicarbonate $(50 \mathrm{~mL})$ was added. The layers were separated, and the organic fraction was washed twice with water, dried with magnesium sulfate, filtered, and concentrated under reduced pressure. The resulting colorless oil was used without further purification $(2.2 \mathrm{~g}, 47 \%)$. Characterization was consistent with the literature. ${ }^{6}{ }^{1} \mathbf{H}$ NMR (400 MHz, Chloroform- $d$ ) $\delta 7.06$ (s, 2H), $4.05-3.90$ (m, 4H), 1.90 - $1.79(\mathrm{~m}, 2 \mathrm{H}), 1.68-1.48(\mathrm{~m}, 6 \mathrm{H}), 1.37-1.23(\mathrm{~m}, 6 \mathrm{H}), 1.21-1.10(\mathrm{~m}, 6 \mathrm{H}), 0.93$ (d, J = 6.4 Hz, 6H), $0.87(\mathrm{~d}, \mathrm{~J}=6.6 \mathrm{~Hz}, 12 \mathrm{H})$.

(S)-1,2-dibromo-4,5-bis((3,7-dimethyloctyl)oxy)benzene Synthesized following a modified literature procedure. ${ }^{2}$ To a dry $100 \mathrm{~mL}$ round-bottomed flask was added (S)-1,2-bis((3,7-dimethyloctyl)oxy)benzene $(5.0 \mathrm{~g}, 12.8 \mathrm{mmol}, 1$ equiv.) and dichloromethane $(25 \mathrm{~mL})$ under a nitrogen atmosphere. The apparatus was cooled to $0{ }^{\circ} \mathrm{C}$ and a solution of bromine (4.09 g, $25.60 \mathrm{mmol}, 2.0$ equiv.) in $3 \mathrm{~mL}$ dichloromethane was added dropwise over the course of one hour, with the solution allowed to warm to room temperature during the final 30 minutes of the one-hour addition. The reaction was then stirred for two hours at room temperature. At the completion of the reaction, a saturated aqueous solution of sodium bicarbonate $(50 \mathrm{~mL})$ was added. The layers were separated, and the organic fraction was washed twice with water, dried with magnesium sulfate, filtered, and concentrated under reduced pressure. The resulting yellow oil was used without further purification $(6.9 \mathrm{~g}, 98 \%)$. NMR characterization was consistent with ( $\mathrm{rac}$ )-1,2-dibromo4,5-bis((3,7-dimethyloctyl)oxy)benzene. ${ }^{1} \mathbf{H}$ NMR (400 MHz, Chloroform- $d$ ) $\delta 7.06$ (s, 2H), $4.08-3.87$ $(\mathrm{m}, 4 \mathrm{H}), 1.93-1.77(\mathrm{~m}, 2 \mathrm{H}), 1.72-1.46(\mathrm{~m}, 6 \mathrm{H}), 1.41-1.24(\mathrm{~m}, 6 \mathrm{H}), 1.22-1.10(\mathrm{~m}, 6 \mathrm{H}), 0.94(\mathrm{~d}, \mathrm{~J}=$ $6.4 \mathrm{~Hz}, 6 \mathrm{H}), 0.87(\mathrm{~d}, \mathrm{~J}=6.6 \mathrm{~Hz}, 12 \mathrm{H}) .{ }^{13} \mathrm{C}$ NMR $(151 \mathrm{MHz}$, Chloroform- $d$ ) $\delta 149.16,117.99,114.76$, 
68.10, 39.38, 37.42, 36.12, 30.02, 28.14, 24.86, 22.85, 22.76, 19.81. HRMS (DART/AccuTOF) m/z: [M] ${ }^{+}$

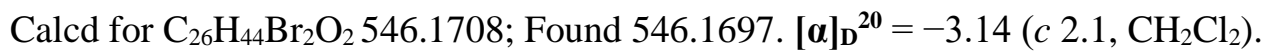

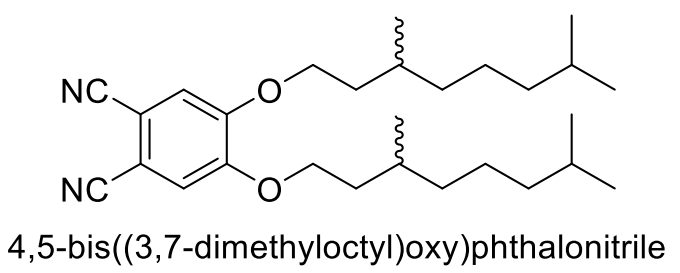

(R)-4,5-bis((3,7-dimethyloctyl)oxy)phthalonitrile Synthesized following a modified literature procedure. ${ }^{7}$ To a $100 \mathrm{~mL}$ round-bottomed flask topped with a reflux condenser was added $(R)$-1,2-dibromo4,5-bis((3,7-dimethyloctyl)oxy)benzene (2.5 g, $4.56 \mathrm{mmol}, 1$ equiv.) and dimethylformamide (40 $\mathrm{mL})$. Then copper(I) cyanide (1.63 g, 18.23 mmol, 4 equiv.) was added carefully. CAUTION: Copper cyanide is highly toxic and liberates highly toxic hydrogen cyanide gas upon exposure to acid. The solution was heated to reflux under an atmosphere of nitrogen for 6 hours. After cooling to room temperature, saturated aqueous ammonium hydroxide $(25 \mathrm{~mL})$ was added, and the slurry was stirred overnight. Then the precipitate was collected by filtration, and washed with saturated aqueous ammonium hydroxide and water. The greenish residue was dissolved in chloroform, dried over magnesium sulfate, decolored by the addition of activated charcoal, filtered, and concentrated under reduced pressure. The resulting white solid did not require further purification (1.32 g, 59\%). NMR characterization consistent with (rac)-4,5-bis((3,7dimethyloctyl)oxy)phthalonitrile. ${ }^{1}$ H NMR (400 MHz, Chloroform- $d$ ) $\delta 7.12$ (s, 2H), $4.14-4.02$ (m, 4H), $1.97-1.81(\mathrm{~m}, 2 \mathrm{H}), 1.71-1.49(\mathrm{~m}, 6 \mathrm{H}), 1.38-1.24(\mathrm{~m}, 6 \mathrm{H}), 1.23-1.08(\mathrm{~m}, 6 \mathrm{H}), 0.95(\mathrm{~d}, \mathrm{~J}=6.3 \mathrm{~Hz}$, $6 \mathrm{H}), 0.87$ (d, J = 6.6 Hz, 12H). ${ }^{13} \mathrm{C}$ NMR (151 MHz, CDCl3) $\delta 152.58,116.10,115.82,108.54,68.31$, 39.31, 37.30, 35.76, 30.02, 28.12, 24.83, 22.83, 22.73, 19.76. HRMS (DART/AccuTOF) m/z: [M] ${ }^{+}$Calcd for $\mathrm{C}_{28} \mathrm{H}_{44} \mathrm{~N}_{2} \mathrm{O}_{2} 440.3403$; Found 440.3386. $[\boldsymbol{\alpha}]_{\mathbf{D}}{ }^{20}=+5.26\left(c 2.0, \mathrm{CH}_{2} \mathrm{Cl}_{2}\right)$.

(rac)-4,5-bis((3,7-dimethyloctyl)oxy)phthalonitrile Synthesized following a modified literature procedure. ${ }^{7}$ To a $100 \mathrm{~mL}$ round-bottomed flask topped with a reflux condenser was added $(R)$-1,2-dibromo4,5-bis((3,7-dimethyloctyl)oxy)benzene (2.5 g, $4.56 \mathrm{mmol}, 1$ equiv.) and dimethylformamide (40 mL). Then copper(I) cyanide (1.63 g, 18.23 mmol, 4 equiv.) was added carefully. CAUTION: Copper cyanide is highly toxic and liberates highly toxic hydrogen cyanide gas upon exposure to acid. The solution was heated to reflux under an atmosphere of nitrogen for 6 hours. After cooling to room temperature, saturated aqueous ammonium hydroxide $(75 \mathrm{~mL})$ was added, and the slurry was stirred overnight. Then the precipitate was collected by filtration, and washed with saturated aqueous ammonium hydroxide and water. The greenish residue was dissolved in chloroform, washed with saturated aqueous ammonium hydroxide and water in a separatory funnel, dried over magnesium sulfate, filtered, and concentrated under reduced 
pressure. The resulting brown residue was purified by silica gel column chromatography with a solution of $5 \%$ diethyl ether in hexanes as the eluant, recovering a white solid product. (1.32 g, 59\%). Characterization consistent with the literature. ${ }^{2}{ }^{1} \mathbf{H}$ NMR $(400 \mathrm{MHz}$, Chloroform- $d$ ) $\delta 7.11(\mathrm{~s}, 2 \mathrm{H}), 4.14-4.01$ (m, 4H), 1.95 - $1.83(\mathrm{~m}, 2 \mathrm{H}), 1.71-1.61(\mathrm{~m}, 4 \mathrm{H}), 1.57-1.48(\mathrm{~m}, 2 \mathrm{H}), 1.36-1.22(\mathrm{~m}, 6 \mathrm{H}), 1.22-1.11(\mathrm{~m}, 6 \mathrm{H}), 0.95$ $(\mathrm{d}, \mathrm{J}=6.2 \mathrm{~Hz}, 6 \mathrm{H}), 0.87(\mathrm{~d}, \mathrm{~J}=6.6 \mathrm{~Hz}, 12 \mathrm{H}) .{ }^{13} \mathbf{C} \mathbf{N M R}(151 \mathrm{MHz}, \mathrm{CDCl} 3) \delta 152.59,116.10,115.82$, $108.54,68.31,39.32,37.33,37.31,35.75,30.02,28.11,24.82,22.83,22.74,19.76$. HRMS (DART/AccuTOF) m/z: [M] ${ }^{+}$Calcd for $\mathrm{C}_{28} \mathrm{H}_{44} \mathrm{~N}_{2} \mathrm{O}_{2} 440.3403$; Found 440.3386 .

(S)-4,5-bis((3,7-dimethyloctyl)oxy)phthalonitrile Synthesized following a modified literature procedure. ${ }^{7}$ To a $100 \mathrm{~mL}$ round-bottomed flask topped with a reflux condenser was added (S)-1,2-dibromo4,5-bis((3,7-dimethyloctyl)oxy)benzene (5.9 g, $10.76 \mathrm{mmol}, 1$ equiv.) and dimethylformamide (60 mL). Then copper(I) cyanide (3.85 g, 43.03 mmol, 4 equiv.) was added carefully. CAUTION: Copper cyanide is highly toxic and liberates highly toxic hydrogen cyanide gas upon exposure to acid. The solution was heated to reflux under an atmosphere of nitrogen for 6 hours. After cooling to room temperature, saturated aqueous ammonium hydroxide $(25 \mathrm{~mL})$ was added, and the slurry was stirred overnight. Then the precipitate was collected by filtration, and washed with saturated aqueous ammonium hydroxide and water. The greenish residue was dissolved in chloroform, dried over magnesium sulfate, decolored by the addition of activated charcoal, filtered, and concentrated under reduced pressure. The resulting brown residue was purified by silica gel column chromatography with a solution of 5\% ethyl acetate in hexanes as the eluant, recovering an off-white solid product $(2.75 \mathrm{~g}, 58 \%)$. NMR characterization consistent with ( $\mathrm{rac}$ )-4,5bis((3,7-dimethyloctyl)oxy)phthalonitrile. ${ }^{1} \mathbf{H}$ NMR (400 MHz, Chloroform- $d$ ) $\delta 7.12$ (s, 2H), $4.13-4.04$ (m, 4H), $1.96-1.82(\mathrm{~m}, 2 \mathrm{H}), 1.73-1.59(\mathrm{~m}, 4 \mathrm{H}), 1.58-1.48(\mathrm{~m}, 2 \mathrm{H}), 1.38-1.25(\mathrm{~m}, 6 \mathrm{H}), 1.22-1.08$ $(\mathrm{m}, 6 \mathrm{H}), 0.95(\mathrm{~d}, \mathrm{~J}=6.0 \mathrm{~Hz}, 6 \mathrm{H}), 0.87(\mathrm{~d}, \mathrm{~J}=6.6 \mathrm{~Hz}, 12 \mathrm{H}) .{ }^{13} \mathbf{C} \mathbf{N M R}(151 \mathrm{MHz}, \mathrm{CDCl} 3) \delta 152.58,116.10$, $115.82,108.54,68.31,39.31,37.31,35.76,30.02,28.12,24.83,22.83,22.74,19.76$. HRMS

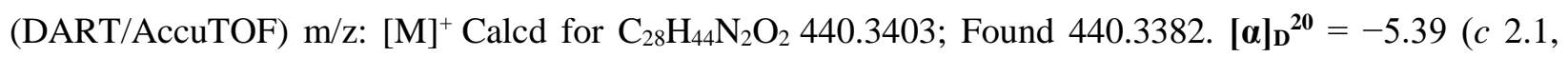
$\mathrm{CH}_{2} \mathrm{Cl}_{2}$ ).

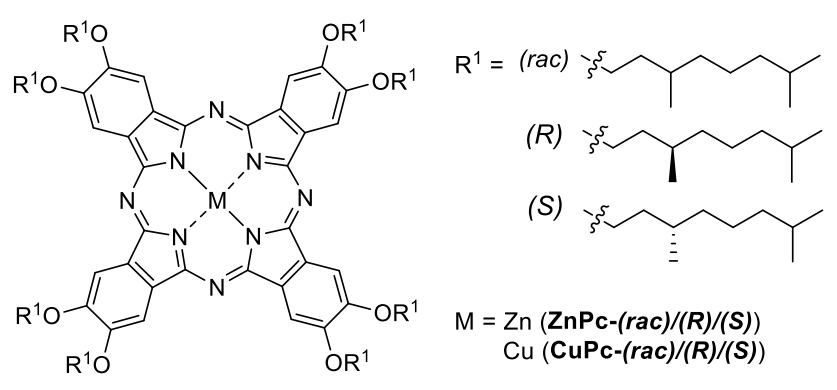

ZnPc-(R) Synthesized following a modified literature procedure. ${ }^{8}$ To a dry $25 \mathrm{~mL}$ round-bottom flask topped with a condenser was added $(R)-4,5$-bis((3,7-dimetthyloctyl)oxy)phthalonitrile (500 mg, $1.13 \mathrm{mmol}$, 
1.0 equiv.), zinc(II) chloride (38.66 mg, $0.283 \mathrm{mmol}, 0.25$ equiv.) and pentane-1-ol (10 $\mathrm{mL})$ under a nitrogen atmosphere. Then 1,8-diazabicyclo[5.4.0]undec-7-ene ( $0.169 \mathrm{~mL}, 1.13 \mathrm{mmol}, 1$ equiv) was added. The solution was heated to reflux for 18 hours. Upon cooling to room temperature, the solution was poured into methanol. The precipitate was collected by centrifugation ( $4000 \mathrm{rpm}, 15$ minutes) followed by removal of the supernatant, and then dried under reduced pressure. The residue was purified by silica gel column chromatography with a $1 \%$ solution of pyridine in dichloromethane as the eluant, giving the product as a green greasy solid (362 mg, 69\%). HRMS (MALDI/TOF) m/z: [M] ${ }^{+}$Calcd for $\mathrm{C}_{112} \mathrm{H}_{176} \mathrm{~N}_{8} \mathrm{O}_{8} \mathrm{Zn} 1825.2903$; Found 1825.29. Elemental Analysis Anal. Calcd for $\mathrm{C}_{112} \mathrm{H}_{176} \mathrm{~N}_{8} \mathrm{O}_{8} \mathrm{Zn}: \mathrm{C}, 73.59 ; \mathrm{H}, 9.70 ; \mathrm{N}$, 6.13. Found: C, 72.70; H, 9.59; N, 6.00. UV/Vis (Chloroform): $\lambda_{\max }(\log \varepsilon)=293$ (4.64), 354 (4.85), 613 (4.31), 679 (5.12).

ZnPc-(rac) Synthesized following a modified literature procedure. ${ }^{8}$ To a dry $25 \mathrm{~mL}$ round-bottom flask topped with a condenser was added (rac)-4,5-bis((3,7-dimetthyloctyl)oxy)phthalonitrile (250 mg, 0.567 mmol, 1.0 equiv.), zinc(II) chloride (19.3 mg, $0.141 \mathrm{mmol}, 0.25$ equiv.) and pentane-1-ol (5 mL) under a nitrogen atmosphere. Then 1,8-diazabicyclo[5.4.0]undec-7-ene (0.084 $\mathrm{mL}, 0.567 \mathrm{mmol}, 1$ equiv.) was added. The solution was heated to reflux for 18 hours. Upon cooling to room temperature, the solution was poured into methanol. The precipitate was collected by centrifugation ( $4000 \mathrm{rpm}, 15$ minutes) followed by removal of the supernatant, and then dried under reduced pressure. The residue was purified by silica gel column chromatography with a $1 \%$ solution of pyridine in dichloromethane as the eluant, giving the product as a green greasy solid (177 mg, 68\%). HRMS (MALDI/TOF) m/z: [M] $]^{+}$Calcd for $\mathrm{C}_{112} \mathrm{H}_{176} \mathrm{~N}_{8} \mathrm{O}_{8} \mathrm{Zn}$ 1825.2903; Found 1825.34. Elemental Analysis Anal. Calcd for $\mathrm{C}_{112} \mathrm{H}_{176} \mathrm{~N}_{8} \mathrm{O}_{8} \mathrm{Zn}: \mathrm{C}, 73.59 ; \mathrm{H}, 9.70$; N, 6.13. Found: C, 73.45; H, 9.52; N, 6.33. UV/Vis (Chloroform): $\lambda_{\max }(\log \varepsilon)=279$ (4.85), 355 (5.01), 613 (4.49), 680 (5.27).

ZnPc-(S) Synthesized following a modified literature procedure. ${ }^{8}$ To a dry $25 \mathrm{~mL}$ round-bottom flask topped with a condenser was added (S)-4,5-bis((3,7-dimetthyloctyl)oxy)phthalonitrile (500.0 mg, 1.13 mmol, 1.0 equiv.), zinc(II) chloride (38.66 mg, $0.283 \mathrm{mmol}, 0.25$ equiv.) and pentane-1-ol (10 mL) under a nitrogen atmosphere. Then 1,8-diazabicyclo[5.4.0]undec-7-ene $(0.169 \mathrm{~mL}, 1.13 \mathrm{mmol}, 1$ equiv.) was added. The solution was heated to reflux for 18 hours. Upon cooling to room temperature, the solution was poured into methanol. The precipitate was collected by centrifugation ( $4000 \mathrm{rpm}, 15$ minutes) followed by removal of the supernatant, and then dried under reduced pressure. The residue was purified by silica gel column chromatography with a $1 \%$ solution of pyridine in dichloromethane as the eluant, giving the product as a green greasy solid (406 mg, 78\%). HRMS (MALDI/TOF) m/z: [M] $]^{+}$Calcd for $\mathrm{C}_{112} \mathrm{H}_{176} \mathrm{~N}_{8} \mathrm{O}_{8} \mathrm{Zn}$ 1825.2903; Found 1825.44. Elemental Analysis Anal. Calcd for $\mathrm{C}_{112} \mathrm{H}_{176} \mathrm{~N}_{8} \mathrm{O}_{8} \mathrm{Zn}$ : C, 73.59; H, 9.70; N, 
6.13. Found: C, 73.24; H, 9.56; N, 6.10. UV/Vis (Chloroform): $\lambda_{\max }(\log \varepsilon)=277$ (4.74), 354 (4.87), 613 (4.31), 680 (5.08).

CuPc-(R) Synthesized following a modified literature procedure. ${ }^{8}$ To a dry $25 \mathrm{~mL}$ round-bottom flask topped with a condenser was added $(R)-4,5$-bis((3,7-dimetthyloctyl)oxy)phthalonitrile (250 mg, 0.567 mmol, 1.0 equiv.), copper(II) chloride (19.1 mg, $0.141 \mathrm{mmol}, 0.25$ equiv.) and pentane-1-ol (5 mL) under a nitrogen atmosphere. Then 1,8-diazabicyclo[5.4.0]undec-7-ene $(0.084 \mathrm{~mL}, 0.567 \mathrm{mmol}, 1$ equiv.) was added. The solution was heated to reflux for 18 hours. Upon cooling to room temperature, the solution was poured into methanol. The precipitate was collected by centrifugation (4000 rpm, 15 minutes) followed by removal of the supernatant, and then dried under reduced pressure. The residue was purified by silica gel column chromatography with a $1 \%$ solution of pyridine in dichloromethane as the eluant, giving the product as a green greasy solid (197 mg, 69\%). HRMS (MALDI/TOF) m/z: [M] ${ }^{+}$Calcd for $\mathrm{C}_{112} \mathrm{H}_{176} \mathrm{~N}_{8} \mathrm{O}_{8} \mathrm{Cu}$ 1824.2907: Found 1824.34. Elemental Analysis Anal. Calcd for $\mathrm{C}_{112} \mathrm{H}_{176} \mathrm{~N}_{8} \mathrm{O}_{8} \mathrm{Cu}: \mathrm{C}, 73.66 ; \mathrm{H}, 9.71 ; \mathrm{N}$, 6.14. Found: C, 73.40; H, 9.49; N, 6.02. UV/Vis (Chloroform): $\lambda_{\max }(\log \varepsilon)=296$ (4.84), 340 (4.90), 419 (4.51), 613 (4.61), $680(5.40)$.

CuPc-(rac) Synthesized following a modified literature procedure. ${ }^{8}$ To a dry $25 \mathrm{~mL}$ round-bottom flask topped with a condenser was added (rac)-4,5-bis((3,7-dimetthyloctyl)oxy)phthalonitrile (250 mg, 0.567 mmol, 1.0 equiv.), copper(II) chloride (19.1 mg, $0.141 \mathrm{mmol}, 0.25$ equiv.) and pentane- 1 -ol (5 mL) under a nitrogen atmosphere. Then 1,8-diazabicyclo[5.4.0]undec-7-ene (0.084 mL, $0.567 \mathrm{mmol}, 1$ equiv.) was added. The solution was heated to reflux for 18 hours. Upon cooling to room temperature, the solution was poured into methanol. The precipitate was collected by centrifugation (4000 rpm, 15 minutes) followed by removal of the supernatant, and then dried under reduced pressure. The residue was purified by silica gel column chromatography with a $1 \%$ solution of pyridine in dichloromethane as the eluant, giving the product as a green greasy solid (166 mg, 64\%). HRMS (MALDI/TOF) m/z: [M] ${ }^{+}$Calcd for $\mathrm{C}_{112} \mathrm{H}_{176} \mathrm{~N}_{8} \mathrm{O}_{8} \mathrm{Cu}$ 1824.2907; Found 1824.38. Elemental Analysis Anal. Calcd for $\mathrm{C}_{112} \mathrm{H}_{176} \mathrm{~N}_{8} \mathrm{O}_{8} \mathrm{Cu}: \mathrm{C}, 73.66 ; \mathrm{H}, 9.71 ; \mathrm{N}$, 6.14. Found: C, 73.23; H, 9.82; N, 6.05. UV/Vis (Chloroform): $\lambda_{\max }(\log \varepsilon)=295$ (4.82), 340 (4.90), 420 (4.50), 613 (4.61), 680 (5.40).

CuPc-(S) Synthesized following a modified literature procedure. ${ }^{8}$ To a dry $25 \mathrm{~mL}$ round-bottom flask topped with a condenser was added $(S)$-4,5-bis((3,7-dimetthyloctyl)oxy)phthalonitrile (200.0 mg, 0.453 mmol, 1.0 equiv.), copper(II) chloride ( $15.25 \mathrm{mg}, 0.113 \mathrm{mmol}, 0.25$ equiv.) and pentane-1-ol ( $5 \mathrm{~mL}$ ) under a nitrogen atmosphere. Then 1,8-diazabicyclo[5.4.0]undec-7-ene (0.067 mL, $0.453 \mathrm{mmol}, 1$ equiv.) was added. The solution was heated to reflux for 18 hours. Upon cooling to room temperature, the solution was poured into methanol. The precipitate was collected by centrifugation (4000 rpm, 15 minutes) followed by removal of the supernatant, and then dried under reduced pressure. The residue was purified by silica gel 
column chromatography with a $1 \%$ solution of pyridine in dichloromethane as the eluant, giving the product as a green greasy solid (137 mg, 66\%). HRMS (MALDI/TOF) m/z: [M] ${ }^{+}$Calcd for $\mathrm{C}_{112} \mathrm{H}_{176} \mathrm{~N}_{8} \mathrm{O}_{8} \mathrm{Cu}$ : 1824.2907; Found 1824.44. Elemental Analysis Anal. Calcd for $\mathrm{C}_{112} \mathrm{H}_{176} \mathrm{~N}_{8} \mathrm{O}_{8} \mathrm{Cu}: \mathrm{C}, 73.66 ; \mathrm{H}, 9.71 ; \mathrm{N}$, 6.14. Found: C, 71.00; H, 9.37; N, 5.79. UV/Vis (Chloroform): $\lambda_{\max }(\log \varepsilon)=296$ (4.76), 340 (4.84), 420 (4.44), 613 (4.56), 680 (5.35).

\section{Synthesis of SubPc}

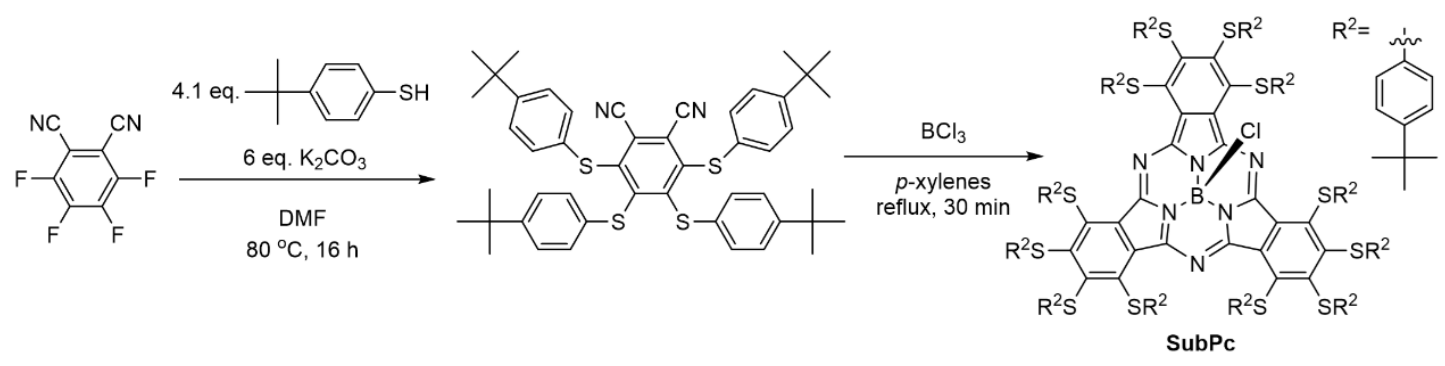

Figure S8 Synthetic route for SubPc.

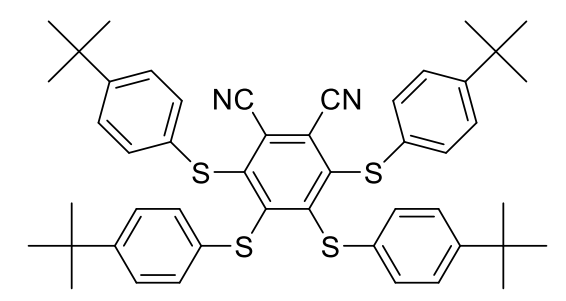

3,4,5,6-tetrakis((4-(tert-butyl)phenyl)thio)phthalonitrile

3,4,5,6-tetrakis((4-(tert-butyl)phenyl)thio)phthalonitrile Procedure identical to previously reported procedure, as the chemical used in this report is from the same batch. ${ }^{9}$ To a $250 \mathrm{~mL}$ Schlenk flask with a stirrer containing 3,4,5-tetrafluorophthalonitrile (2.0 g, $10 \mathrm{mmol}, 1$ equiv.) under argon was added dry DMF (100 mL), 4-(tert-butyl)benzenethiol (7.1 mL, $41 \mathrm{mmol}, 4.1$ equiv.). Then $\mathrm{K}_{2} \mathrm{CO}_{3}$ (8.3 g, 60 mmol 6 equiv.) was added under a flow of argon. The reaction was stirred at $80{ }^{\circ} \mathrm{C}$ for 16 hours. The reaction mixture was cooled to room temperature and diluted with water and chloroform. The layers were separated, and the aqueous layer was extracted twice with chloroform. The combined organic layers were washed four times with water and once with brine, dried over $\mathrm{MgSO}_{4}$, and filtered. The filtrate was concentrated under reduced pressure and purified by recrystallization from hot acetonitrile to yield an orange powder $(6.3 \mathrm{~g}, 81 \%) .{ }^{1} \mathbf{H}$ NMR (400 MHz, Chloroform-d) $\delta 7.29$ (d, J = 8.1 Hz, 4H), 7.25 (d, J = 8.3 Hz, 4H), 7.13 (d, J = 8.2 Hz, 4H), $6.95(\mathrm{~d}, \mathrm{~J}=8.1 \mathrm{~Hz}, 4 \mathrm{H}), 1.29(\mathrm{~d}, \mathrm{~J}=2.7 \mathrm{~Hz}, 36 \mathrm{H}) .{ }^{13} \mathrm{C}$ NMR (101 MHz, Chloroform-d) $\delta 152.65$, 
$151.78,150.99,146.16,132.57,131.13,130.70,129.68,126.70,126.57,123.03,113.96,34.81,34.75$, 31.37, 31.33.

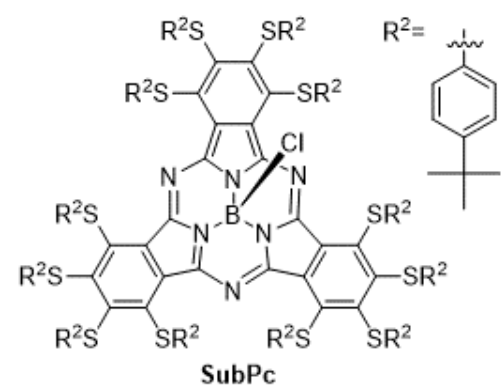

SubPc Procedure identical to previously reported procedure, as the chemical used in this report is from the same batch. ${ }^{9} \mathrm{BCl}_{3}(1.0 \mathrm{~mL}, 1 \mathrm{M}$ solution in $p$-xylene, 1 equiv.) was added to 3,4,5,6-tetrakis((4-(tertbutyl)phenyl)thio)phthalonitrile (785 mg, $1 \mathrm{mmol}, 1$ equiv.) and stirrer under argon in a $25 \mathrm{~mL}$ two-necked round-bottomed flask fitted with a condenser and septum. The septum was replaced with a glass stopper, and the apparatus was placed in a pre-heated oil bath at $160{ }^{\circ} \mathrm{C}$ and stirred for 30 minutes. After cooling to room temperature, the solution was concentrated under reduced pressure. The resulting blue solid was subjected to silica gel column chromatography with toluene/hexanes (2:3, v:v) as eluent, yielding SubPc as a dark blue solid (62 mg, 8\%). ${ }^{1} \mathbf{H}$ NMR (600 MHz, Chloroform-d) $\delta 7.32$ (d, J=8.7 Hz, 12H), 7.11 (d, $\mathrm{J}=8.7 \mathrm{~Hz}, 12 \mathrm{H}), 7.06(\mathrm{~d}, \mathrm{~J}=8.7 \mathrm{~Hz}, 12 \mathrm{H}), 6.92(\mathrm{~d}, \mathrm{~J}=8.7 \mathrm{~Hz}, 12 \mathrm{H}), 1.21(\mathrm{~s}, 54 \mathrm{H}), 1.15(\mathrm{~s}, 54 \mathrm{H}) .{ }^{13} \mathrm{C}$ NMR (151 MHz, Chloroform-d) $\delta 149.45,149.36,149.31$, 147.73, 139.80, 134.72, 134.60, 133.69, 129.42, 128.63, 125.95, 125.92, 34.54, 34.49, 31.42, 31.35. HRMS (MALDI/TOF) m/z: Calcd for $\mathrm{C}_{144} \mathrm{H}_{156} \mathrm{BClN}_{6} \mathrm{~S}_{12}[\mathrm{M}]^{+}$2397.886; Found 2397.9159. UV/Vis (Toluene): $\lambda_{\max }(\log \varepsilon)=310$ (4.77), 645 (4.93).

\section{Synthesis of $\mathrm{TbPc}_{2}-(\mathrm{rac})$}
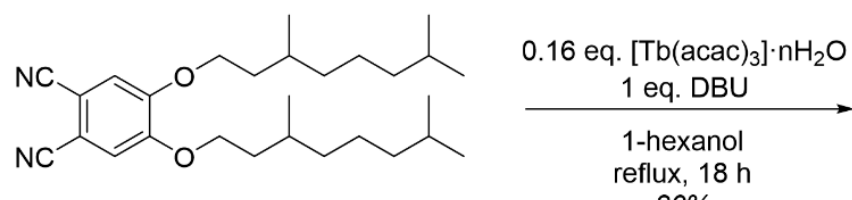

$30 \%$

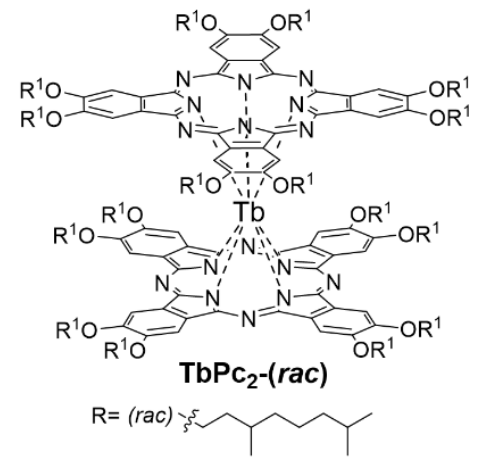

Figure S9 Synthesis of $\mathbf{T b P c}_{2}-(\mathbf{r a c})$. 
$\mathbf{T b P c}_{2}$-(rac) To a stirred solution of 4,5-bis((3,7-dimethyloctyl)oxy)phthalonitrile (200.0 mg, $0.45 \mathrm{mmol}$, 1 equiv.) in 1-hexanol, (3 ml) [ $\left.\mathrm{Tb}(\mathrm{acac})_{3}\right] \cdot n \mathrm{H}_{2} \mathrm{O}(32.9 \mathrm{mg}, 0.072 \mathrm{mmol}, 0.16$ equiv) was added followed by 1,8-diazabicyclo[5.4.0]undec-7-ene $(0.067 \mathrm{~mL}, 0.45 \mathrm{mmol}, 1$ equiv). The reaction was heated to reflux and stirred for 16 hours. The dark-green mixture was cooled to room temperature and methanol $(20 \mathrm{~mL})$ was added. The precipitate was separated via centrifugation ( $8000 \mathrm{rpm}, 10$ minutes) and then further purified by flash chromatography using hexanes/ethyl acetate (9:1) as the eluent to obtain a green solid (61.6 $\mathrm{mg}$, 30\%). HRMS (MALDI/TOF) m/z: $[\mathrm{M}+3 \mathrm{H}]^{+}$Calcd for $\mathrm{C}_{224} \mathrm{H}_{355} \mathrm{~N}_{16} \mathrm{O}_{16} \mathrm{~Tb}$ 3684.671; Found 3684.672. Elemental Analysis Anal. Calcd for $\mathrm{C}_{224} \mathrm{H}_{352} \mathrm{~N}_{16} \mathrm{O}_{16} \mathrm{~Tb}$ : C, 73.03; H, 9.63; N, 6.08. Found: C, 73.56; H, 10.05; N, 5.69. UV-Vis (Dichloromethane): $\lambda_{\max }(\log \varepsilon)=292$ (5.04), 336 (5.01), 368 (5.00), 486 (4.48), 609 (4.40), 673 (5.01).

\section{Synthesis of ZnPc-OT}
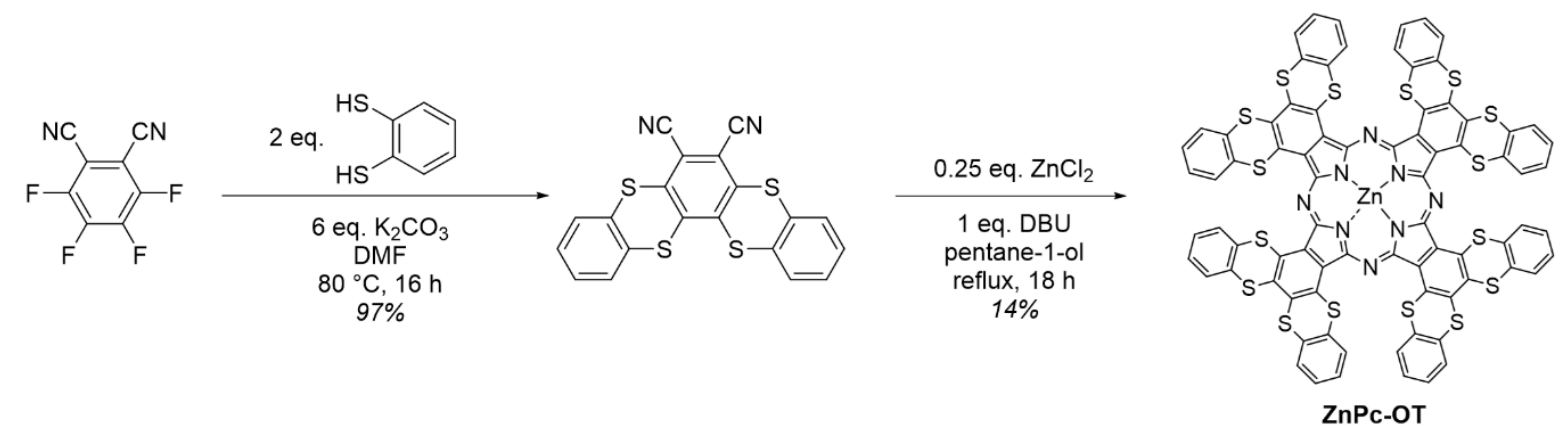

Figure S10 Synthetic route for ZnPc-OT.

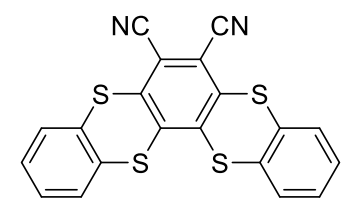

benzo[5,6][1,4]dithiino[2,3-a]thianthrene-

6,7-dicarbonitrile

Benzo[5,6][1,4]dithiino[2,3-a]thianthrene-6,7-dicarbonitrile: Following a previously reported procedure, ${ }^{10}$ to an oven-dried $50 \mathrm{~mL}$ round bottomed flask under argon was added tetrafluorophthalonitrile (200 mg, $1 \mathrm{mmol}, 1$ equiv.), potassium carbonate (829 mg, $6 \mathrm{mmol}, 6$ equiv.), and $10 \mathrm{~mL}$ dry dimethylformamide. After stirring until the dissolution of tetrafluorophthalonitrile, 1,2-benzenedithiol $\left(0.230 \mathrm{~mL}, 2 \mathrm{mmol}, 2\right.$ eqiv.) was added. The reaction was stirred at $80{ }^{\circ} \mathrm{C}$ for 16 hours. Upon cooling to room temperature, $10 \mathrm{~mL} 1 \mathrm{M} \mathrm{HCl}$ was added. The precipitate was collected by vacuum filtration, and washed with water and methanol, and dried under reduced pressure to obtain a yellow solid (394 mg, 97\%). 
Characterization in agreement with the literature. ${ }^{10}{ }^{1} \mathbf{H}$ NMR $\left(600 \mathrm{MHz}, \mathrm{DMSO}-d_{6}\right) \delta 7.79-7.74(\mathrm{~m}, 4 \mathrm{H})$, $7.52-7.48(\mathrm{~m}, 4 \mathrm{H})$.

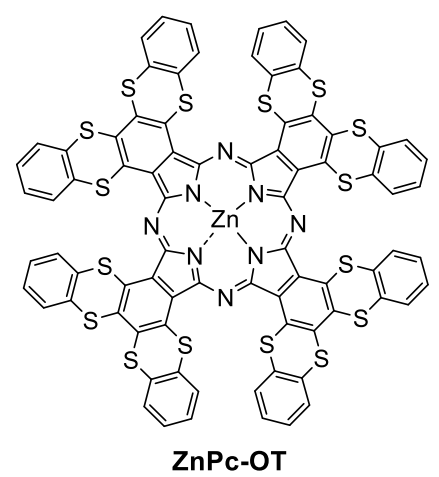

ZnPc-OT: To an oven-dried two dram vial under argon was added benzo[5,6][1,4]dithiino[2,3a]thianthrene-6,7-dicarbonitrile (200 mg, 0.49 mmol, 4 equiv.), zinc(II) chloride (16.8 mg, $0.12 \mathrm{mmol}, 1$ equiv.) and pentane-1-ol (4 mL). After stirring until the solids dissolved, 1,8-diazabicyclo[5.4.0]undec-7ene $\left(0.074 \mathrm{~mL}, 0.49 \mathrm{mmol}, 4\right.$ equiv.) was added by syringe. The vessel was heated to $140{ }^{\circ} \mathrm{C}$ under a flow of argon, and then sealed. The reaction was stirred at $140{ }^{\circ} \mathrm{C}$ for 16 hours. Upon cooling to room temperature, hot methanol was added. The precipitate was collected by vacuum filtration and washed with water and methanol, and dried under reduced pressure. The solid was purified by silica gel column chromatography using chloroform as the eluent to obtain a deep brown powder (29.6 mg, 14\%). HRMS (MALDI/TOF) $\mathrm{m} / \mathrm{z}$ : $[\mathrm{M}]^{+}$Calcd for $\mathrm{C}_{80} \mathrm{H}_{32} \mathrm{~N}_{8} \mathrm{~S}_{16} \mathrm{Zn}$ 1679.7573; Found 1679.9732. Elemental Analysis Anal. Calcd for $\mathrm{C}_{80} \mathrm{H}_{32} \mathrm{~N}_{8} \mathrm{~S}_{16} \mathrm{Zn}$ : C, 57.08; H, 1.92; N, 6.66. Found: C, 57.27; H, 2.25; N, 6.29. UV-Vis (Chloroform): $\lambda_{\max }(\log \varepsilon)=276$ (5.05), 350 (4.73), 695 (4.49), 776 (5.13).

\section{Faraday Rotation Measurement}

For solid samples, thin films (50-300 nm typically) were deposited via spin coating onto a highprecision \#1.5H glass coverslip (170 $\pm 5 \mu \mathrm{m}$, Thorlabs CG15KH). Substrates were cleaned by sequential sonication in acetone, isopropanol, and Milli-Q purified water, followed by UV-ozone treatment. Typically, solutes were dissolved in chloroform at a concentration of $20 \mathrm{mg} \mathrm{mL}^{-1}$, and applied to the substrate before spinning at $1000 \mathrm{rpm}$. For solutes with poor solubility, pyridine may be added at a concentration of $1 \%$ with respect to the mass of the solute. For liquid samples, solutions were loaded into a PTFE-stoppered quartz cuvette with a $0.5 \mathrm{~mm}$ light path (FireflySci Type 21 macro cuvette). The thicknesses of thin films were measured by either contact profilometry (Dektak 6M profilometer, Dektak32 analysis software) or alternatively atomic-force microscopy (AFM) for soft samples (Nanoscope V with Dimension 3100 D31005-1 in tapping mode, NanoScope analysis software). 


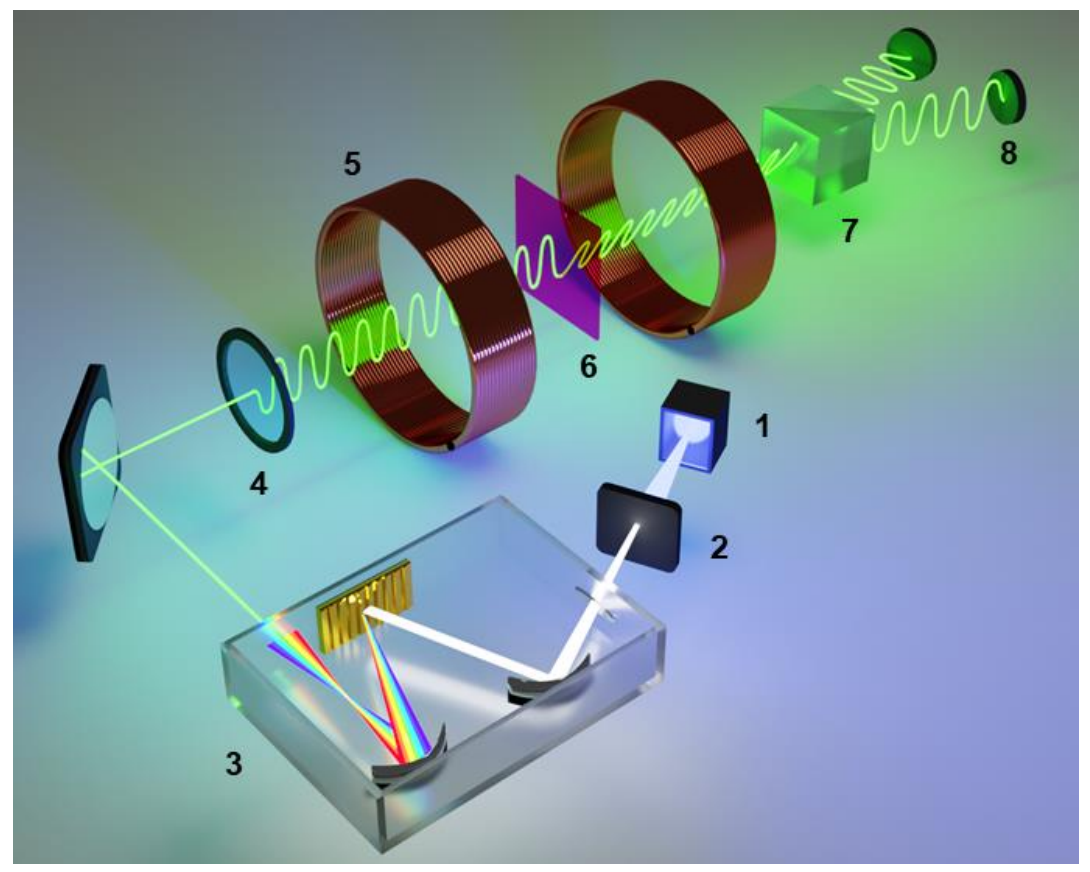

Figure S11 Design schematic of the Faraday rotation spectrometer. (1) 300W xenon arc lamp (2) filter wheel, (3) monochromator (4) $45^{\circ}$ wire-grid polarizer (5) DC electromagnet (6) sample (7) Wollaston prism (8) balanced photodetector.

The Faraday rotation instrument is depicted schematically in Figure S11, and is based off of established designs. ${ }^{11-13}$ Light is generated by a tunable light source (Newport TLS260-300X). The beam is then linearly polarized $\left(45^{\circ}\right)$ by a wire-grid polarizer, before passing through the sample. The sample is placed in the gap of an electromagnet (GMW 3470) which is powered by a Crown DC-300 Series II amplifier. The beam is then split into divergent beams of orthogonal polarization by an $\alpha$-BBO Wollaston prism (Thorlabs WPA10), and finally recorded by a balanced photodetector (Thorlabs PDB210A). The signal is additionally modulated by an optical chopper (Stanford Research SR541, $1 \mathrm{kHz}$ ). The signal of one photodiode array and of the difference between both photodiode arrays are sent to lock-in amplifiers (Stanford Research, SR-830 and SR-850 respectively) which isolate the signal at the frequency of the chopper. Both lock-in amplifiers employ a $10 \mathrm{~ms}$ time constant.

Since Faraday rotation was measured using a home-built instrument, a discussion of the instrument and data processing is instructive. To calculate magnetic circular birefringence (MCB), we must first calculate CB from the signal received by the detectors. To do so, we define the stokes vector for our unpolarized input light of total irradiance $I_{0}$. 
Equation S1

$$
S_{\text {in }}=\left[\begin{array}{l}
I_{0} \\
0 \\
0 \\
0
\end{array}\right]
$$

Next, we define the Muller matrices of our optical elements, beginning with our $45^{\circ}$ linear polarizer.

Equation S2

$$
M_{45}=\frac{1}{2}\left[\begin{array}{llll}
1 & 0 & 1 & 0 \\
0 & 0 & 0 & 0 \\
1 & 0 & 1 & 0 \\
0 & 0 & 0 & 0
\end{array}\right]
$$

For our sample we omit magnetic-field dependencies and ignore absorption for convenience. We include two polarization effects: circular dichroism $(\mathrm{CD})$ and $\mathrm{CB}$.

\section{Equation S3}

$$
M_{\text {sample }}=\left[\begin{array}{cccc}
1 & 0 & 0 & C D \\
0 & 1 & C B & 0 \\
0 & -C B & 1 & 0 \\
C D & 0 & 0 & 1
\end{array}\right]
$$

Finally, we can model the effect of the Wollaston prism by treating each divergent beam as passing through either a vertical linear polarizer by:

\section{Equation S4}

$$
M_{\text {vert }}=\frac{1}{2}\left[\begin{array}{cccc}
1 & -1 & 0 & 0 \\
-1 & 1 & 0 & 0 \\
0 & 0 & 0 & 0 \\
0 & 0 & 0 & 0
\end{array}\right]
$$

or horizontal linear polarizer by:

\section{Equation S5}

$$
M_{\text {horz }}=\frac{1}{2}\left[\begin{array}{llll}
1 & 1 & 0 & 0 \\
1 & 1 & 0 & 0 \\
0 & 0 & 0 & 0 \\
0 & 0 & 0 & 0
\end{array}\right]
$$

Now we have all of the required elements to construct our system in Stokes-Muller form. The Stokes vectors for the light incident on each detector, labelled A and B, are given by:

$$
\begin{array}{ll}
\text { Equation S6 } & S_{A}=M_{\text {vert }} M_{\text {sample }} M_{45} S_{\text {in }} \\
\text { Equation S7 } & S_{B}=M_{\text {horz }} M_{\text {sample }} M_{45} S_{\text {in }}
\end{array}
$$

Simplifying we find: 
Equation S8

$$
\begin{aligned}
& S_{A}=\frac{1}{4}\left[\begin{array}{c}
I_{0}(-C B+1) \\
I_{0}(C B-1) \\
0 \\
0
\end{array}\right] \\
& S_{B}=\frac{1}{4}\left[\begin{array}{c}
I_{0}(C B+1) \\
I_{0}(C B+1) \\
0 \\
0
\end{array}\right]
\end{aligned}
$$

Thus, the signal measured by the difference detector is given by the difference in total irradiance between detectors $\mathrm{A}\left(I_{A}\right)$ and $\mathrm{B}\left(I_{B}\right)$, which we may write as:

$$
\text { Equation S10 } \quad I_{A}-I_{B}=\frac{1}{2} C B I_{0}
$$

In order to correct for any fluctuations in light intensity or absorption by the sample, we normalize to the light intensity giving:

\section{Equation S11 $\frac{I_{A}-I_{B}}{I_{A}+I_{B}}=C B$}

Practically we expect that CB will be small when compared to the overall light intensity, and so we can approximate $I_{A} \approx I_{B}$, thus:

Equation $\mathrm{S12} \frac{I_{A}-I_{B}}{2 I_{A}}=C B$

$\mathrm{CB}$ is now expressed in terms which are directly measured by the balanced photodetector.

For Verdet constant measurements, the signal from one photodiode array and the difference between both photodiode arrays are measured while the magnetic field is swept discontinuously between -0.5 and +0.5 T. MCB is determined by a linear regression of CB (as measured by Equation S12) as a function of magnetic field strength. An empirical calibration factor is then applied to determine the MCB (or Faraday rotation) in degrees per Tesla. The calibration factor is determined and validated using samples of terbium-gallium garnet (TGG) and optical borosilicate glass (BK7) with known Verdet constants ${ }^{14}$ and measured thickness, as reported in Table S1. This procedure is repeated at each wavelength, and the entire

\begin{tabular}{|c|c|c|c|c|c|}
\hline & Sample & $532 \mathrm{~nm}$ & $633 \mathrm{~nm}$ & $670 \mathrm{~nm}$ & $980 \mathrm{~nm}$ \\
\hline \multirow{2}{*}{ BK7 } & Measured & 371 & 255 & 219 & 97 \\
\hline & Literature Reported $^{a}$ & 360 & 250 & 223 & 100 \\
\hline \multirow{2}{*}{ TGG } & Measured & -13082 & -8433 & -7132 & -2782 \\
\hline & Literature Reported $^{a}$ & -10120 & -8130 & -7300 & -3400 \\
\hline
\end{tabular}
process is automated using custom software implemented in LabView.

Table S1 Measured Verdet Constants of Standard Materials $\left(\operatorname{deg} \mathrm{T}^{-1} \mathrm{~m}^{-1}\right)$ 


\begin{tabular}{llllll}
\hline $\begin{array}{c}\text { 0.17 mm } \\
\text { glass slide }\end{array}$ & Measured & 372 & 259 & 219 & 98 \\
\hline
\end{tabular}

${ }^{a}$ Chem. Mater. 2011, 23, 516-521.

From this data the Verdet constant and an estimation of uncertainty may be calculated. Most samples are not free-standing; therefore, background subtraction is necessary. Given the experimental Faraday rotation of the sample with support $\left(\varphi_{e x}\right)$, the background rotation $\left(\varphi_{b k}\right)$ in degrees per tesla, and the thickness of the sample $(d)$ in meters, then the Verdet constant of the sample $\left(V_{s}\right)$ in degrees per tesla per meter is found by:

\section{Equation S13 $\quad V_{S}=\frac{\varphi_{e x}-\varphi_{b k}}{d}$}

Using the root-mean-square deviation of the Faraday rotation measurements ( $\sigma_{e x}$ and $\sigma_{b k}$ ), and from the standard deviation estimated for thickness determination $\left(\sigma_{d}\right)$, the standard deviation of the Verdet constant $\left(\sigma_{V}\right)$ may be estimated using the following formula with the simplifying assumption of negligible covariance:

\section{Equation S14}

$$
\sigma_{V} \approx\left|V_{S}\right| \sqrt{\left(\frac{\sqrt{\sigma_{e x}^{2}+\sigma_{b k}^{2}}}{\varphi_{e x}-\varphi_{b k}}\right)^{2}+\left(\frac{\sigma_{d}}{d}\right)^{2}}
$$

The results of these calculations are reported for the wavelength corresponding to the maximum Verdet constant for each material in Table 1. For solutions the Verdet constant also depends on the concentration of the chromophore, and so the mass specific magnetic rotation $\left([\alpha]_{\mathrm{sp}}\right)$ in units of deg $\mathrm{mL} \mathrm{T}^{-1} \mathrm{dm}^{-1} \mathrm{~g}^{-1} \mathrm{using}$ the units and notation of Shashoua. ${ }^{15}$. This property may be calculated by dividing the Verdet constant $\left(V_{s}\right)$ by the sample concentration $(c)$ in units of $\mathrm{g} \mathrm{mL}^{-1}$ as shown in the following equation:

$$
\text { Equation S15 } \quad[\alpha]_{s p}=\frac{\varphi_{e x}-\varphi_{b k}}{d \cdot c}
$$

With the standard deviation of the concentration $\left(\sigma_{c}\right)$, the standard deviation of the mass specific magnetic rotation may also be estimated according to the following formula:

\section{Equation S16}

$$
\sigma_{[\varphi]} \approx|[\varphi]| \sqrt{\left(\frac{\sqrt{\sigma_{e x}^{2}+\sigma_{b k}^{2}}}{\varphi_{e x}-\varphi_{b k}}\right)^{2}+\left(\frac{|d \cdot c| \sqrt{\left(\frac{\sigma_{d}}{d}\right)^{2}+\left(\frac{\sigma_{c}}{c}\right)^{2}}}{d \cdot c}\right)^{2}}
$$

Thus, the Verdet constant and mass specific magnetic rotation of solid and solution-state materials respectively, and the associated standard deviations, may be calculated for each wavelength. 

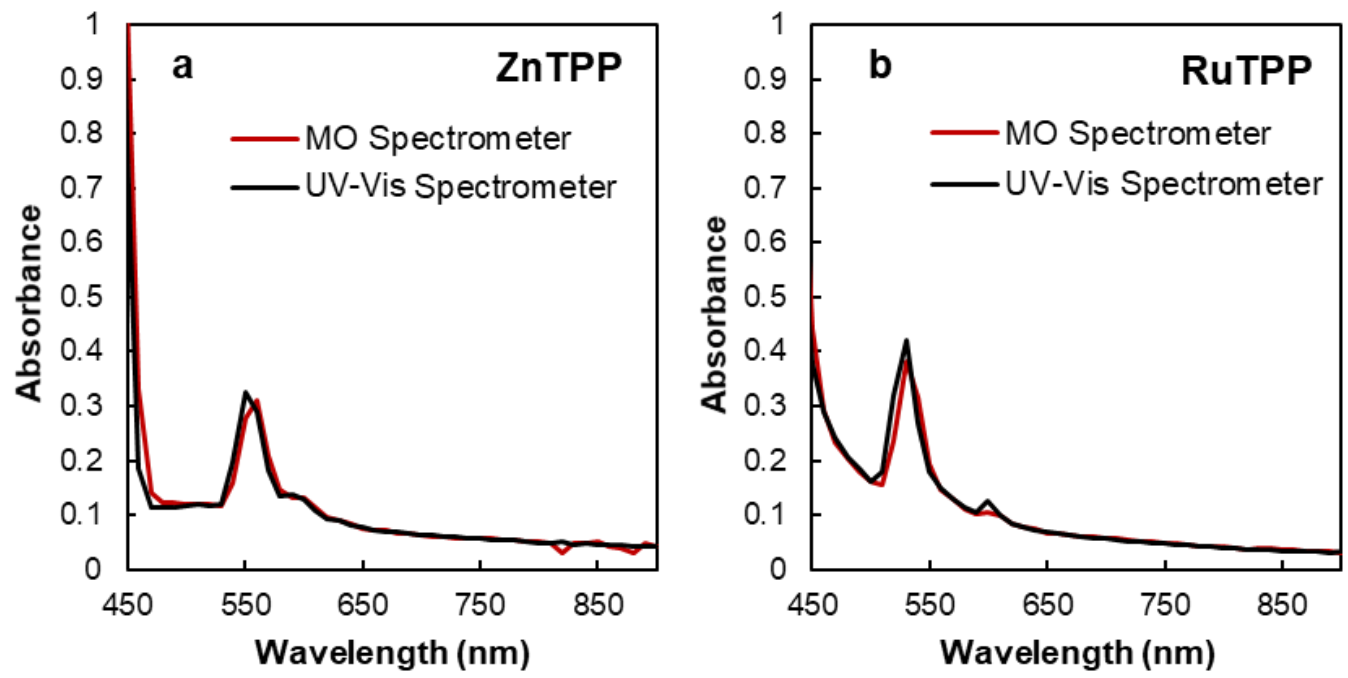

Figure S12 Visible to near-infrared absorbance spectra acquired with an Agilent Cary $4000 \mathrm{Uv-Vis}$ spectrometer (black) and our home-built magneto-optical spectrometer (red) for (a) ZnTPP and (b) RuTPP using a $10 \mathrm{~nm}$ wavelength increment.

In addition to measuring Faraday rotation, the magneto-optical instrument is able to simultaneously record absorbance spectra. With the practical assumption that CB will be small when compared to the overall light intensity, we can approximate $I_{A} \approx I_{B}$, and so the absorbance $(A)$ at a given wavelength may be calculated by the following equation:

$$
\text { Equation S17 } A=\log _{10}\left(\frac{I_{A, b k}}{I_{A, \text { ex }}}\right)
$$

where $I_{A, b k}$ is the intensity of light reaching one detector for the background sample and $I_{A, e x}$ is the intensity of light reaching the same detector when the sample is added. For optical-quality samples, the magnetooptical instrument reproduces absorbance spectra recorded using a commercial Agilent Cary $4000 \mathrm{Uv}$-Vis spectrometer as shown in Figure S12. We preferentially utilize the absorbance values recorded by our magneto-spectrometer when calculating figure-of-merit and plotting absorbance and Faraday rotation in the same graph. This ensures that the effects of temperature, humidity, and sample age and other external variables are minimized since the magneto-optic and absorbance data are collected simultaneously.

\section{Density Functional Theory (DFT) Calculations}

DFT and time-dependent DFT (TDDFT) calculations may be used to illustrate the contribution of degenerate molecular orbitals to the Q-band electronic transition, which is ultimately responsible for the magneto-optical activity arising from a Faraday A-term mechanism. ${ }^{16}$ In this mechanism, electronic transitions from the ground state to degenerate excited states are perturbed in the presence of a magnetic 
field due to Zeeman splitting of the formerly degenerate excited states. An electronic transition which results in degenerate excited states in the absence of a magnetic field requires the contribution of degenerate molecular orbitals, assuming the transition is spin-allowed. It is well established that the Q-band found in porphyrins and phthalocyanines fulfil these requirements, but an in-depth discussion of their electronic structures is beyond the scope of this text. ${ }^{17}$ However, even such simple analysis as demonstrated here assists in the identification of compounds which may exhibit large Faraday rotation by an A-term electronic mechanism, even when the electronic structure is not well established in the literature.

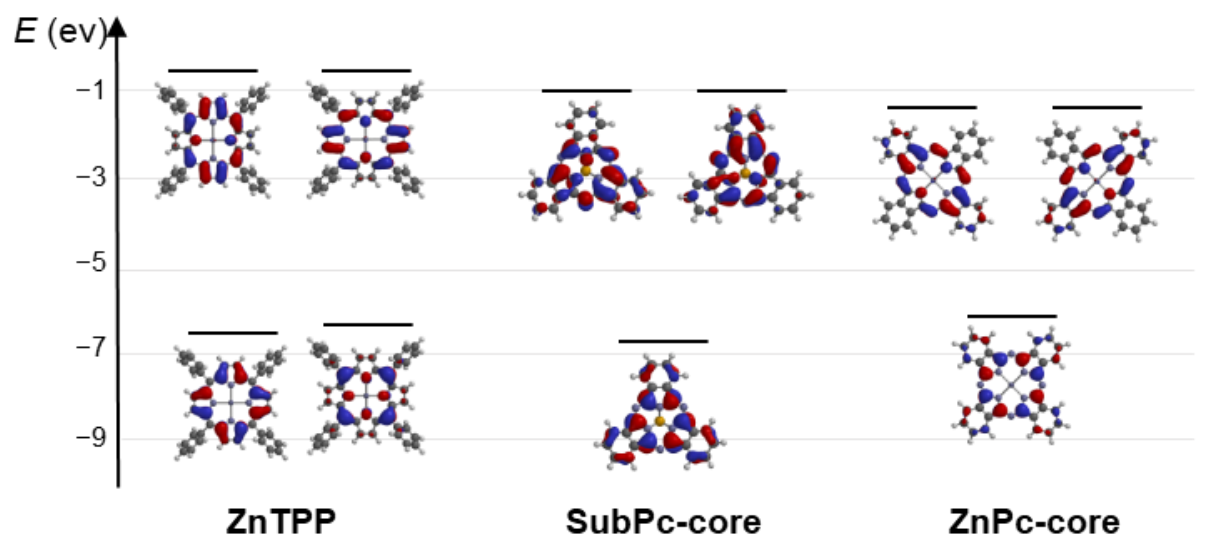

Figure S13 Energy levels and contour plots of the frontier molecular orbitals of ZnTPP, SubPc-core, and ZnPc-core. Calculations were performed at the $\omega \mathrm{B} 97 \mathrm{X}-\mathrm{D} / 6-31 \mathrm{G}^{*}$ level of theory.

Three molecular structures were chosen to demonstrate this approach: Zinc tetraphenylporphyrin (ZnTPP), the parent subphthalocyanine (SubPc-core), and the parent zinc phthalocyanine (ZnPc-core). These species demonstrate the essential electronic features of the three categories of molecules explored in the main text, and are also amenable to calculation due to their diamagnetism, small atom count, and limited degrees of rotational freedom. Optimized geometries and frontier molecular orbital energies were calculated using ground state DFT with $\omega$ B97X-D as the functional and 6-31G* as the basis set, in the Spartan '18 package (Wavefunction Inc. Irvine CA) ${ }^{18}$ Allowed UV-Vis transitions and molecular orbital contributions were calculated using TDDFT with $\omega$ B97X-D as the functional and 6-31G* as the basis set, in the Spartan '18 package.

Table S2 TDDFT allowed transitions corresponding to Q-band for ZnTPP, SubPc-core and ZnPc-core. $\left(\omega \mathrm{B} 97 \mathrm{X}-\mathrm{D} / 6-31 \mathrm{G}^{*}\right)$.

\begin{tabular}{ccccc} 
Compound & $\begin{array}{c}\Delta\left(\boldsymbol{E}_{\text {LUMo }}-\boldsymbol{E}_{\text {Hомо }}\right) \\
(\mathrm{eV})\end{array}$ & $\begin{array}{c}\boldsymbol{\lambda} \\
(\mathrm{nm})\end{array}$ & $\boldsymbol{f}^{a}$ & MO Composition $(\%)^{b}$ \\
\hline ZnTPP & 5.63 & 509.19 & 0.0048 & $\mathrm{H} \rightarrow \mathrm{L}+1(54 \%), \mathrm{H}-1 \rightarrow \mathrm{L}(46 \%)$ \\
& & 508.97 & 0.0070 & $\mathrm{H} \rightarrow \mathrm{L}(52 \%), \mathrm{H}-1 \rightarrow \mathrm{L}+1(45 \%)$ \\
SubPc-core & 5.70 & 431.35 & 0.5021 & $\mathrm{H} \rightarrow \mathrm{L}(87 \%)$
\end{tabular}




\begin{tabular}{|c|c|c|c|c|}
\hline \multirow{3}{*}{ ZnPc-core } & \multirow[b]{2}{*}{4.69} & 427.23 & 0.4788 & $\mathrm{H} \rightarrow \mathrm{L}+1(86 \%)$ \\
\hline & & 539.92 & 0.6769 & $\mathrm{H} \rightarrow \mathrm{L}-1(82 \%)$ \\
\hline & & 539.87 & 0.6774 & $\mathrm{H} \rightarrow \mathrm{L}(82 \%)$ \\
\hline
\end{tabular}

${ }^{a}$ Oscillator strength. ${ }^{b} \mathrm{H}-1, \mathrm{H}, \mathrm{L}$, and $\mathrm{L}+1$ denote HOMO-1, HOMO, LUMO, and LUMO+1 respectively.

Each species investigated fulfills the requirements for exhibiting a Faraday A-term within their MCB spectra according to DFT and TDDFT calculations. First, the LUMO and LUMO+1 were found to be near in energy $(\Delta E<0.04 \mathrm{eV})$ and related by symmetry $\left(\mathrm{C}_{2}\right.$ or $\mathrm{C}_{3}$ rotations) for each molecule, indicating their formal degeneracy. Both of these featured may be observed in Figure S13. Second, the degenerate LUMOs contribute to the calculated allowed transition which corresponds with the Q-band in phthalocyanines and porphyrins (Table S2). The allowed transition may be identified with the Q-band due to its low energy, and for its large oscillator strength in phthalocyanines and subphthalocyanines. In SubPccore and ZnPc-core the Q-band is primarily made up of HOMO to degenerate LUMO components, whereas in ZnTPP the HOMO-1 to degenerate LUMO components also makes a major contribution. In either case the dominant contribution from the degenerate LUMOs results in the experimental observation of large Faraday A-term MCB signals. The magnitude of the Faraday A-term at any one of these transitions is governed by Equation 3 in the main text, and methods to calculate this value for molecular species are an active area of research, ${ }^{19}$ but beyond the scope of this work.

Table S3 Cartesian coordinates and total electron energy for ZnTPP.

Method: $\omega B 97 X-D$

Basis set: $6-31 \mathrm{G}^{*}$

Energy: -3691.156094 hartrees

\begin{tabular}{cccc}
\hline Element & \multicolumn{3}{c}{ Coordinates (Angstroms) } \\
\hline C & -5.446711 & -5.484923 & -0.138603 \\
C & -5.357087 & -4.681052 & 0.994589 \\
C & -4.381402 & -3.691775 & 1.075042 \\
C & -3.483006 & -3.492137 & 0.022971 \\
C & -2.433148 & -2.432282 & 0.094061 \\
C & -1.097169 & -2.849757 & 0.135222 \\
C & -0.677284 & -4.227097 & 0.220341 \\
C & 0.677753 & -4.227128 & 0.220087 \\
C & 1.097526 & -2.849969 & 0.134689 \\
C & 2.433166 & -2.432279 & 0.093155 \\
C & 3.483084 & -3.492225 & 0.022856 \\
C & 3.584237 & -4.303325 & -1.111539 \\
C & 4.557824 & -5.293333 & -1.191648 \\
C & 5.446329 & -5.485469 & -0.136987 \\
C & 5.354951 & -4.682716 & 0.996811 \\
C & 4.379478 & -3.693183 & 1.076419 \\
C & 2.853893 & -1.097086 & 0.077038 \\
C & 4.228272 & -0.677448 & -0.048916 \\
C & 4.228272 & 0.677448 & -0.048916 \\
C & 2.853893 & 1.097086 & 0.077038
\end{tabular}




\begin{tabular}{|c|c|c|c|}
\hline $\mathrm{N}$ & 2.037581 & 0 & 0.146024 \\
\hline C & 2.433166 & 2.432279 & 0.093155 \\
\hline C & 3.483084 & 3.492225 & 0.022856 \\
\hline C & 4.379477 & 3.693183 & 1.076419 \\
\hline $\mathrm{C}$ & 5.354951 & 4.682716 & 0.996811 \\
\hline C & 5.446329 & 5.485469 & -0.136987 \\
\hline C & 4.557824 & 5.293333 & -1.191648 \\
\hline C & 3.584237 & 4.303325 & -1.111539 \\
\hline C & 1.097526 & 2.849969 & 0.134689 \\
\hline C & 0.677753 & 4.227128 & 0.220087 \\
\hline C & -0.677284 & 4.227097 & 0.220341 \\
\hline C & -1.097169 & 2.849757 & 0.135222 \\
\hline C & -2.433148 & 2.432282 & 0.094061 \\
\hline C & -3.483006 & 3.492137 & 0.022971 \\
\hline C & -4.381402 & 3.691775 & 1.075042 \\
\hline C & -5.357087 & 4.681052 & 0.994589 \\
\hline C & -5.446711 & 5.484923 & -0.138603 \\
\hline C & -4.556219 & 5.294185 & -1.191766 \\
\hline C & -3.582439 & 4.304418 & -1.110786 \\
\hline C & -2.853722 & 1.097132 & 0.078466 \\
\hline C & -4.227957 & 0.677326 & -0.049707 \\
\hline C & -4.227957 & -0.677326 & -0.049707 \\
\hline C & -2.853722 & -1.097132 & 0.078466 \\
\hline $\mathrm{N}$ & -2.037481 & 0 & 0.147084 \\
\hline C & -3.582439 & -4.304418 & -1.110786 \\
\hline C & -4.556219 & -5.294185 & -1.191766 \\
\hline $\mathrm{H}$ & -6.207989 & -6.256782 & -0.20098 \\
\hline $\mathrm{H}$ & -6.046273 & -4.826086 & 1.821319 \\
\hline $\mathrm{H}$ & -4.307964 & -3.066 & 1.959959 \\
\hline $\mathrm{H}$ & -1.33953 & -5.078081 & 0.287352 \\
\hline $\mathrm{H}$ & 1.339964 & -5.078179 & 0.2868 \\
\hline $\mathrm{H}$ & 2.891626 & -4.14933 & -1.93398 \\
\hline $\mathrm{H}$ & 4.62437 & -5.913022 & -2.081029 \\
\hline $\mathrm{H}$ & 6.207392 & -6.257594 & -0.198708 \\
\hline $\mathrm{H}$ & 6.042523 & -4.828839 & 1.824683 \\
\hline $\mathrm{H}$ & 4.304602 & -3.068321 & 1.961869 \\
\hline $\mathrm{H}$ & 5.076618 & -1.339506 & -0.145152 \\
\hline $\mathrm{H}$ & 5.076617 & 1.339506 & -0.145152 \\
\hline $\mathrm{H}$ & 4.304602 & 3.068321 & 1.961869 \\
\hline $\mathrm{H}$ & 6.042523 & 4.828839 & 1.824683 \\
\hline $\mathrm{H}$ & 6.207392 & 6.257594 & -0.198708 \\
\hline $\mathrm{H}$ & 4.62437 & 5.913022 & -2.081029 \\
\hline $\mathrm{H}$ & 2.891626 & 4.14933 & -1.93398 \\
\hline $\mathrm{H}$ & 1.339964 & 5.078179 & 0.2868 \\
\hline $\mathrm{H}$ & -1.33953 & 5.078081 & 0.287352 \\
\hline $\mathrm{H}$ & -4.307964 & 3.066 & 1.959959 \\
\hline $\mathrm{H}$ & -6.046273 & 4.826086 & 1.821319 \\
\hline $\mathrm{H}$ & -6.207989 & 6.256782 & -0.20098 \\
\hline $\mathrm{H}$ & -4.621379 & 5.914671 & -2.080691 \\
\hline $\mathrm{H}$ & -2.888365 & 4.151434 & -1.932201 \\
\hline $\mathrm{H}$ & -5.076141 & 1.339416 & -0.146975 \\
\hline $\mathrm{H}$ & -5.076141 & -1.339416 & -0.146975 \\
\hline $\mathrm{H}$ & -2.888365 & -4.151434 & -1.932201 \\
\hline $\mathrm{H}$ & -4.621379 & -5.914671 & -2.08069 \\
\hline $\mathrm{Zn}$ & 0.000275 & 0 & 0.136035 \\
\hline $\mathrm{N}$ & -0.000011 & 2.031944 & 0.10136 \\
\hline
\end{tabular}



$\mathrm{N}$
$-0.000011$
$-2.031944$
0.101366

Table S4 Cartesian coordinates and total electron energy for SubPc core.

Method: $\omega B 97 X-D$

Basis set: $6-31 G^{*}$

Energy: -1735.065586 hartrees

\begin{tabular}{cccc}
\hline Element & X & Coordinates (Angstroms) & \\
\hline $\mathrm{C}$ & 1.825798 & -2.406802 & -4.600043 \\
$\mathrm{C}$ & 2.416291 & -1.15176 & -4.810638 \\
$\mathrm{C}$ & -3.770154 & -3.526418 & 1.88985 \\
$\mathrm{C}$ & 0.413374 & 5.465235 & 0.367479 \\
$\mathrm{C}$ & -4.087982 & -2.456204 & 2.742649 \\
$\mathrm{C}$ & -0.492252 & 5.283236 & 1.429682 \\
$\mathrm{C}$ & 1.353384 & -2.774134 & -3.359644 \\
$\mathrm{C}$ & 2.545717 & -0.24077 & -3.785608 \\
$\mathrm{C}$ & -2.580018 & -3.558947 & 1.201127 \\
$\mathrm{C}$ & 1.13278 & 4.412929 & -0.143847 \\
$\mathrm{C}$ & -3.222463 & -1.401967 & 2.921358 \\
$\mathrm{C}$ & -0.691063 & 4.047518 & 1.995173 \\
$\mathrm{C}$ & 1.503252 & -1.872426 & -2.310705 \\
$\mathrm{C}$ & 2.096611 & -0.611437 & -2.522024 \\
$\mathrm{C}$ & -1.68315 & -2.509922 & 1.393363 \\
$\mathrm{C}$ & 0.960311 & 3.15592 & 0.437372 \\
$\mathrm{C}$ & -2.001952 & -1.43532 & 2.249734 \\
$\mathrm{C}$ & 0.051596 & 2.973085 & 1.503268 \\
$\mathrm{C}$ & 1.06132 & -1.909607 & -0.923339 \\
$\mathrm{C}$ & 2.013776 & 0.117222 & -1.26347 \\
$\mathrm{C}$ & -0.402042 & -2.201934 & 0.78157 \\
$\mathrm{C}$ & 1.492049 & 1.850644 & 0.103687 \\
$\mathrm{C}$ & -0.914791 & -0.476213 & 2.154509 \\
$\mathrm{C}$ & 0.035065 & 1.557715 & 1.810071 \\
$\mathrm{Cl}$ & 2.724593 & -0.902747 & 2.185312 \\
$\mathrm{~N}$ & 0.163778 & -2.672929 & -0.324645 \\
$\mathrm{~N}$ & 2.072173 & 1.407921 & -1.010168 \\
$\mathrm{~N}$ & -0.874333 & 0.813598 & 2.426796 \\
$\mathrm{~N}$ & 0.026437 & -1.085513 & 1.393603 \\
$\mathrm{~N}$ & 1.005608 & 1.016504 & 1.041082 \\
$\mathrm{H}$ & 1.737847 & -3.088733 & -5.426238 \\
$\mathrm{H}$ & 2.768428 & -0.898386 & -5.794153 \\
$\mathrm{H}$ & -4.475438 & -4.329129 & 1.773102 \\
$\mathrm{H}$ & 0.536444 & 6.447927 & -0.050625 \\
$\mathrm{H}$ & -5.030241 & -2.463394 & 3.260056 \\
$\mathrm{H}$ & -1.040346 & 6.131349 & 1.798475 \\
$\mathrm{H}$ & 0.886707 & -3.728007 & -3.198831 \\
$\mathrm{H}$ & 2.983454 & 0.726274 & -3.948958 \\
$\mathrm{H}$ & -2.340028 & -4.368114 & 0.536803 \\
$\mathrm{H}$ & 1.814048 & 4.546534 & -0.963411 \\
$\mathrm{H}$ & -3.471616 & -0.57663 & 3.561888 \\
$\mathrm{H}$ & -1.392372 & 3.905334 & 2.796141 \\
$\mathrm{~N}$ & 1.54013 & -0.779046 & -0.368898 \\
$\mathrm{~B}$ & 1.309269 & -0.432458 & 1.051091 \\
& & & \\
\hline
\end{tabular}


Table S5 Cartesian coordinates and total electron energy for ZnPc core.

Method: $\omega B 97 X-D$

Basis set: $6-31 \mathrm{G}^{*}$

Energy: -3445.798988 hartrees

\begin{tabular}{|c|c|c|c|}
\hline \multirow{2}{*}{ Element } & \multicolumn{3}{|c|}{ Coordinates (Angstroms) } \\
\hline & $X$ & Y & Z \\
\hline C & 1.796121 & 3.183607 & 2.124735 \\
\hline C & 2.809779 & 4.004353 & 2.610466 \\
\hline C & 2.449834 & 5.018519 & 3.487961 \\
\hline C & 1.111189 & 5.208162 & 3.872748 \\
\hline C & 0.100481 & 4.387839 & 3.389357 \\
\hline C & 0.461631 & 3.37206 & 2.509079 \\
\hline C & -0.314904 & 2.344025 & 1.825164 \\
\hline $\mathrm{N}$ & -1.625462 & 2.203414 & 1.961084 \\
\hline C & -2.338578 & 1.2612 & 1.361502 \\
\hline C & -3.778855 & 1.107827 & 1.534626 \\
\hline C & -4.713948 & 1.820603 & 2.279741 \\
\hline C & -6.0361 & 1.399319 & 2.224442 \\
\hline C & -6.415681 & 0.293446 & 1.445131 \\
\hline C & -5.482498 & -0.417385 & 0.70197 \\
\hline C & -4.157559 & 0.005841 & 0.756929 \\
\hline C & -2.94164 & -0.491119 & 0.123233 \\
\hline $\mathrm{N}$ & -2.914509 & -1.538685 & -0.6877 \\
\hline C & -1.815431 & -2.008899 & -1.259152 \\
\hline C & -1.799296 & -3.168795 & -2.143398 \\
\hline C & -2.807466 & -4.014759 & -2.596274 \\
\hline C & -2.443477 & -5.050509 & -3.44661 \\
\hline C & -1.106059 & -5.237474 & -3.835383 \\
\hline C & -0.100475 & -4.393263 & -3.382962 \\
\hline C & -0.465893 & -3.354657 & -2.53137 \\
\hline C & 0.305698 & -2.304299 & -1.875939 \\
\hline $\mathrm{N}$ & 1.617356 & -2.168646 & -2.006356 \\
\hline C & 2.330763 & -1.225743 & -1.4083 \\
\hline C & 3.776685 & -1.096125 & -1.550585 \\
\hline C & 4.156175 & 0.003304 & -0.768766 \\
\hline C & 2.934742 & 0.523412 & -0.164949 \\
\hline $\mathrm{N}$ & 1.881124 & -0.240559 & -0.576974 \\
\hline $\mathrm{N}$ & 2.908089 & 1.567532 & 0.650487 \\
\hline C & 1.807617 & 2.0449 & 1.213207 \\
\hline C & 5.486711 & 0.402415 & -0.681924 \\
\hline C & 6.42444 & -0.328488 & -1.399236 \\
\hline C & 6.043929 & -1.431332 & -2.183318 \\
\hline C & 4.716483 & -1.829668 & -2.268946 \\
\hline $\mathrm{N}$ & -1.891216 & 0.288689 & 0.51375 \\
\hline $\mathrm{H}$ & 3.840025 & 3.848289 & 2.308187 \\
\hline $\mathrm{H}$ & -0.935657 & 4.524203 & 3.680842 \\
\hline $\mathrm{H}$ & -4.410119 & 2.672822 & 2.878648 \\
\hline $\mathrm{H}$ & -5.764617 & -1.272941 & 0.097217 \\
\hline $\mathrm{H}$ & -3.83677 & -3.861728 & -2.289172 \\
\hline $\mathrm{H}$ & 0.935269 & -4.529016 & -3.676265 \\
\hline $\mathrm{H}$ & 5.769413 & 1.254879 & -0.073157 \\
\hline $\mathrm{H}$ & 4.412158 & -2.67976 & -2.870555 \\
\hline $\mathrm{Zn}$ & -0.012422 & 0.050835 & -0.065678 \\
\hline $\mathrm{N}$ & -0.542057 & -1.53327 & -1.133953 \\
\hline $\mathrm{N}$ & 0.529988 & 1.586681 & 1.066432 \\
\hline
\end{tabular}




$\begin{array}{cccc}\mathrm{H} & 3.213661 & 5.679085 & 3.887139 \\ \mathrm{H} & 0.867203 & 6.011494 & 4.561385 \\ \mathrm{H} & -6.793317 & 1.931474 & 2.792323 \\ \mathrm{H} & -7.458743 & -0.007687 & 1.426357 \\ \mathrm{H} & -3.203058 & -5.730707 & -3.820043 \\ \mathrm{H} & -0.85812 & -6.0587 & -4.501102 \\ \mathrm{H} & 6.805217 & -1.97949 & -2.730178 \\ \mathrm{H} & 7.472149 & -0.046525 & -1.355901\end{array}$

\section{UV-Vis Absorption Spectra}

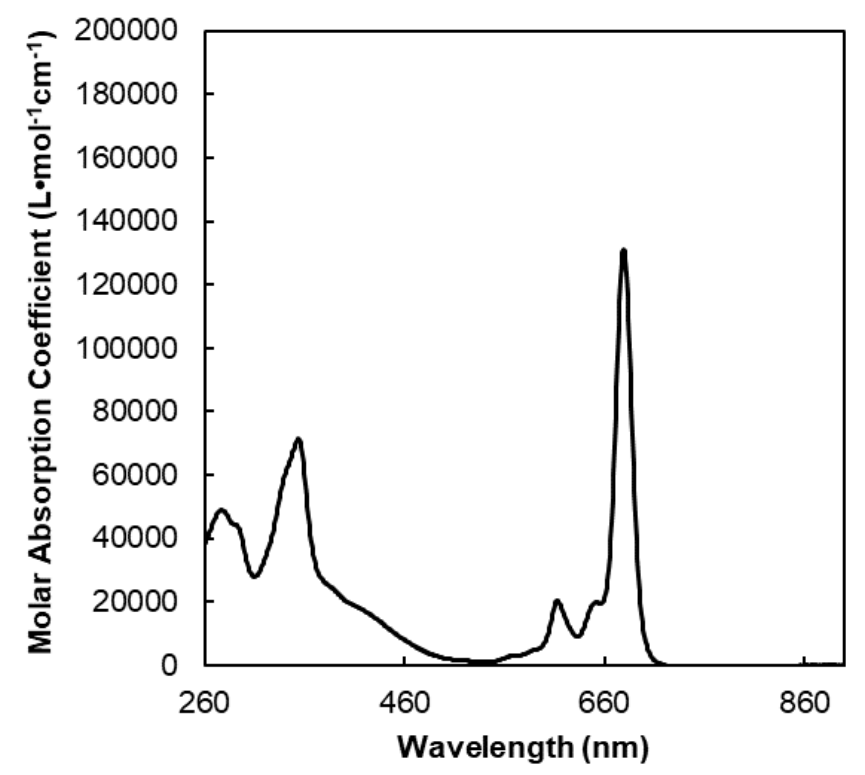

Figure S14 UV-Vis spectrum of ZnPc-(R) in chloroform. 


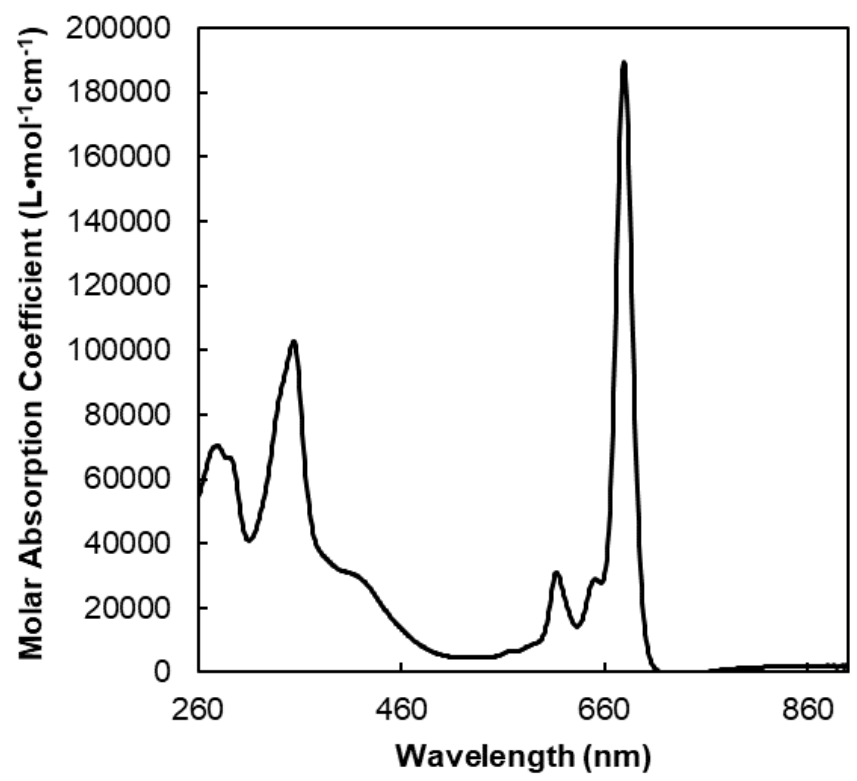

Figure S15 UV-Vis spectrum of ZnPc-(rac) in chloroform.

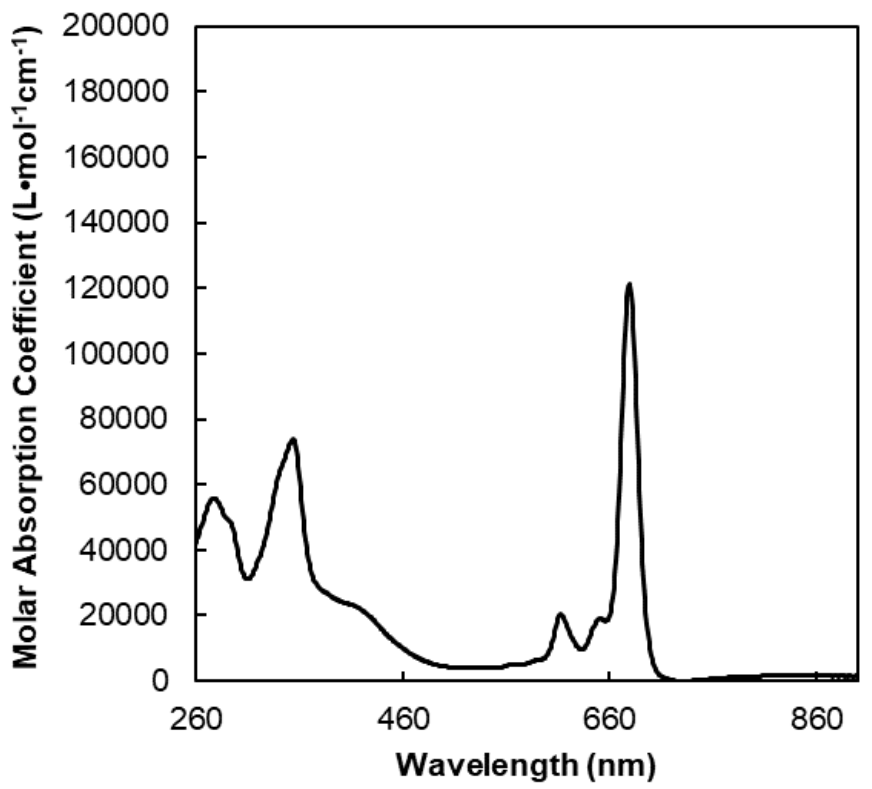

Figure S16 UV-Vis spectrum of $\mathbf{Z n P c}-(S)$ in chloroform. 


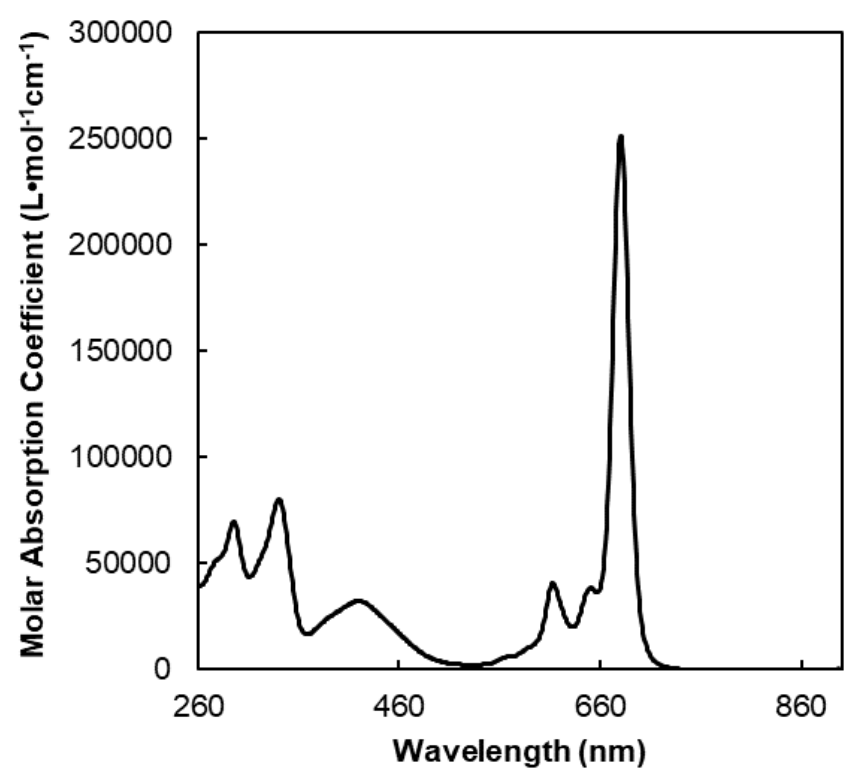

Figure S17 UV-Vis spectrum of $\mathbf{C u P c}-(\boldsymbol{R})$ in chloroform.

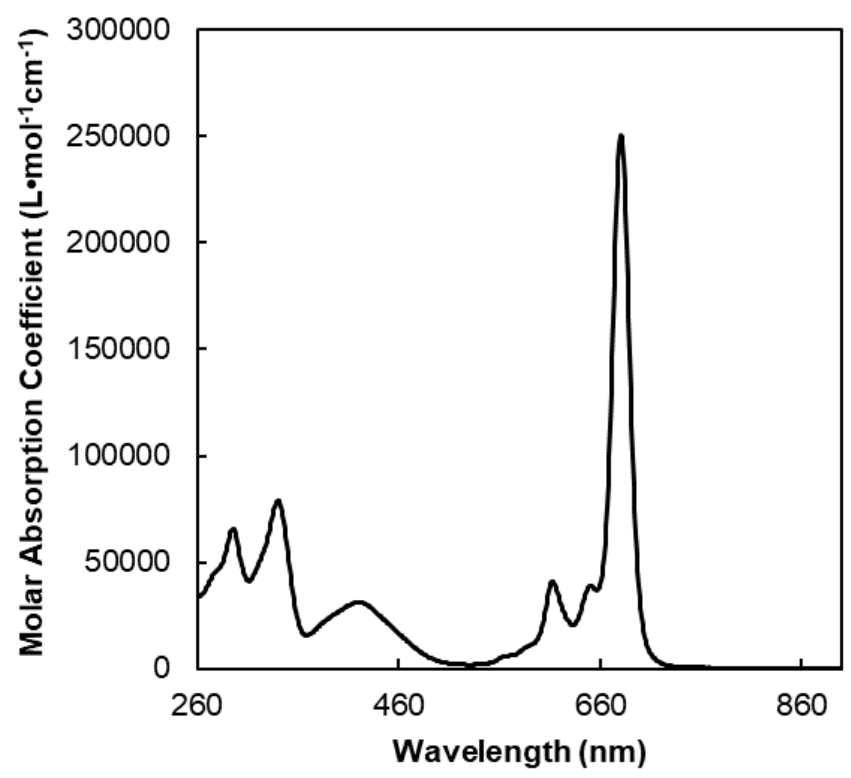

Figure S18 UV-Vis spectrum of CuPc-(rac) in chloroform. 


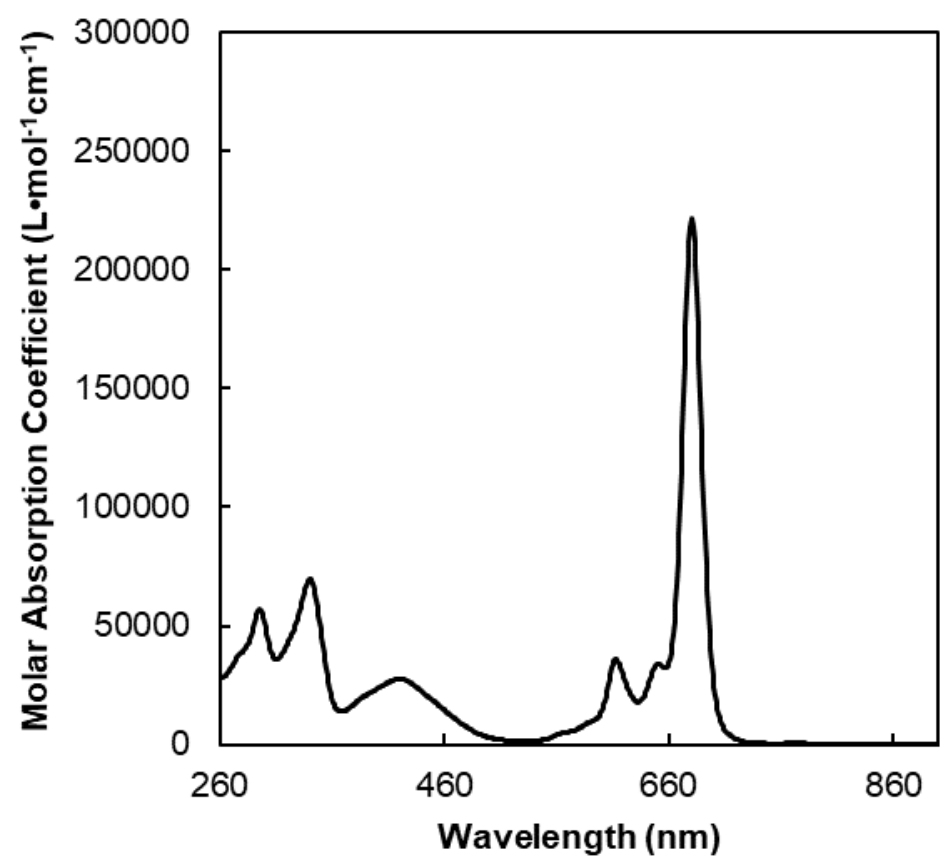

Figure S19 UV-Vis spectrum of $\mathbf{C u P c}-(S)$ in chloroform.

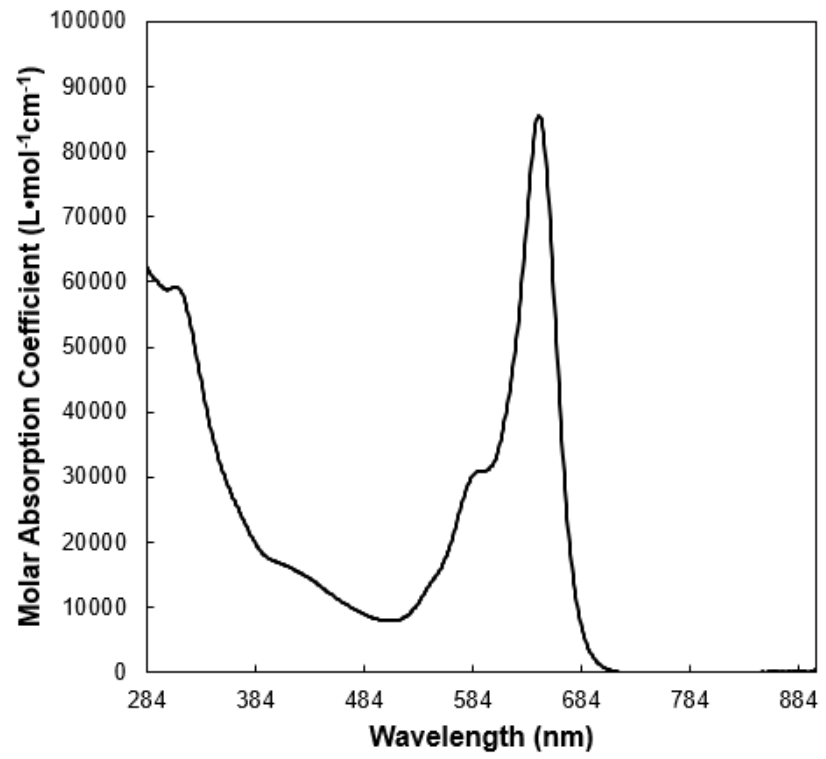

Figure S20 UV-Vis spectrum of SubPc in toluene. 


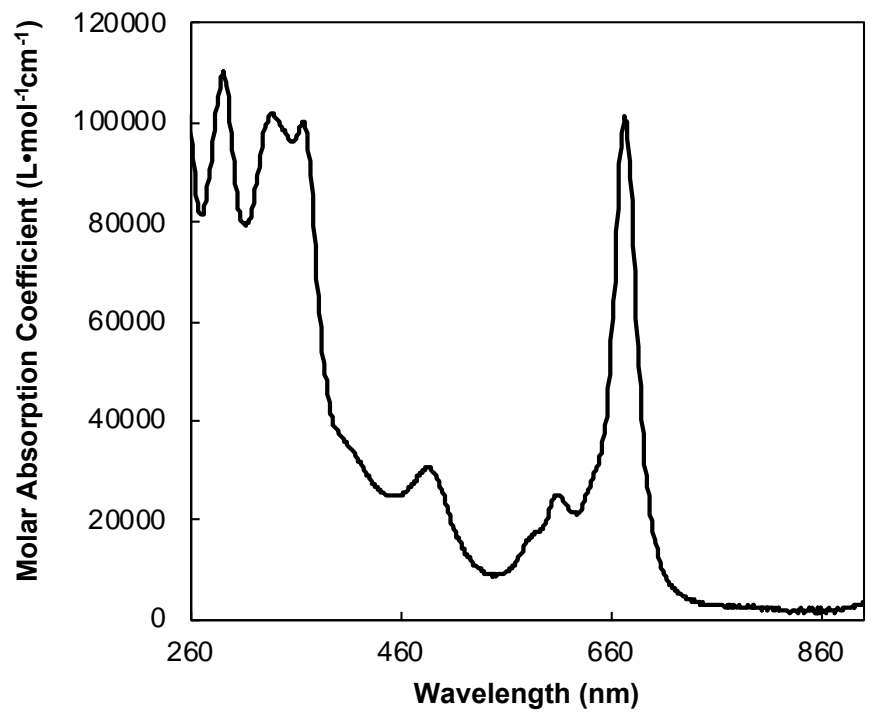

Figure S21 UV-Vis spectrum of $\mathbf{T b P c}_{2}-(\mathbf{r a c})$ in dichloromethane.

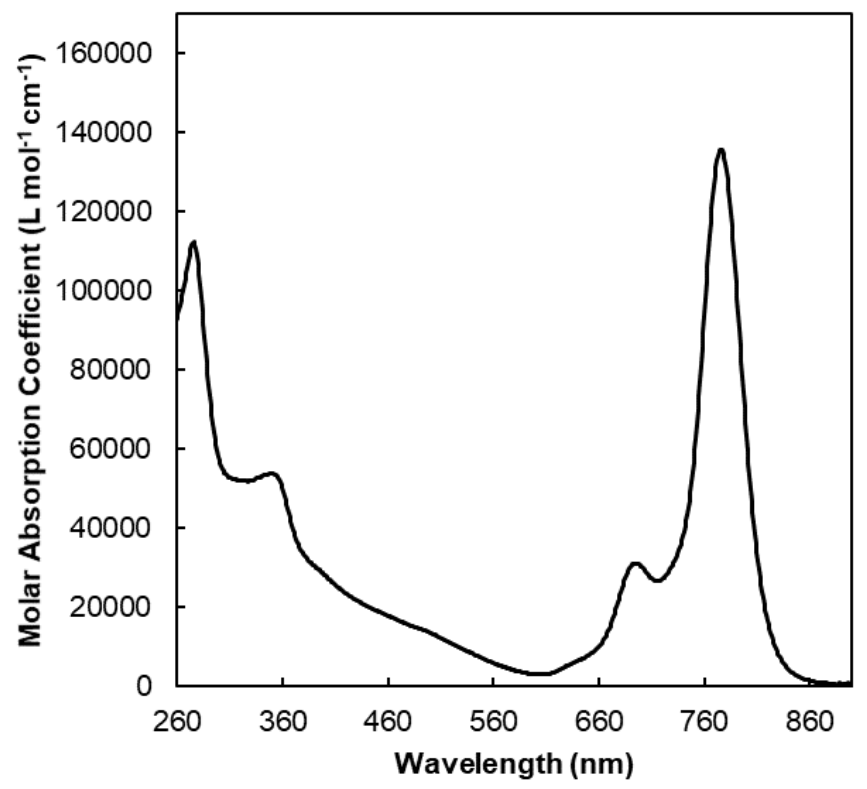

Figure S22 UV-Vis spectrum of ZnPc-OT in chloroform. 


\section{MALDI Mass Spectra}

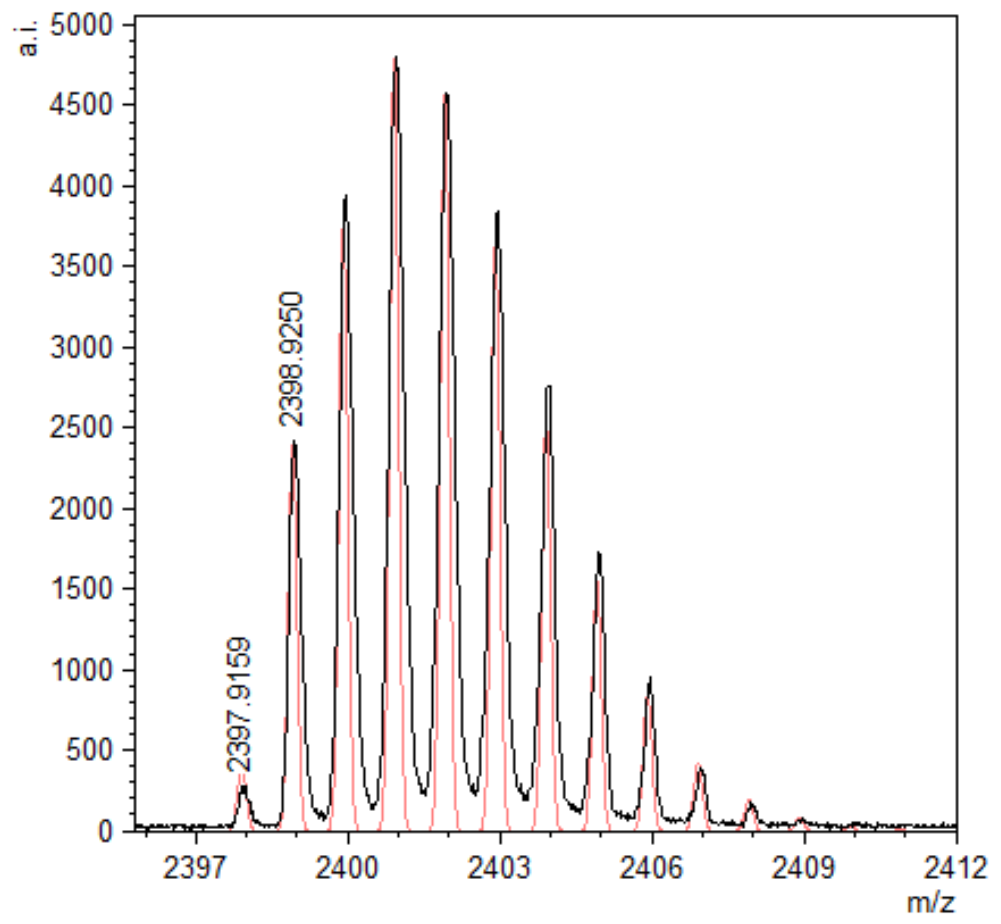

Figure S23 MALDI-TOF mass spectrum of SubPc shown in black. Simulated isotopic distribution for $\mathrm{C}_{144} \mathrm{H}_{156} \mathrm{BClN}_{6} \mathrm{~S}_{12}$ shown in red. 


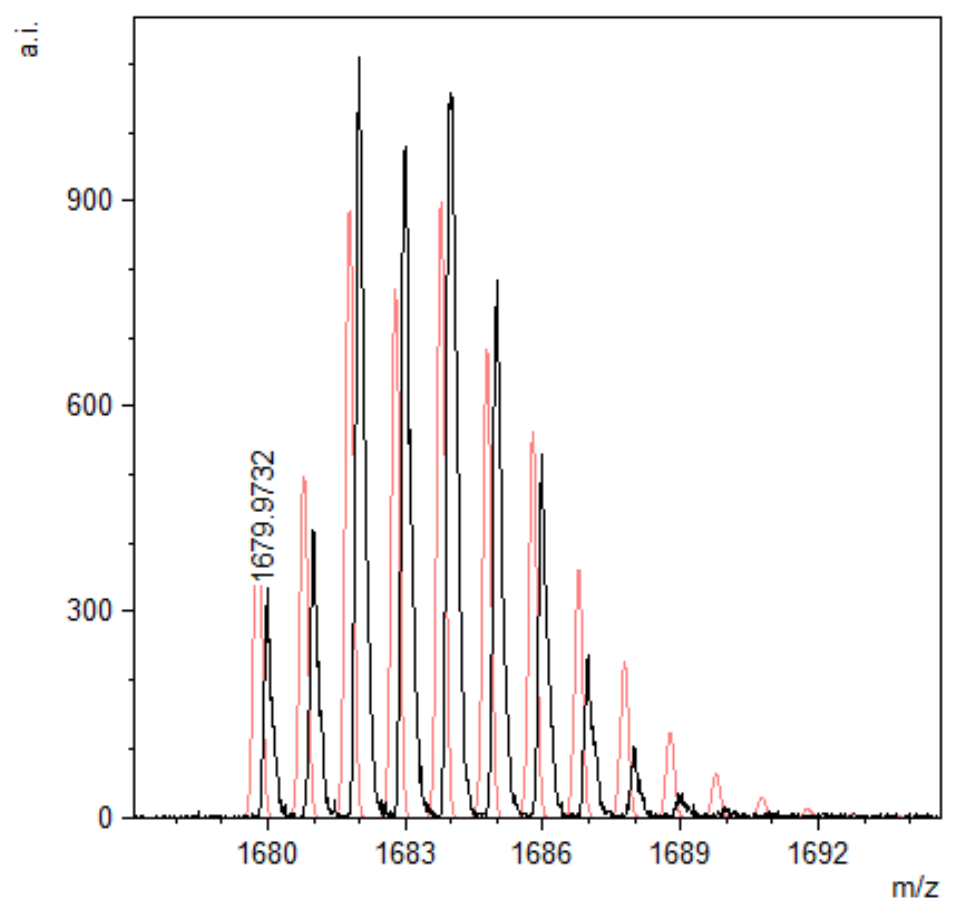

Figure S24 MALDI-TOF mass spectrum of ZnPc-OT shown in black. Simulated isotopic distribution for $\mathrm{C}_{80} \mathrm{H}_{32} \mathrm{~N}_{8} \mathrm{~S}_{16} \mathrm{Zn}$ shown in red.

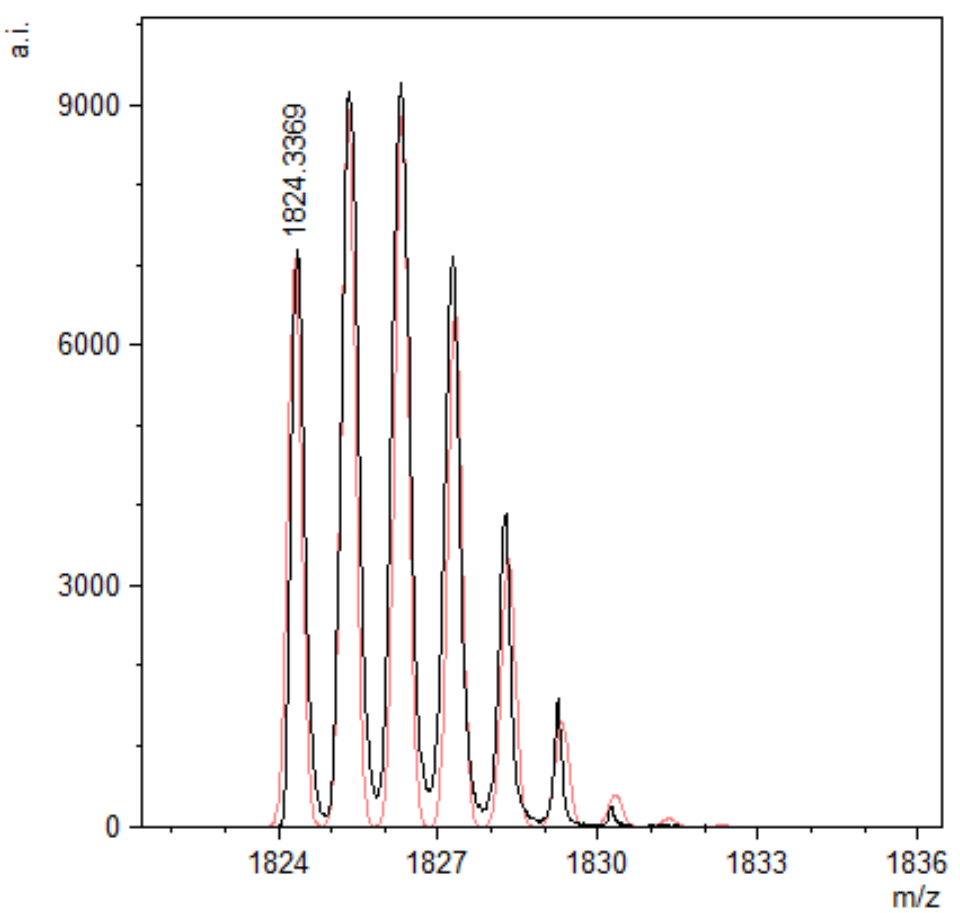

Figure S25 MALDI-TOF mass spectrum of $\mathbf{C u P c}-(\boldsymbol{R})$ shown in black. Simulated isotopic distribution for $\mathrm{C}_{112} \mathrm{H}_{176} \mathrm{CuN}_{8} \mathrm{O}_{8}$ shown in red. 


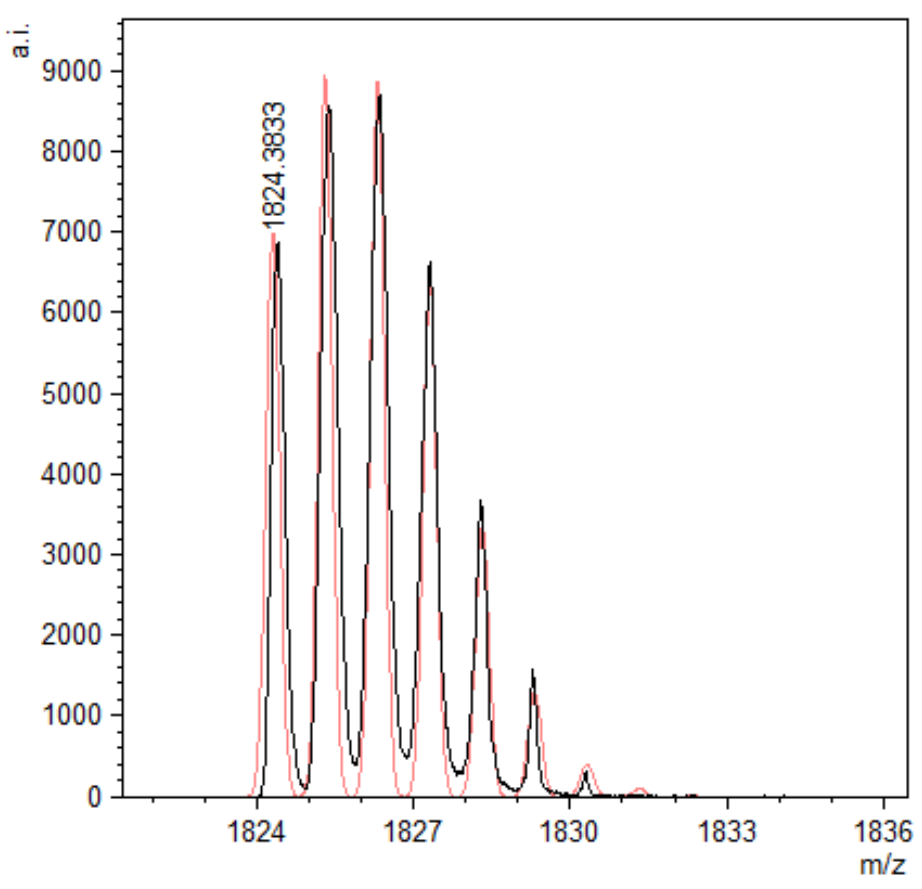

Figure S26 MALDI-TOF mass spectrum of CuPc-(rac) shown in black. Simulated isotopic distribution for $\mathrm{C}_{112} \mathrm{H}_{176} \mathrm{CuN}_{8} \mathrm{O}_{8}$ shown in red.

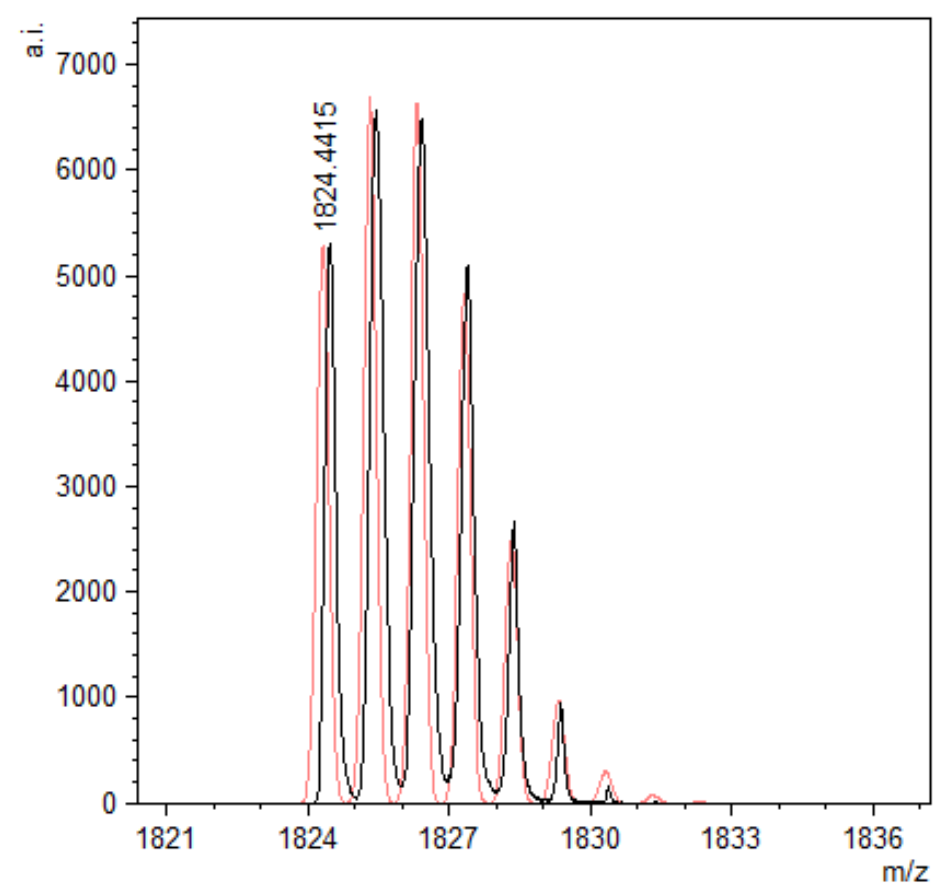

Figure S27 MALDI-TOF mass spectrum of $\mathbf{C u P c}-(S)$ shown in black. Simulated isotopic distribution for $\mathrm{C}_{112} \mathrm{H}_{176} \mathrm{CuN}_{8} \mathrm{O}_{8}$ shown in red. 


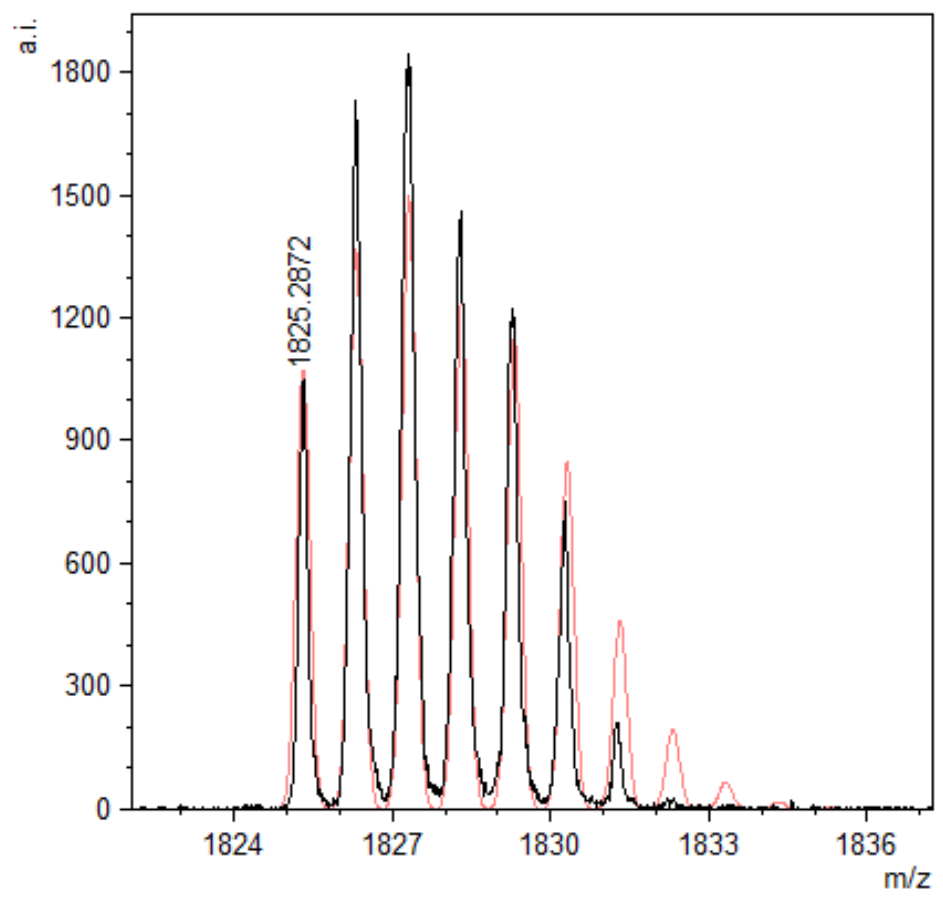

Figure S28 MALDI-TOF mass spectrum of ZnPc- $(\boldsymbol{R})$ shown in black. Simulated isotopic distribution for $\mathrm{C}_{112} \mathrm{H}_{176} \mathrm{~N}_{8} \mathrm{O}_{8} \mathrm{Zn}$ shown in red.

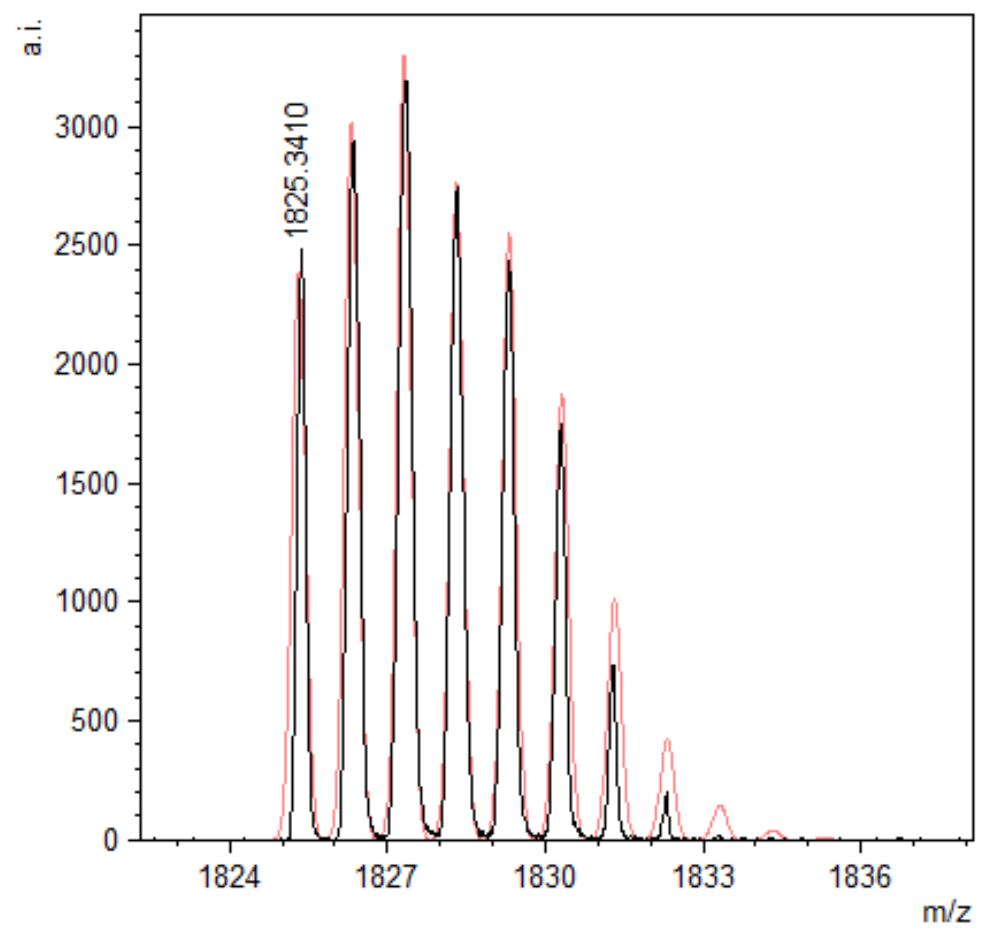

Figure S29 MALDI-TOF mass spectrum of ZnPc-(rac) shown in black. Simulated isotopic distribution for $\mathrm{C}_{112} \mathrm{H}_{176} \mathrm{~N}_{8} \mathrm{O}_{8} \mathrm{Zn}$ shown in red. 


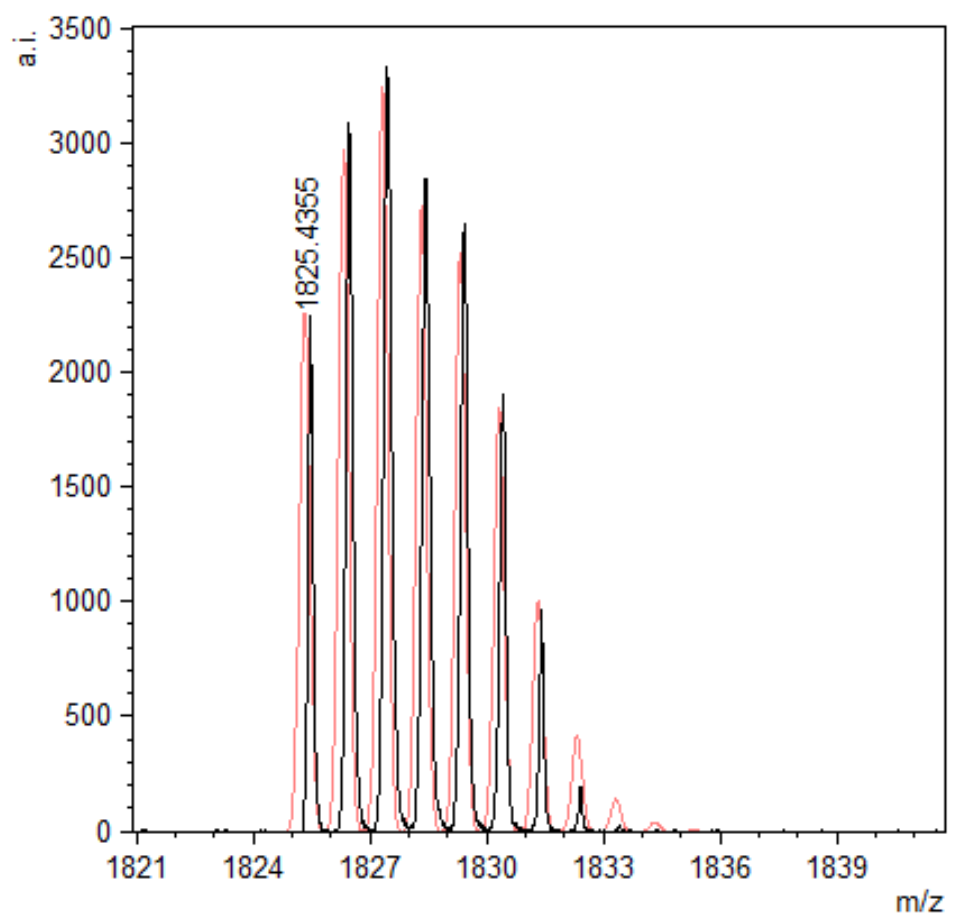

Figure S30 MALDI-TOF mass spectrum of ZnPc-(S) shown in black. Simulated isotopic distribution for $\mathrm{C}_{112} \mathrm{H}_{176} \mathrm{~N}_{8} \mathrm{O}_{8} \mathrm{Zn}$ shown in red.

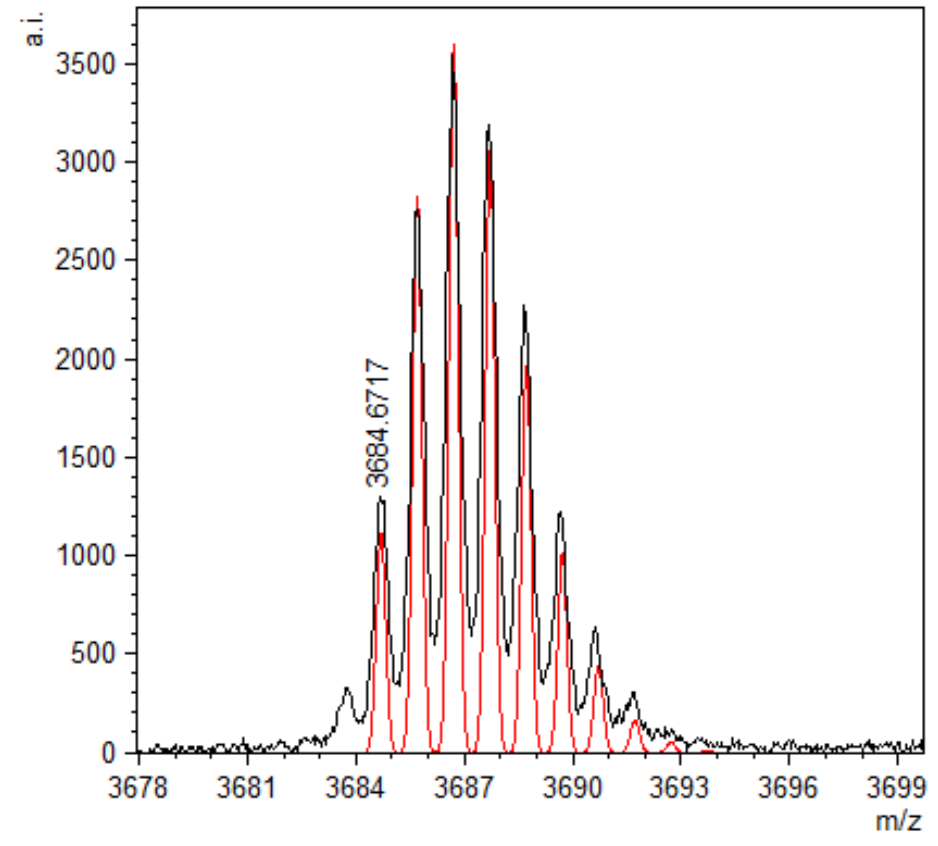

Figure S31 MALDI-TOF mass spectrum of $\mathbf{T b P c}_{2}-(\mathbf{r a c})$ shown in black. Simulated isotopic distribution for $\mathrm{C}_{224} \mathrm{H}_{355} \mathrm{~N}_{16} \mathrm{O}_{16} \mathrm{~Tb}$ shown in red. 


\section{NMR Spectra}
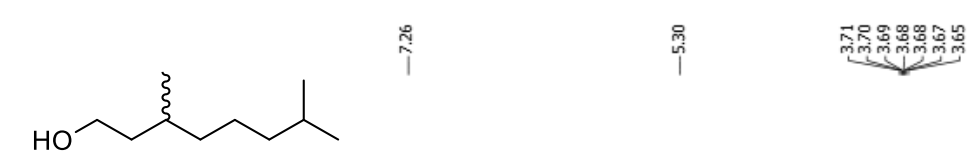

3,7-dimethyloctan-1-ol

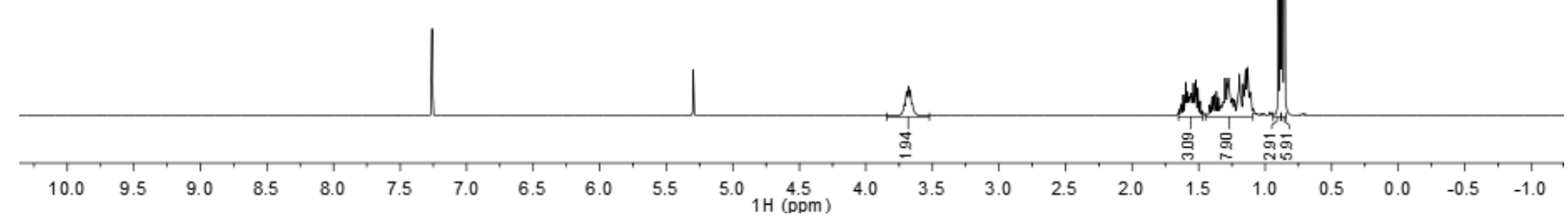

Figure S32 ${ }^{1} \mathrm{H}$ NMR spectrum (400 MHz, Chloroform- $d$ ) of (S)-3,7-dimethyloctano-1-ol.<smiles>CC(C)CCC[C@@H](C)CCBr</smiles>

1-bromo-3,7-dimethyloctane

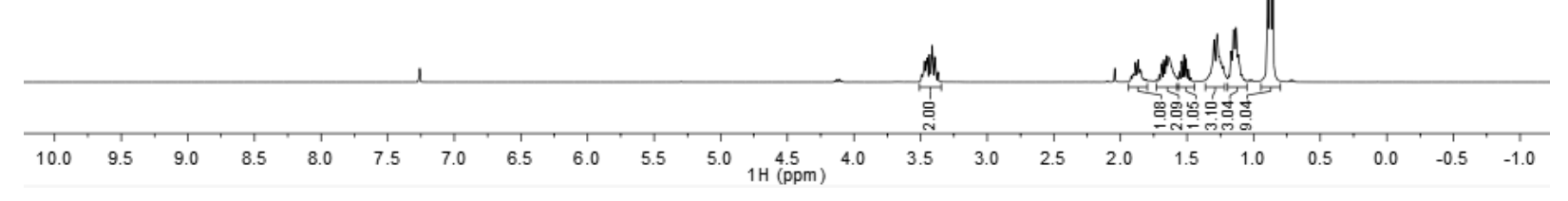

Figure S33 ${ }^{1}$ H NMR spectrum (400 MHz, Chloroform- $d$ ) of (R)-1-bromo-3,7-dimethyloctane.<smiles>CC(C)CCC[C@@H](C)CCBr</smiles>

1-bromo-3,7-dimethyloctane

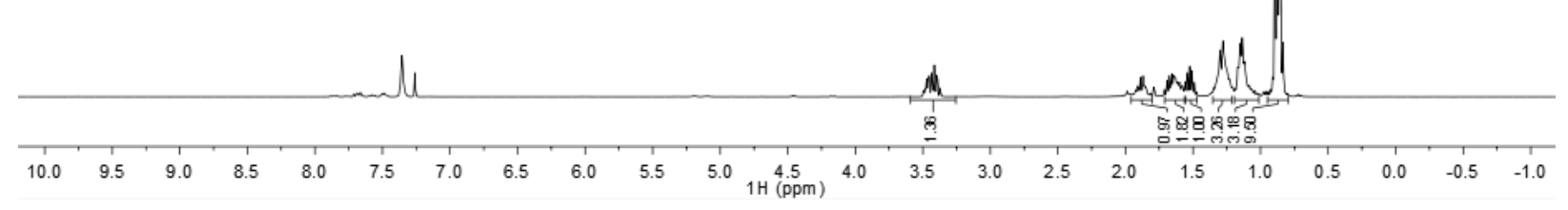

Figure S34 ${ }^{1} \mathrm{H}$ NMR spectrum (400 MHz, Chloroform- $d$ ) of (rac)-1-bromo-3,7-dimethyloctane. 
<smiles>CC(C)CCC[C@@H](C)CCBr</smiles>

1-bromo-3,7-dimethyloctane

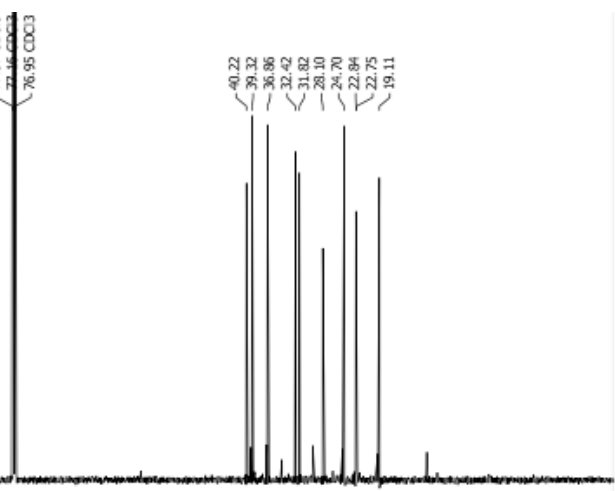

$\begin{array}{lllllllllll}210 & 200 & 190 & 180 & 170 & 160 & 150 & 140 & 130 & 120 & 110 \quad \begin{array}{l}100 \\ 13 \mathrm{C}(\mathrm{ppm})\end{array}\end{array}$

Figure S35 ${ }^{13} \mathrm{C}$ NMR spectrum (151 MHz, Chloroform- $d$ ) of (rac)-1-bromo-3,7-dimethyloctane.<smiles>CC(C)CCC[C@@H](C)CCBr</smiles>

1-bromo-3,7-dimethyloctane

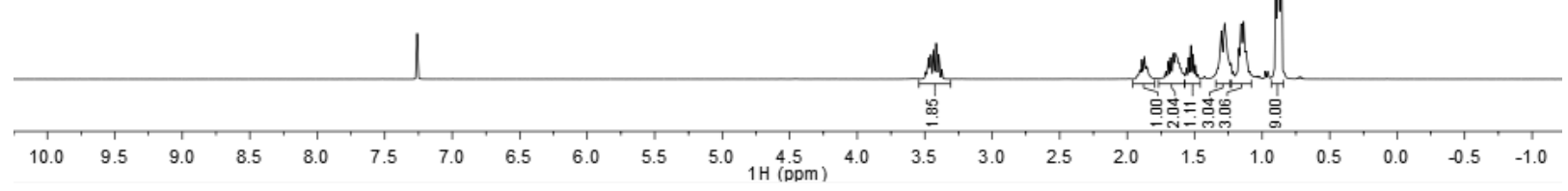

Figure S36 ${ }^{1} \mathrm{H}$ NMR spectrum (400 MHz, Chloroform- $d$ ) of (S)-1-bromo-3,7-dimethyloctane.<smiles>CC(C)CCC[C@H](C)CCCOc1ccccc1OCC[C@H](C)CCCC(C)C</smiles>

1,2-bis((3,7-dimethyloctyl)oxy)benzene

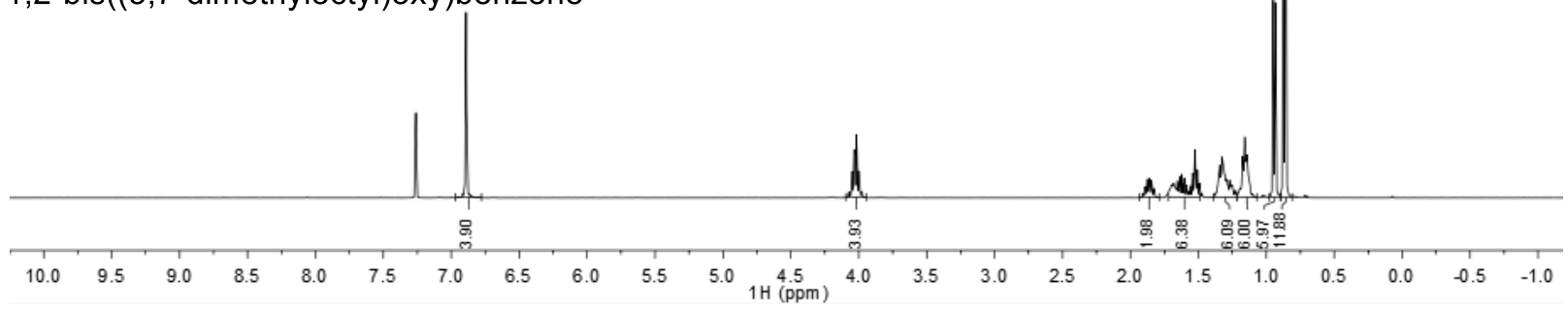

Figure S37 ${ }^{1} \mathrm{H}$ NMR spectrum (400 MHz, Chloroform- $d$ ) of (R)-1,2-bis((3,7dimethyloctyl)oxy)benzene. 


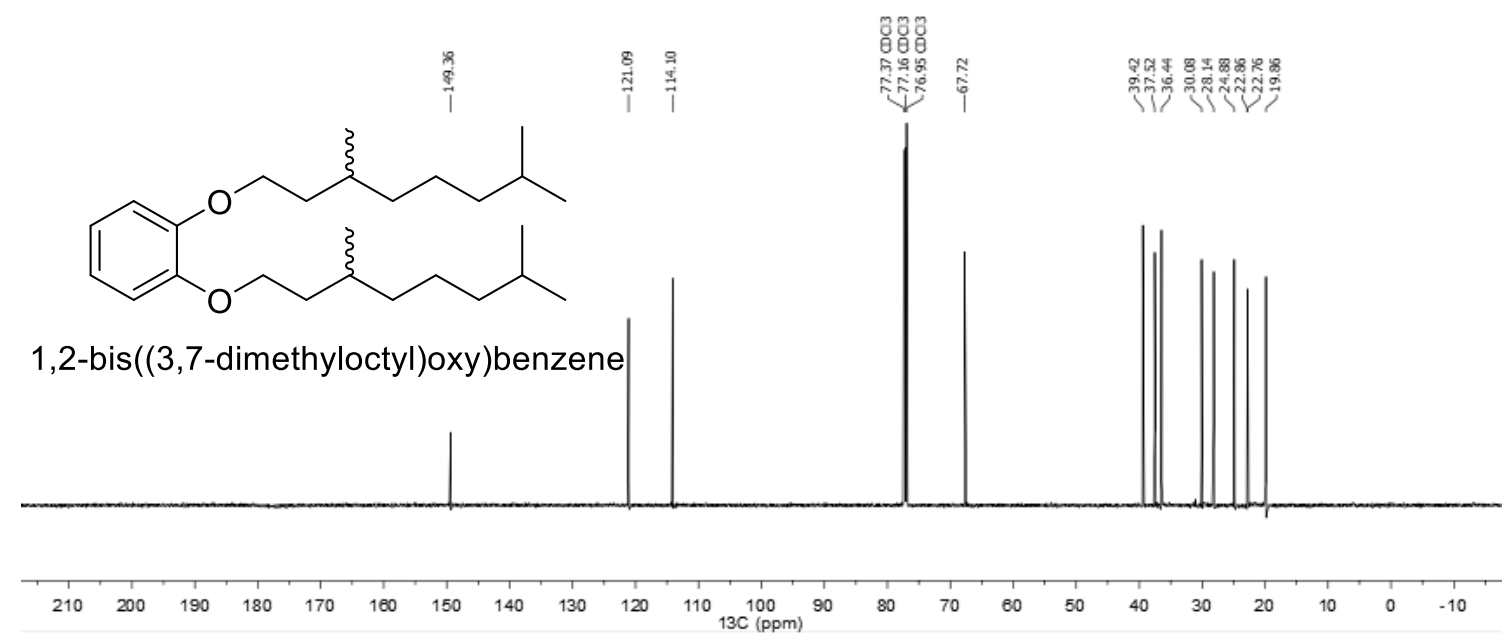

Figure S38 ${ }^{13} \mathrm{C}$ NMR spectrum $(151 \mathrm{MHz}$, Chloroform- $d)$ of $(\boldsymbol{R})-\mathbf{1 , 2}$-bis((3,7dimethyloctyl)oxy)benzene.

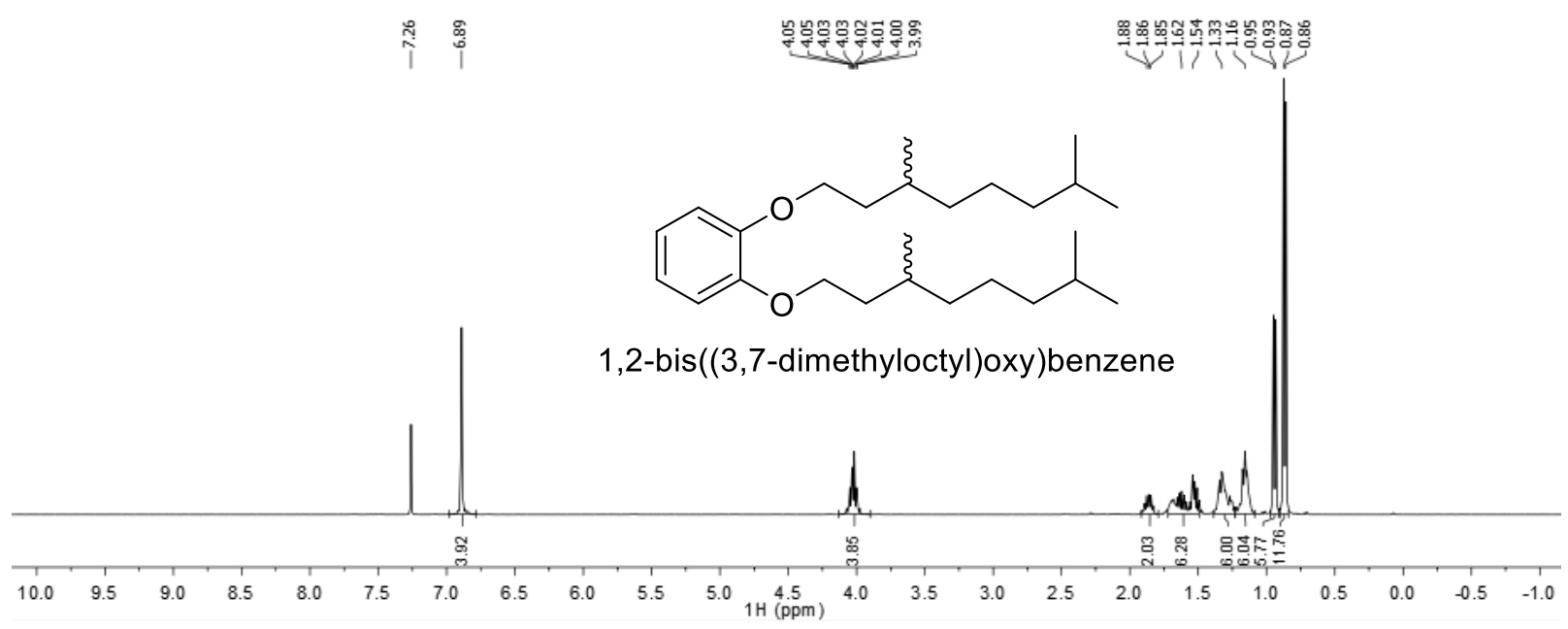

Figure S39 ${ }^{1} \mathrm{H}$ NMR spectrum $(400 \mathrm{MHz}$, Chloroform- $d$ ) of (rac)-1,2-bis((3,7dimethyloctyl)oxy)benzene. 


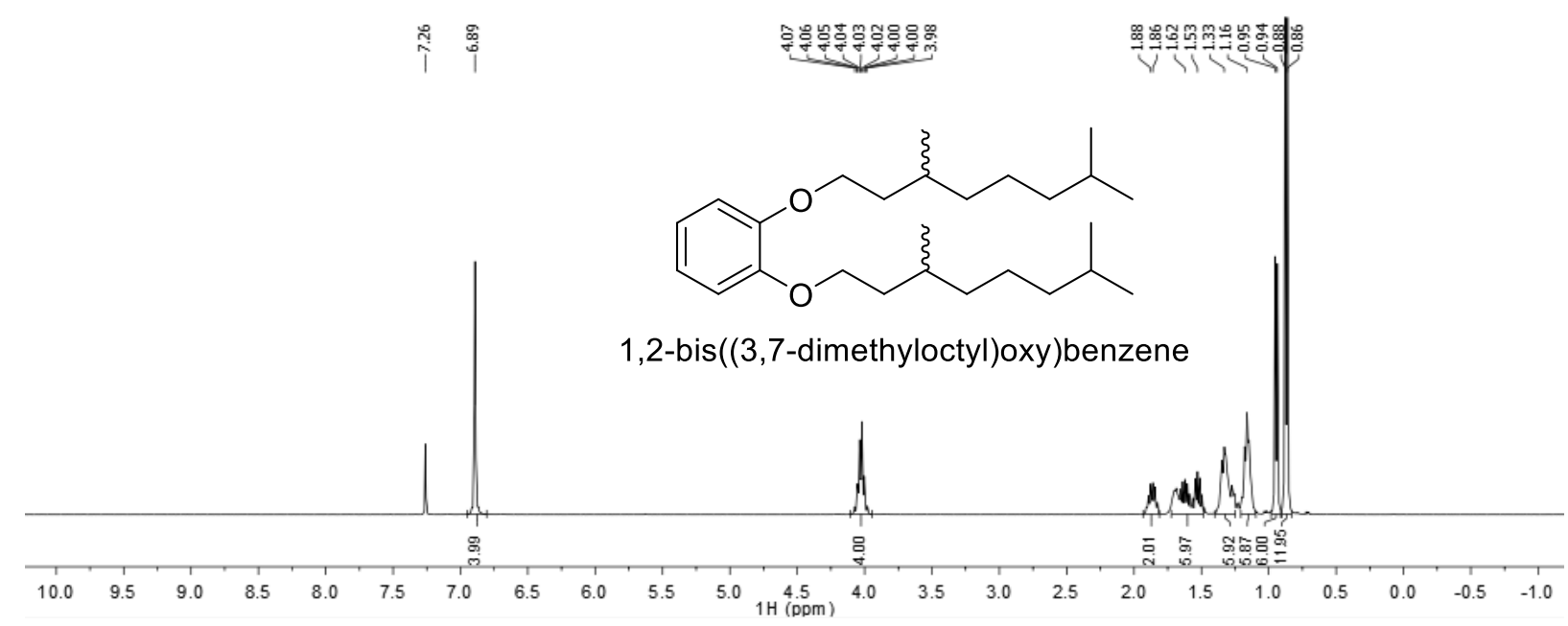

Figure $\mathbf{S 4 0}{ }^{1} \mathrm{H}$ NMR spectrum (400 MHz, Chloroform- $d$ ) of (S)-1,2-bis((3,7dimethyloctyl)oxy)benzene.

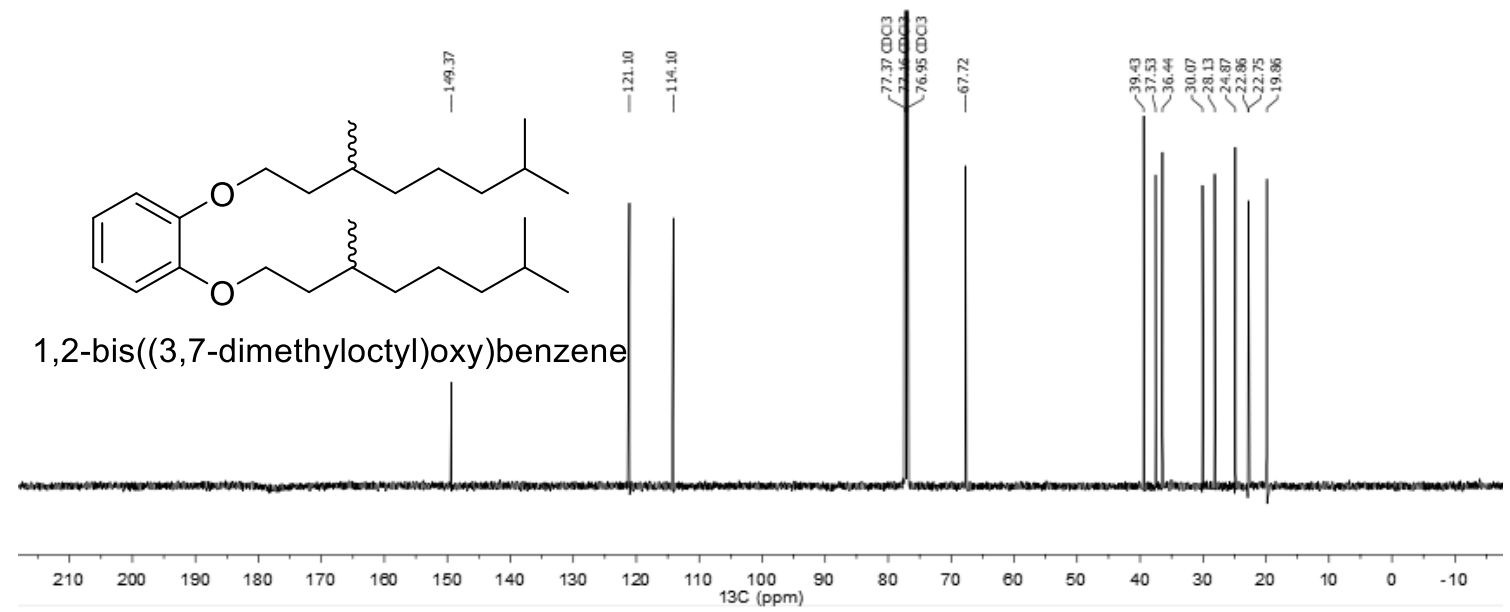

Figure $41{ }^{13} \mathrm{C}$ NMR spectrum (151 MHz, Chloroform- $d$ ) of (S)-1,2-bis((3,7-dimethyloctyl)oxy)benzene. 


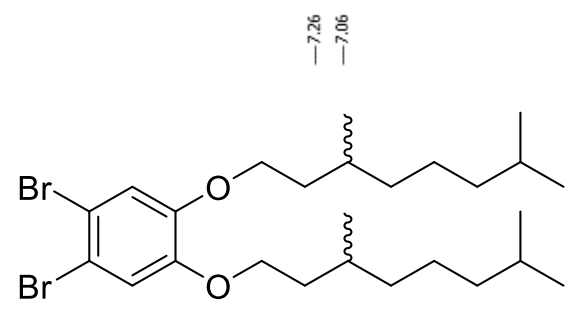

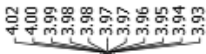

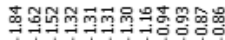

1,2-dibromo-4,5-bis((3,7-dimethyloctyl)oxy)benzene

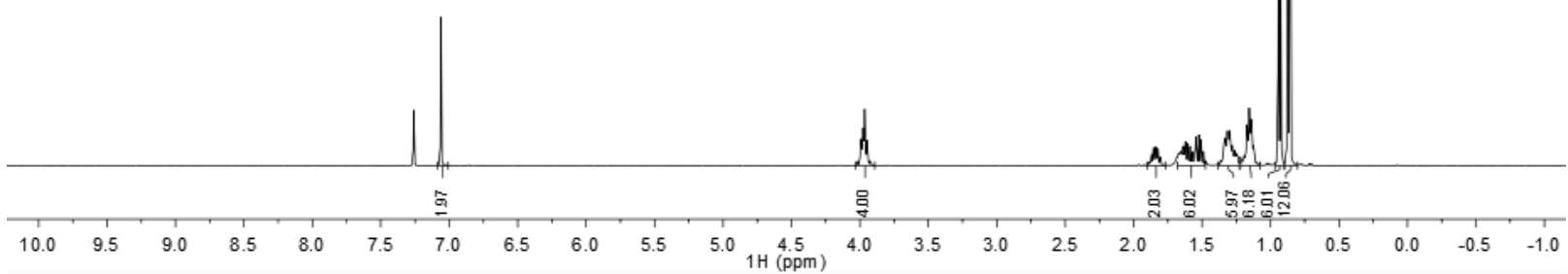

Figure S42 ${ }^{1} \mathrm{H}$ NMR spectrum (400 MHz, Chloroform- $d$ ) of (R)-1,2-dibromo-4,5-bis((3,7dimethyloctyl)oxy)benzene.

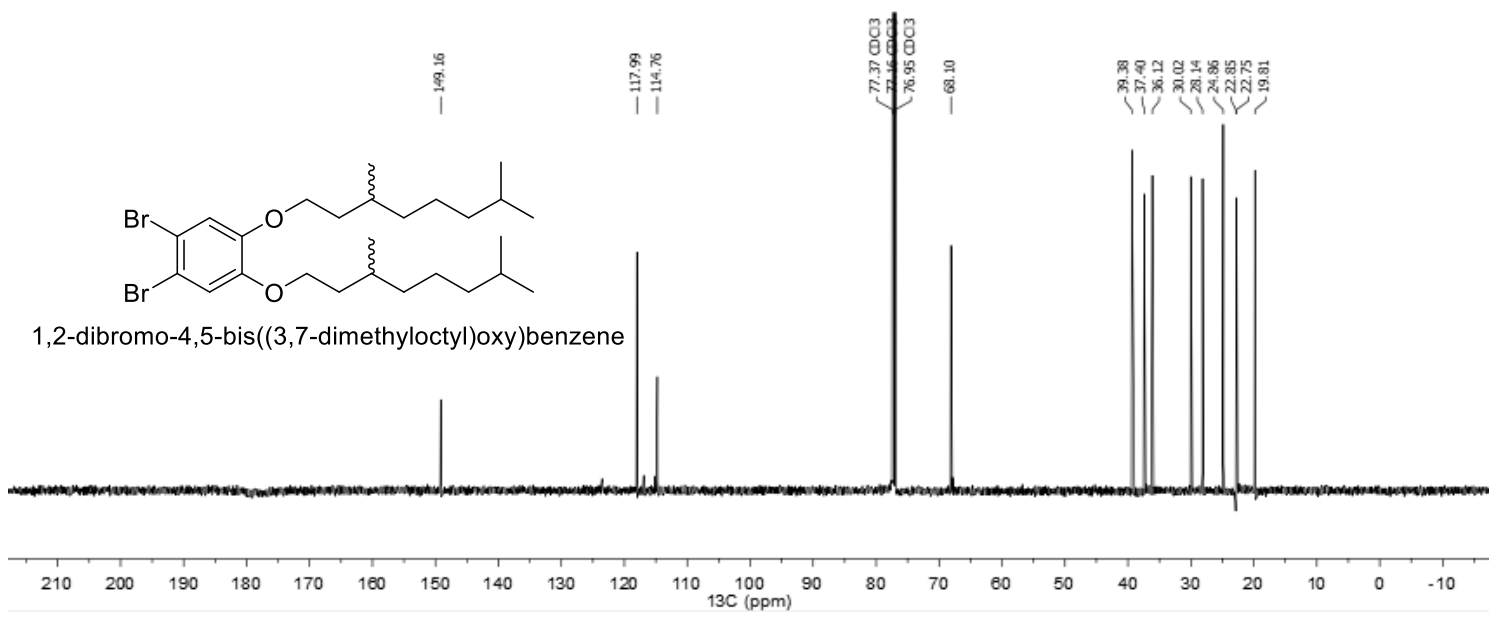

Figure $43{ }^{13} \mathrm{C}$ NMR spectrum $(151 \mathrm{MHz}$, Chloroform- $d$ ) of (R)-1,2-dibromo-4,5-bis((3,7dimethyloctyl)oxy)benzene. 


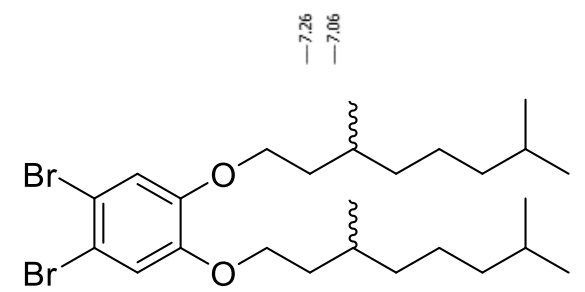

$\mathrm{B}$

1,2-dibromo-4,5-bis((3,7-dimethyloctyl)oxy)benzene

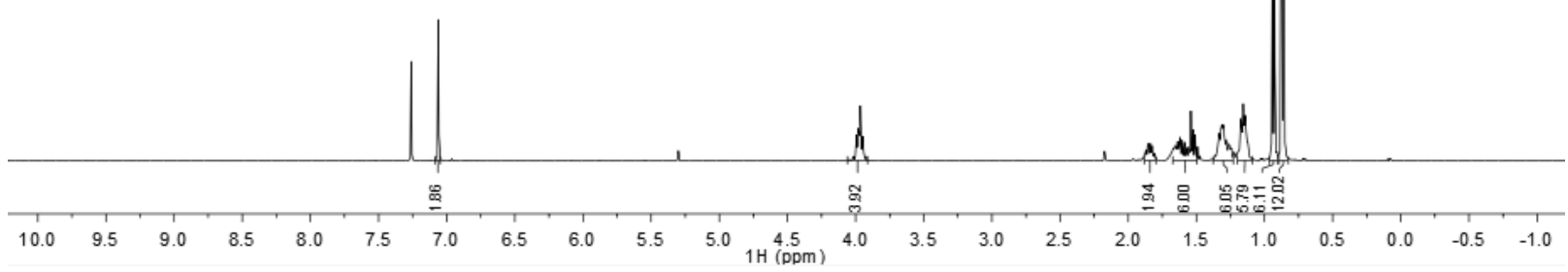

Figure $44{ }^{1} \mathrm{H}$ NMR spectrum (400 MHz, Chloroform- $d$ ) of (rac)-1,2-dibromo-4,5-bis((3,7dimethyloctyl)oxy)benzene.
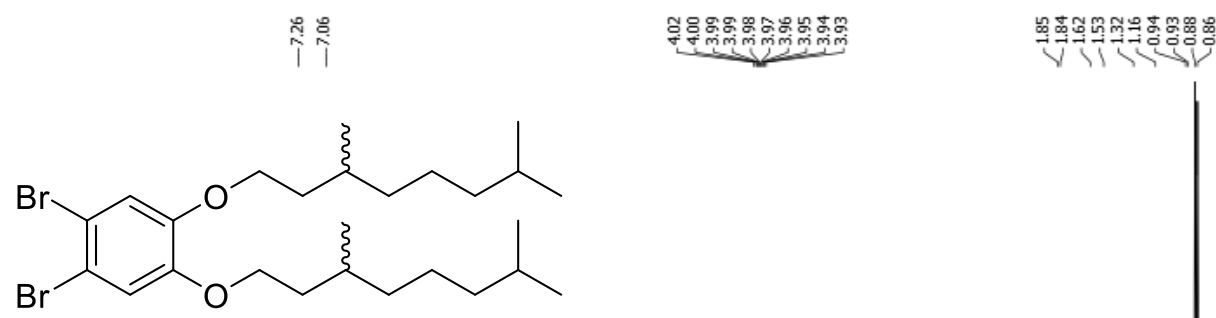

romo-4,5-bis((3,7-dimethyloctyl)oxy)benzene

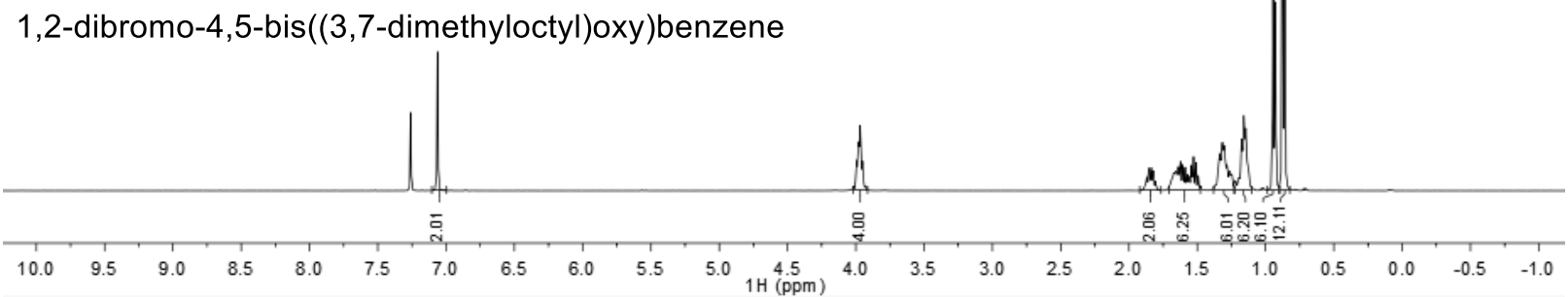

Figure $\mathbf{S 4 5}{ }^{1} \mathrm{H}$ NMR spectrum $(400 \mathrm{MHz}$, Chloroform- $d$ ) of (S)-1,2-dibromo-4,5-bis((3,7dimethyloctyl)oxy)benzene. 


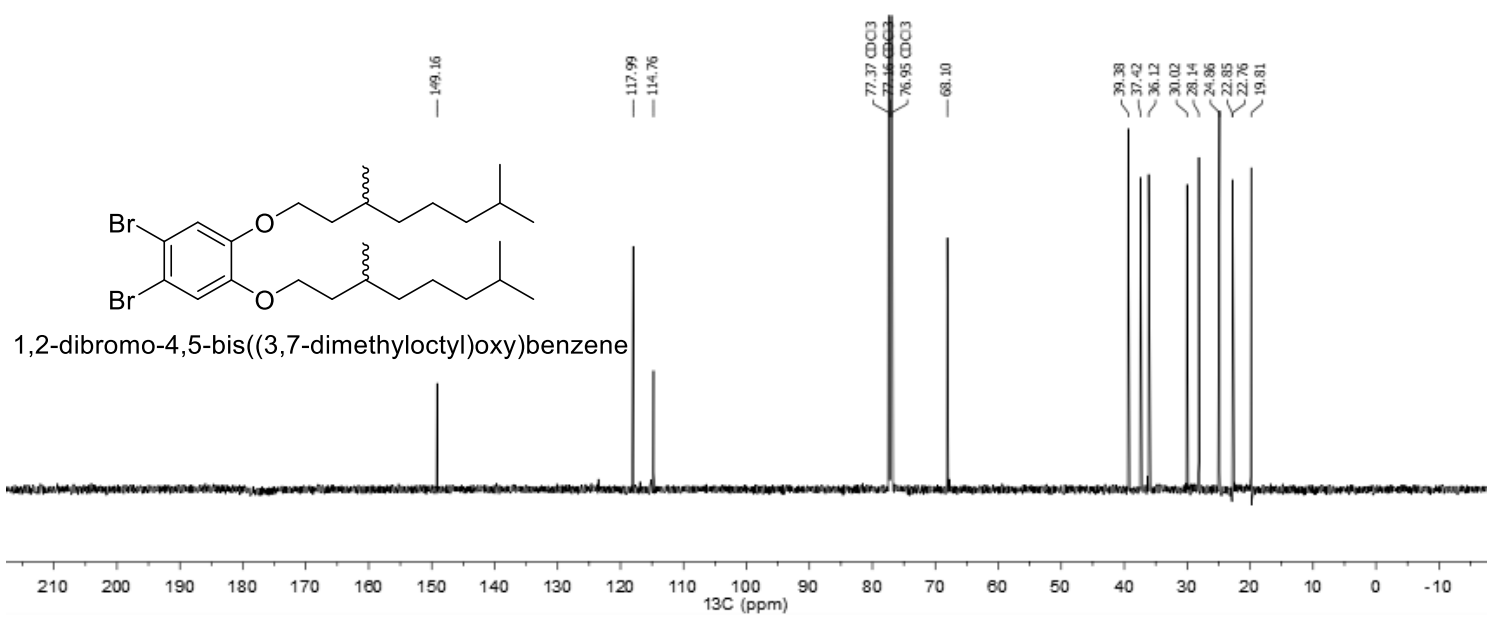

Figure S46 ${ }^{13} \mathrm{C}$ NMR spectrum (151 MHz, Chloroform- $\left.d\right)$ of (S)-1,2-dibromo-4,5-bis((3,7dimethyloctyl)oxy)benzene.
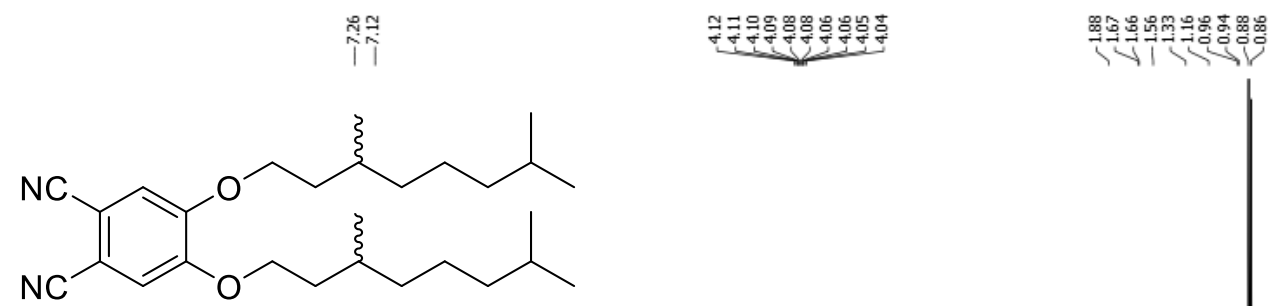

4,5-bis((3,7-dimethyloctyl)oxy)phthalonitrile

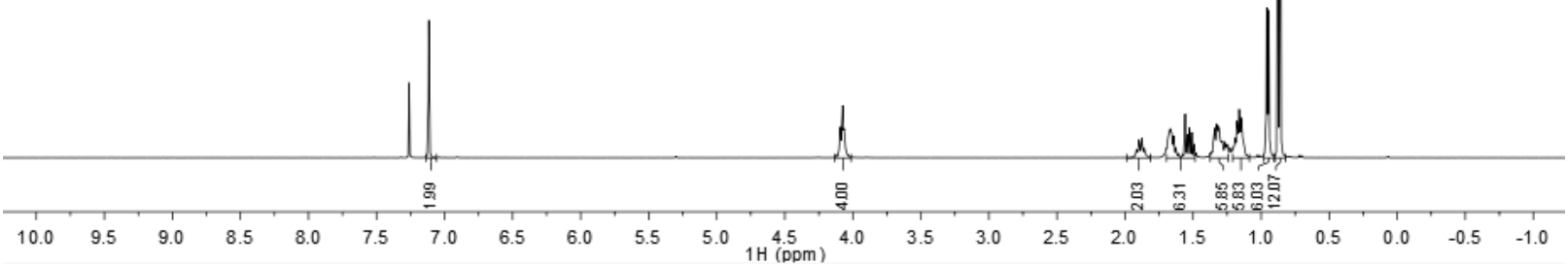

Figure $\mathbf{S 4 7}{ }^{1} \mathrm{H}$ NMR spectrum (400 MHz, Chloroform- $d$ ) of (R)-4,5-bis((3,7dimethyloctyl)oxy)phthalonitrile. 

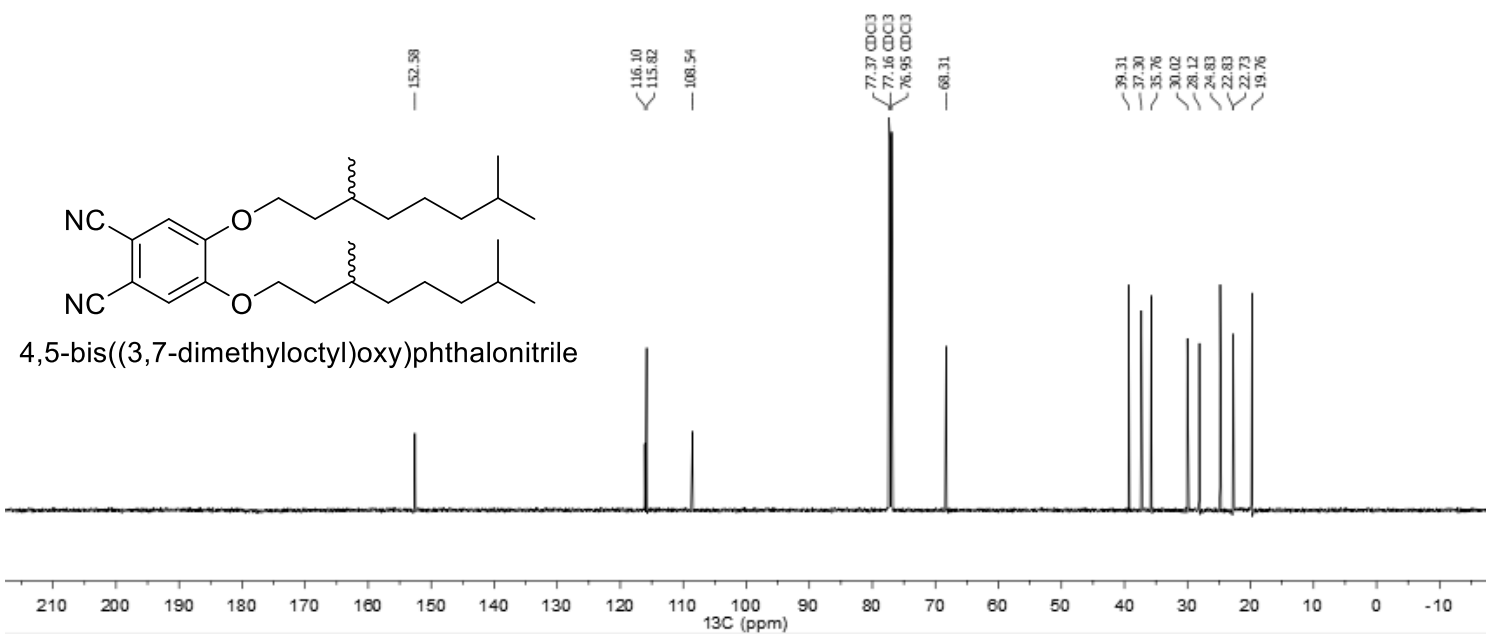

Figure S48 ${ }^{13} \mathrm{C}$ NMR spectrum (151 MHz, Chloroform- $d$ ) of $(\boldsymbol{R})-4,5-b i s((3,7-$ dimethyloctyl)oxy)phthalonitrile.<smiles>CC(C)CCC[C@H](C)CCOc1cc(C#N)c(C#N)cc1OCC[C@H](C#[W])CCCC(C)C</smiles>

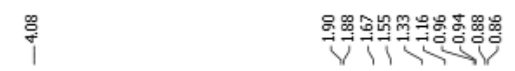

4,5-bis((3,7-dimethyloctyl)oxy)phthalonitrile

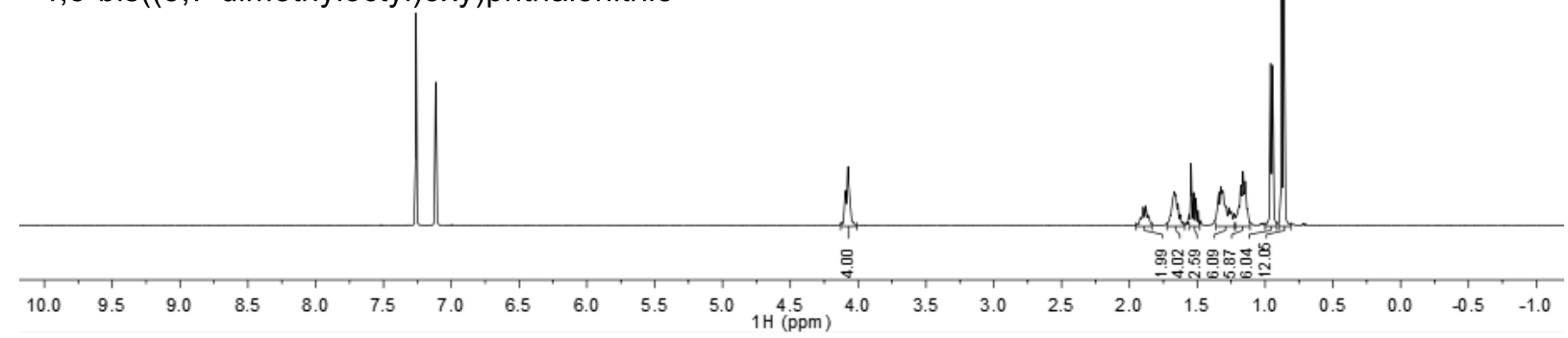

Figure S49 ${ }^{1} \mathrm{H}$ NMR spectrum (400 MHz, Chloroform- $d$ ) of (rac)-4,5-bis((3,7dimethyloctyl)oxy)phthalonitrile. 

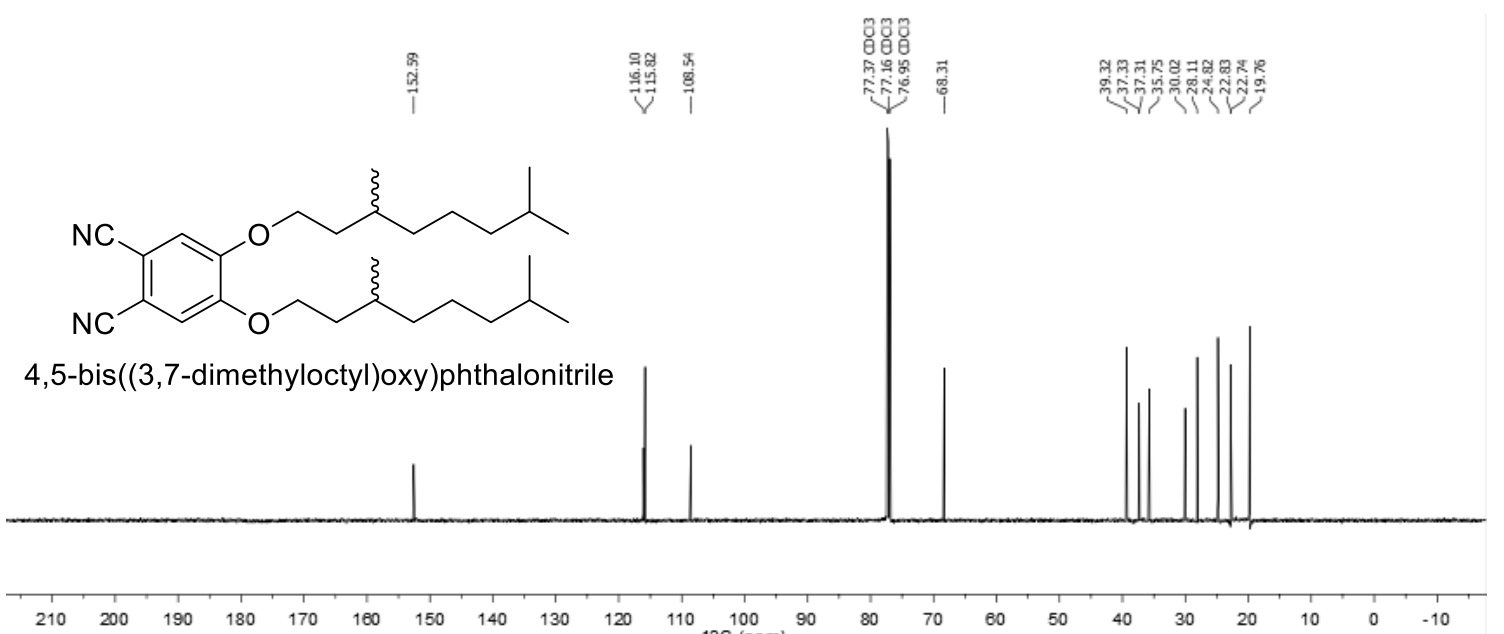

Figure 50 ${ }^{13} \mathrm{C}$ NMR spectrum $(151 \mathrm{MHz}$, Chloroform- $d)$ of (rac)-4,5-bis((3,7dimethyloctyl)oxy)phthalonitrile.
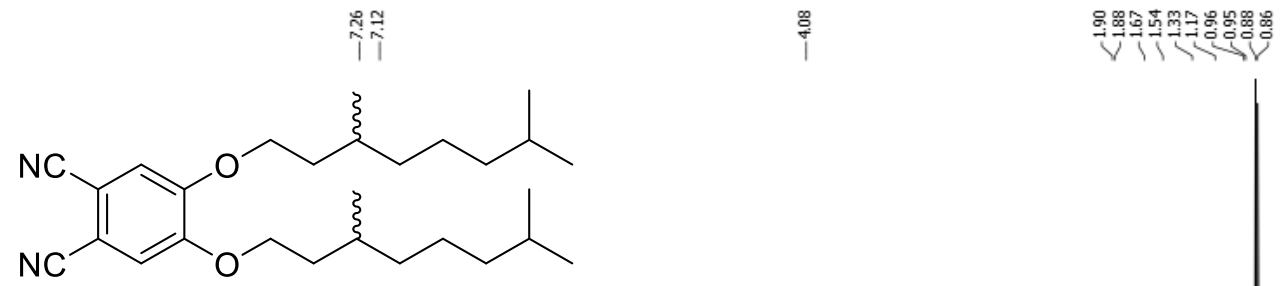

4,5-bis((3,7-dimethyloctyl)oxy)phthalonitrile

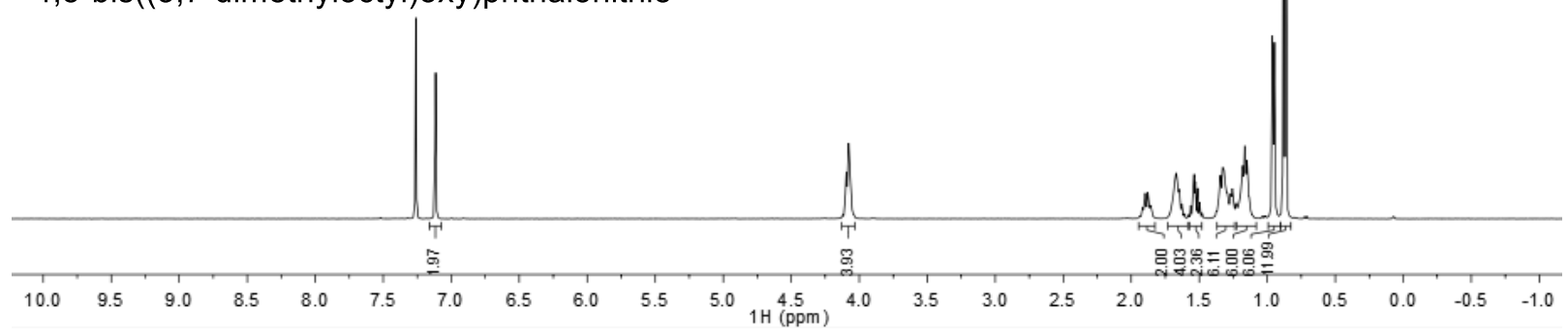

Figure S51 ${ }^{1} \mathrm{H}$ NMR spectrum (400 MHz, Chloroform- $d$ ) of $(\boldsymbol{S})$-4,5-bis((3,7dimethyloctyl)oxy)phthalonitrile. 


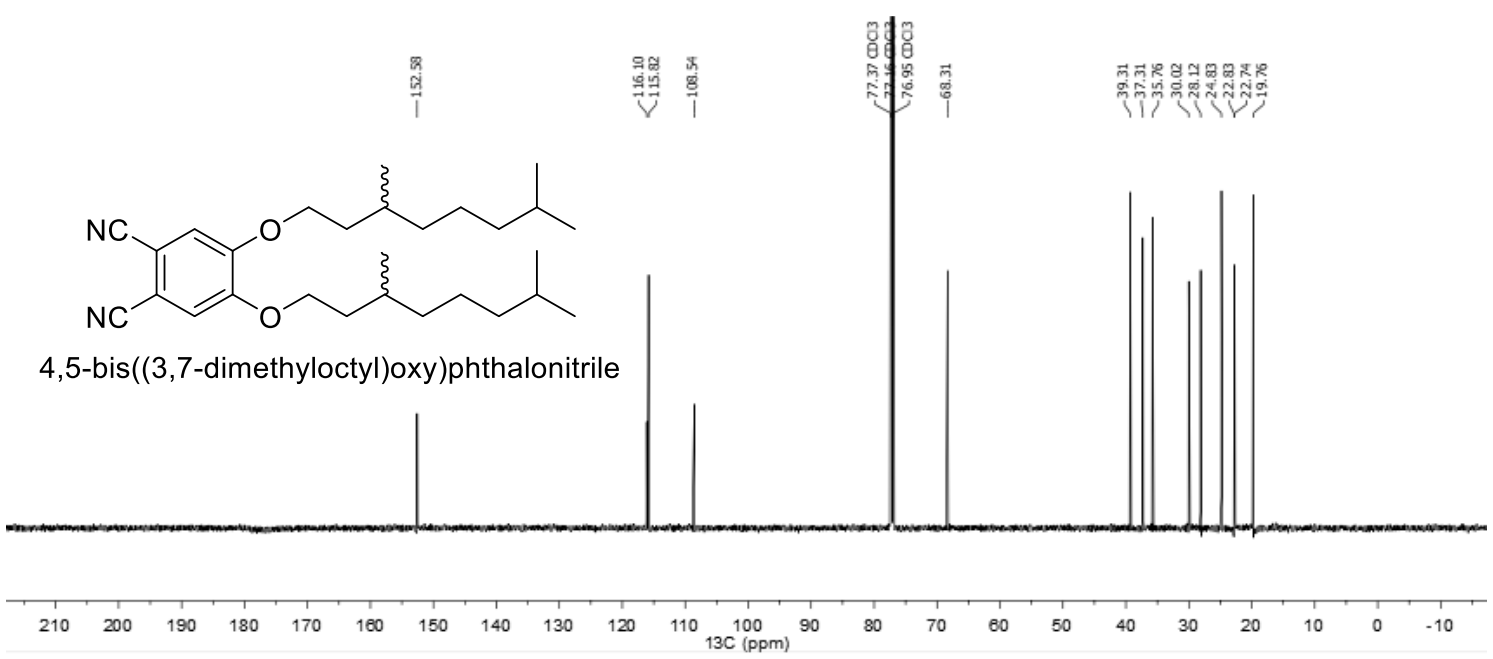

Figure $52{ }^{13} \mathrm{C}$ NMR spectrum $(151 \mathrm{MHz}$, Chloroform- $d$ ) of $(\mathbf{S})-\mathbf{4 , 5 - b i s}((\mathbf{3 , 7 -}$ dimethyloctyl)oxy)phthalonitrile.

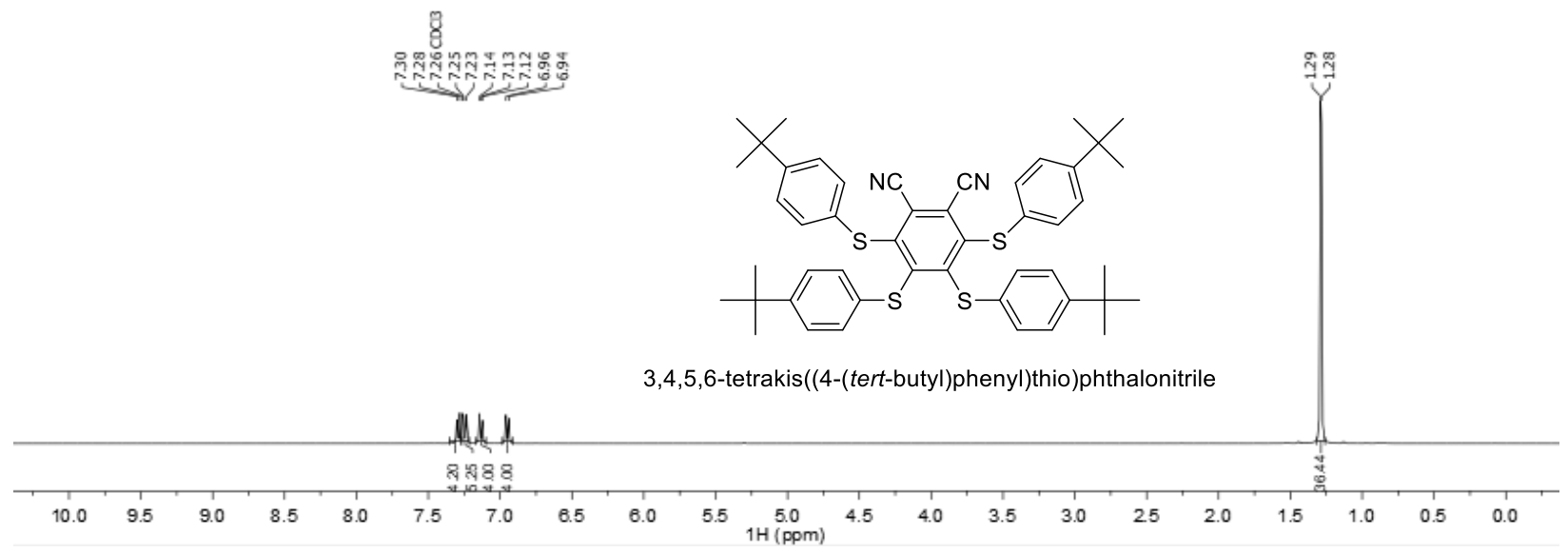

Figure S53 ${ }^{1} \mathrm{H}$ NMR spectrum $(400 \mathrm{MHz}$, Chloroform- $d$ ) of 3,4,5,6-tetrakis((4-(tertbutyl)phenyl)thio)phthalonitrile. 


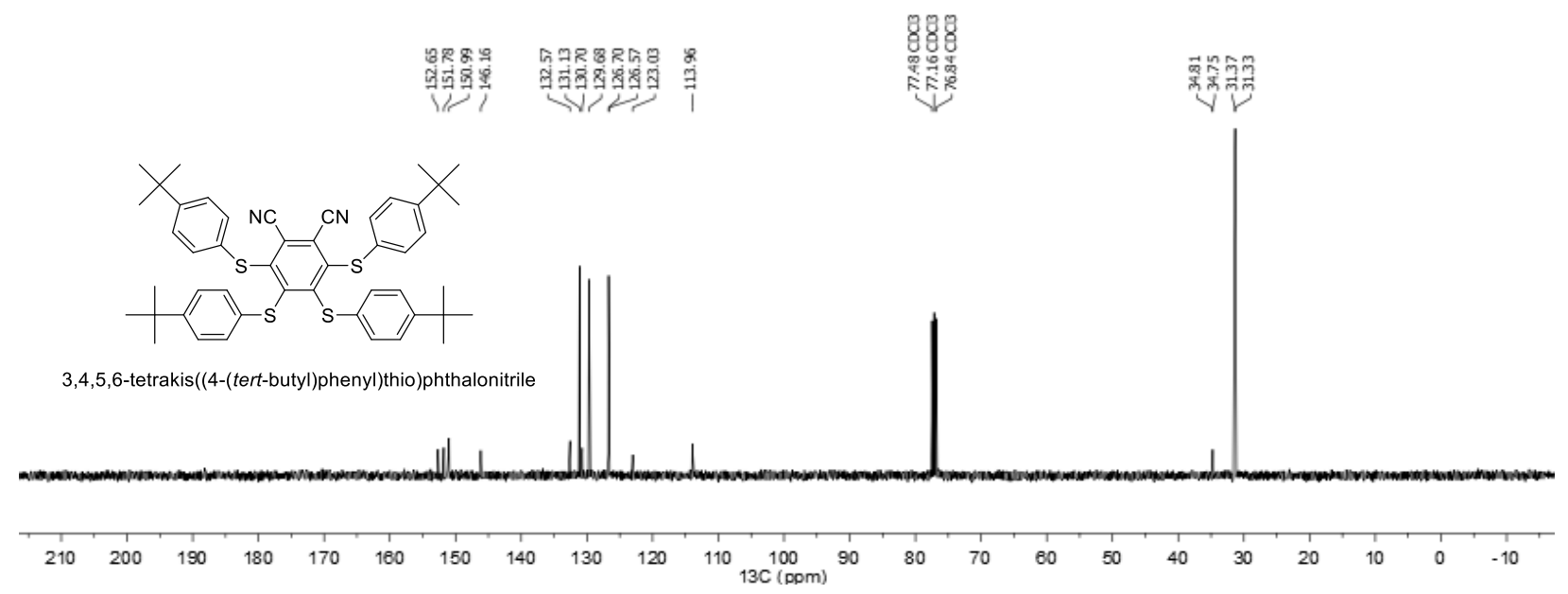

Figure S54 ${ }^{13} \mathrm{C}$ NMR spectrum (101 MHz, Chloroform- $d$ ) of 3,4,5,6-tetrakis((4-(tertbutyl)phenyl)thio)phthalonitrile.

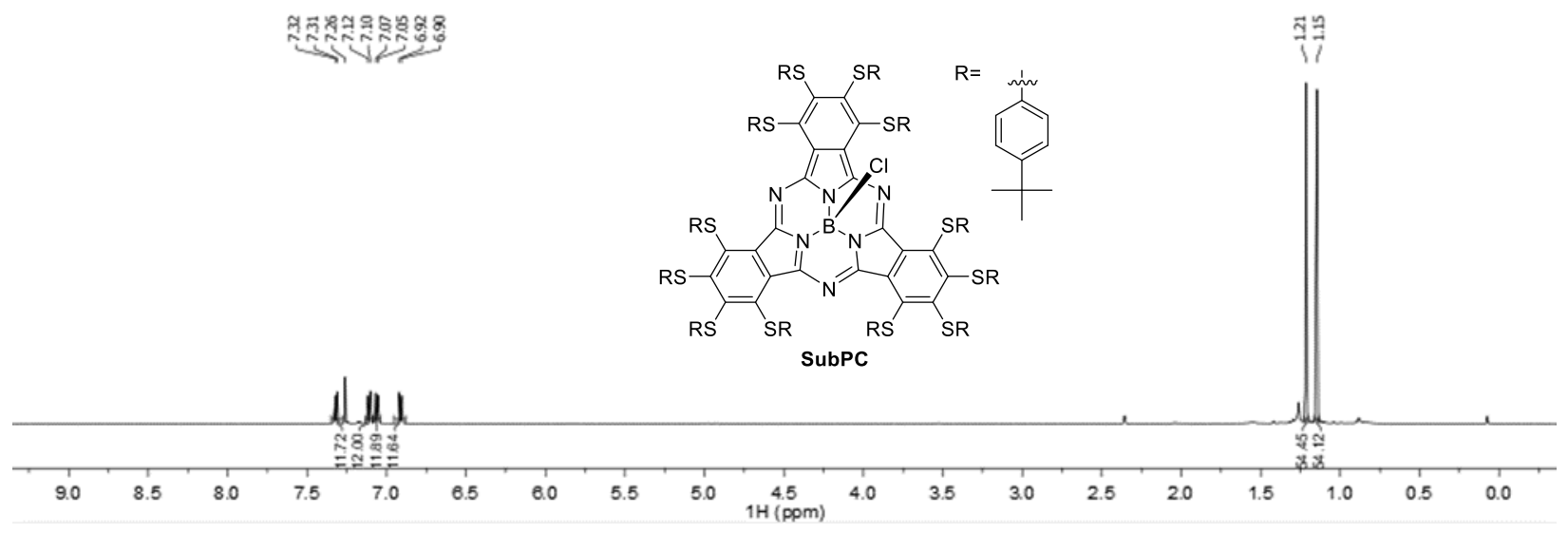

Figure S55 ${ }^{1} \mathrm{H}$ NMR spectrum (600 MHz, Chloroform- $d$ ) of SubPc.

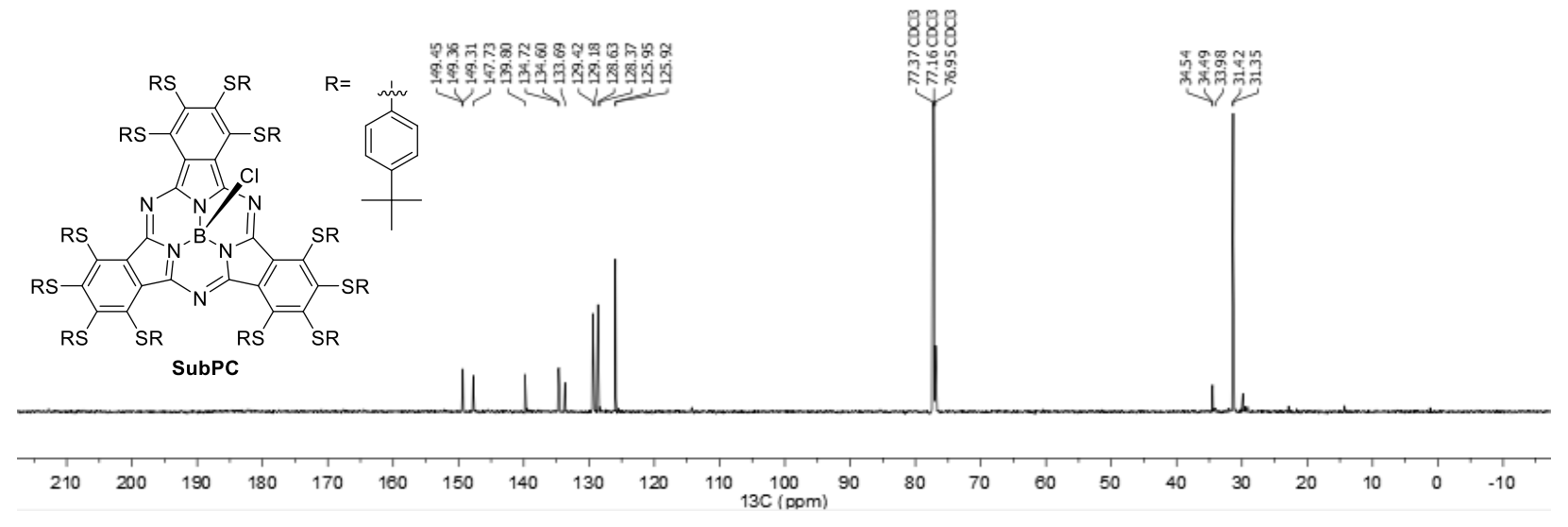

Figure S56 ${ }^{13} \mathrm{C}$ NMR spectrum (151 MHz, Chloroform- $d$ ) of SubPc. 


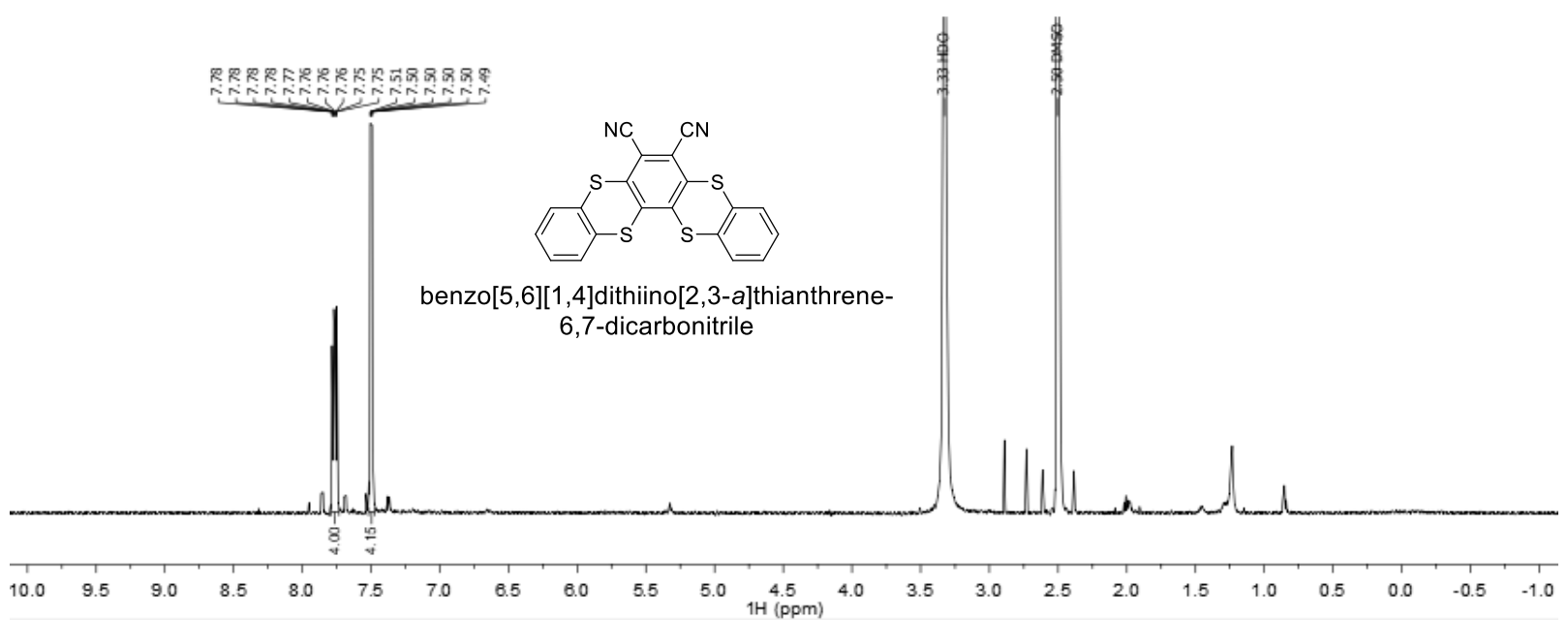

Figure $557{ }^{1} \mathrm{H}$ NMR spectrum $\left(600 \mathrm{MHz}, \mathrm{DMSO}-d_{6}\right)$ of benzo[5,6][1,4]dithiino[2,3-a]thianthrene-6,7dicarbonitrile.

\section{References}

(1) Messmore, B. W.; Sukerkar, P. A.; Stupp, S. I. Mirror Image Nanostructures. J. Am. Chem. Soc. 2005, 127 (22), 7992-7993. https://doi.org/10.1021/ja051183y.

(2) Schouten, P. G.; Van der Pol, J. F.; Zwikker, J. W.; Drenth, W.; Picken, S. J. Peripherally Octasubstituted Phthalocyanines with Branched Alkoxy Chains. Mol. Cryst. Liq. Cryst. 1991, 195, 291-305.

(3) Vieira, A. A.; Cavero, E.; Romero, P.; Gallardo, H.; Serrano, J. L.; Sierra, T. H-Bonded Complexes Containing 1,3,4-Oxadiazole Derivatives: Mesomorphic Behaviour, Photophysical Properties and Chiral Photoinduction. J. Mater. Chem. C 2014, 2 (34), 7029-7038. https://doi.org/10.1039/c4tc00886c.

(4) Therien, M. J.; Susumu, K. NOVEL CONJUGATED MATERIALS FEATURING PROQUINOIDAL UNITS. WO 2007/081991 A2, 2007.

(5) Yelamaggad, C. V.; Achalkumar, A. S.; Rao, D. S. S.; Prasad, S. K. The First Examples of Optically Active Tris(N-Salicylideneaniline)s: Manifestation of Chirality from Molecules to Fluid Columnar Phases. J. Mater. Chem. 2007, 17 (42), 4521-4529. https://doi.org/10.1039/b708432c.

(6) Xia, Y.; Li, Y.; Zhu, Y.; Li, J.; Zhang, P.; Tong, J.; Yang, C.; Li, H.; Fan, D. Dithieno[2,3-d:2',3'D']Naphtho[1,2-b:3,4-B'] Dithiophene-a Novel Electron-Rich Building Block for Low Band Gap Conjugated Polymers. J. Mater. Chem. C 2014, 2 (9), 1601-1604. https://doi.org/10.1039/c3tc32192d. 
(7) Lee, C. H.; Guo, J.; Chen, L. X.; Mandal, B. K. Novel Zinc Phthalocyanine-Benzoquinone Rigid Dyad and Its Photoinduced Electron Transfer Properties. J. Org. Chem. 2008, 73 (21), 8219-8227. https://doi.org/10.1021/jo801293s.

(8) Chen, X.; Thomas, J.; Gangopadhyay, P.; Norwood, R. A.; Peyghambarian, N.; McGrath, D. V. Modification of Symmetrically Substituted Phthalocyanines Using Click Chemistry:

Phthalocyanine Nanostructures by Nanoimprint Lithography. J. Am. Chem. Soc. 2009, 131 (38), 13840-13843. https://doi.org/10.1021/ja905683g.

(9) Li, J.; Savagatrup, S.; Nelson, Z.; Yoshinaga, K.; Swager, T. M. Fluorescent Janus Emulsions for Biosensing of Listeria Monocytogenes. Proc. Natl. Acad. Sci. U. S. A. 2020, 117 (22), 1-8. https://doi.org/10.1073/pnas.2002623117.

(10) Ong, W. J.; Swager, T. M. Dynamic Self-Correcting Nucleophilic Aromatic Substitution. Nat. Chem. 2018, 10 (10), 1023-1030. https://doi.org/10.1038/s41557-018-0122-8.

(11) Vandendriessche, S.; Van Cleuvenbergen, S.; Willot, P.; Hennrich, G.; Srebro, M.; Valev, V. K.; Koeckelberghs, G.; Clays, K.; Autschbach, J.; Verbiest, T. Giant Faraday Rotation in Mesogenic Organic Molecules. Chem. Mater. 2013, 25 (7), 1139-1143. https://doi.org/10.1021/cm4004118.

(12) Phelps, G.; Abney, J.; Broering, M.; Korsch, W. A Sensitive Faraday Rotation Setup Using Triple Modulation. Rev. Sci. Instrum. 2015, 86 (7). https://doi.org/10.1063/1.4926459.

(13) Miles, A.; Gai, Y.; Gangopadhyay, P.; Wang, X.; Norwood, R. A.; Watkins, J. J. Improving Faraday Rotation Performance with Block Copolymer and FePt Nanoparticle Magneto-Optical Composite. Opt. Mater. Express 2017, 7 (6), 2126. https://doi.org/10.1364/ome.7.002126.

(14) Gangopadhyay, P.; Koeckelberghs, G.; Persoons, A. Magneto-Optic Properties of Regioregular Polyalkylthiophenes. Chem. Mater. 2011, 23 (3), 516-521. https://doi.org/10.1021/cm102215a.

(15) Shashoua, V. E. Magneto-Optical Rotation Spectra of Porphyrins and Phthalocyanines. J. Am. Chem. Soc. 1965, 87 (18), 4044-4048. https://doi.org/10.1021/ja01096a003.

(16) Buckingham, A. D.; Stephens, P. J. MAGNETIC OPTICAL ACTIVITY. Annu. Rev. Phys. Chem. 1966, 17, 399-432.

(17) Mack, J.; Stillman, M. J.; Kobayashi, N. Application of MCD Spectroscopy to Porphyrinoids. Coord. Chem. Rev. 2007, 251 (3-4), 429-453. https://doi.org/10.1016/j.ccr.2006.05.011.

(18) Shao, Y.; Molnar, L. F.; Jung, Y.; Kussmann, J.; Ochsenfeld, C.; Brown, S. T.; Gilbert, A. T. B.; 
Slipchenko, L. V.; Levchenko, S. V.; O’Neill, D. P.; et al. Advances in Methods and Algorithms in a Modern Quantum Chemistry Program Package. Phys. Chem. Chem. Phys. 2006, 8 (27), 31723191. https://doi.org/10.1039/b517914a.

(19) Heit, Y. N.; Sergentu, D. C.; Autschbach, J. Magnetic Circular Dichroism Spectra of Transition Metal Complexes Calculated from Restricted Active Space Wavefunctions. Phys. Chem. Chem. Phys. 2019, 21 (10), 5586-5597. https://doi.org/10.1039/c8cp07849a. 